UNIVERSIDAD NACIONAL DE LA PLATA

FACULTAD DE HUMANIDADES Y CIENCIAS DE LA EdUCACIÓN SECRETARÍA DE Posgrado

\title{
DESCENTRALIZACIÓN, REFORMA DE LA GESTIÓN Y AUTONOMÍA DE LA ESCUELA EN COLOMBIA: LA EXPERIENCIA DE LA CERTIFICACIÓN EN EL MUNICIPIO DE SABANETA
}

\author{
Yuly Paola Quintero Londoño
}

Tesis para optar por el grado de Magíster en Políticas de Desarrollo Director Patricio Narodowski, UNLP

Ensenada, 6 de Junio de 2021 


\section{DESCENTRALIZACIÓN, REFORMA DE LA GESTIÓN Y AUTONOMÍA DE LA ESCUELA EN COLOMBIA: LA EXPERIENCIA DE LA CERTIFICACIÓN EN EL MUNICIPIO DE SABANETA}

INTRODUCCIÓN

CAPÍTULO 1. LA DESCENTRALIZACIÓN FISCAL Y LA REFORMA EDUCATIVA EN EL MUNDO Y EN COLOMBIA. PROCESOS Y DEBATES

Descentralización y reformas en la gestión van de la mano

Los problemas de la descentralización fiscal y de las reformas de la gestión en general

CAPÍTULO 2. HITOS DE LA DESCENTRALIZACIÓN DEL ESTADO Y DEBATES EN COLOMBIA

La normativa

Los resultados y los debates

CAPÍTULO 3. DESCENTRALIZACIÓN Y REFORMA DE LA EDUCACIÓN EN COLOMBIA

La normativa

Resultados y debates

CAPÍTULO 4. SABANETA Y SU SISTEMA EDUCATIVO

Antioquia, Área Metropolitana Valle de Aburrá y Sabaneta

Sabaneta y su territorio

El sistema educativo de este municipio y las políticas de los últimos años

CAPÍTULO 5. CAMBIOS DESDE LA CERTIFICACIÓN EN LOS PROCESOS EDUCATIVOS EN EL MUNICIPIO DE SABANETA

Principales cambios institucionales y presupuestarios

La oferta actual y la cobertura 


\section{Introducción}

La presente tesis se propone analizar el impacto de la descentralización educativa con autonomía escolar en Colombia en el proceso iniciado en 2001 (llamada Certificación Educativa) en dos aspectos: por un lado en la cobertura educativa -la cantidad de alumnos que acceden y permanecen en el sistema educativo- en los niveles de educación preescolar, básica y media, y por el otro lado en los cambios que esta estrategia permitió en la gestión del sistema: la capacidad de planificar del municipio y la organización de la escuela. Se aborda la problemática a partir del caso del Municipio de Sabaneta de la Región Metropolitana del valle de Aburra, cuyo principal centro es Medellín, se hace desde el 2010, año en que el municipio fue certificado para iniciar la estrategia, pero se presta especial atención al período 2015-2019 por un problema de acceso a la información.

Se indaga, especialmente en el capítulo 2, la heterogeneidad existente entre los territorios y, en dicho capítulo y en el 3 las diferentes posibilidades que brinda la descentralización y la autonomía en los municipios que están en condiciones de entrar a este proceso, mientras que los otros seguirían dependiendo del Departamento sin poder aprovechar las virtudes del modelo por no existir una transición adecuada para los municipios rezagados. Este análisis se completa luego con el estudio de cómo se aprovechó esta posibilidad en un municipio con capacidades como Sabaneta tanto en cuanto a la mayor cobertura como en las estrategias de la planificación, inversión y gestión encaradas mostrando los beneficios en términos de las condiciones técnicas y administrativas requeridas para escuelas y alumnos ${ }^{1}$.

\footnotetext{
${ }^{1}$ No se ha podido hacer comparaciones con municipios de un PBI per cápita inferior y aun no certificados por problemas de acceso a la información departamental y además, una comparación exhaustiva excedía las posibilidades de este trabajo. Algunas referencias se hacen acerca del municipio vecino, no certificado de La Estrella a partir de la información estadística disponible y la entrevista realizada a un directivo de ese municipio
} 
Se hace uso para la investigación de leyes y decretos que hacen a las reformas, documentos programáticos de gobierno como planes de desarrollo, educativos, etc., páginas webs oficiales y de organismos internacionales así como documentos de investigación y de evaluación de las políticas, también estadísticas sociodemográficas y educativas oficiales del Departamento Nacional de Estadística (DANE ${ }^{2}$ ). A fin de avanzar en el abordaje específico de Sabaneta se describe la evolución de los presupuestos públicos de Egresos Disponibles de los años 2015-2019 brindados por el Municipio.

También se han realizado entrevistas no estructuradas alrededor de las nuevas formas de gestión y sus resultados en el municipio de Sabaneta a informantes claves incluyendo 3 directivo/as municipales, 1 rector/a, 2 docentes, 1 docente con participación sindical en la organización local integrada a la Federación Colombiana de educadores (FECODE); 1 alumna con participación pasada en la conducción educativa que además ha sido becada para seguir estudios universitarios. Finalmente se pudo entrevistar a un directivo de La Estrella, municipio aledaño que no ha sido aún certificado. Los informantes han sido seleccionados a fin de cubrir los principales actores de la comunidad educativa. Las entrevistas han permitido reconstruir los procesos, incluso fueron importantes para llegar a otra documentación, aunque naturalmente las opiniones son parciales. Por otro lado, se procesan los datos de cobertura educativa del municipio de Sabaneta, antes y después de su proceso de certificación y se muestran los progresos. No es parte del objetivo de la tesis la evaluación de la calidad educativa.

La tesis se organiza de la siguiente manera: en el primer capítulo se discute la descentralización y los cambios en la gestión de la educación en el mundo y se brindan algunos datos de Colombia en ese contexto. Para eso se presentan definiciones, se analizan los vaivenes de la descentralización fiscal que serán fundamentales para entender el caso colombiano, se evalúa la cuestión de la

\footnotetext{
${ }^{2}$ Las que se encuentran on line serán identificadas en el texto como DANE (2021)
} 
convergencia que se esperaba y no se dio (generando grandes asimetrías) para luego pasar a los debates sobre la descentralización y la reforma educativa. La heterogeneidad en este caso es tal que se prefiere dejar planteada la cuestión para ser profundizada para Colombia.

El capítulo 2 focaliza en la descentralización colombiana primero con un análisis de la normativa y luego con una presentación de los resultados y los debates, específicamente importa el tema de las asimetrías económicas y fiscales de los municipios. En el capítulo 3 se estudian y debaten los aspectos centrales de las reformas de la gestión de la educación volviendo a los temas pero ya más focalizados en nuestro país.

En el capítulo 4 se aborda al caso de Sabaneta primero con una descripción de la situación socio demográfica en el Departamento de Antioquia, el Área Metropolitana del Valle de Aburra y del municipio en particular, mostrando los datos principales para luego analizar los procesos económicos y sociales vividos en los últimos años en que Sabaneta fue un espacio importante de desarrollo urbano con las ventajas y desventajas que ello implicó. Con este contexto se avanza en el análisis del sistema educativo del municipio y las políticas surgidas de los diversos planes donde se ven los cambios de rumbo y las continuidades de la planificación.

En el capítulo 5 se abordan los cambios verificados en la gestión, tema central de la tesis desde la certificación, especialmente desde el 2015 con énfasis en las lógicas institucionales y la observación de los presupuestos, dónde pueden verse claramente las intensidades otorgadas a los diferentes proyectos. Posteriormente se analiza la oferta actual y la cobertura, para pasar a las innovaciones realizadas: la forma de la conducción escolar, rectoría y de la profesión docente, en el impacto de los currículos, las capacitaciones, las otras actividades y programas, y el impacto en el alumnado. Luego se presentan las conclusiones. 


\section{Agradecimientos}

Agradezco a Dios y a la vida por poner en mi camino personas y entidades que aportan a la transformación de vidas, especialmente la mía que en cada etapa ha estado iluminada por los mejores.

Gracias a mi Director de Tesis el Doctor Patricio Narodowski, sin quien no hubiera sido posible la construcción y recta final de mi tesis, su dedicación, disciplina, exigencia, conocimiento, compromiso, entrega y pasión por su profesión y trabajo, hicieron posible este resultado, GRACIAS SIEMPRE GRACIAS por aportarme tanto desde su conocimiento y experiencia.

Gracias a Cedalc por hacer posible y cercano este sueño llamado educación, a la Universidad Nacional de La Plata por poner a disposición excelentes maestros, a mi amado municipio Sabaneta, por haber creído que a través de la educación con humanidad podemos tener mejores seres humanos y mejor calidad de vida.

Se lo dedico a mis padres quienes siempre me han impulsado a ser una persona íntegra, humana y calificada. A mi Municipio Sabaneta quien me ha permitido crecer y aportar profesionalmente por más de 15 años.

\section{Capítulo 1. La descentralización fiscal y la reforma educativa en el mundo y en Colombia. Procesos y debates}

\section{Descentralización y reformas en la gestión van de la mano}

Uno de los elementos centrales de la reforma del Estado a partir de los años 70s, es la descentralización política y fiscal y junto a ellas, se han sucedido reformas también descentralizadoras en la financiación y prestación de servicios como salud y educación hacia diversas formas de autonomía; por este mecanismo, las 
unidades que prestan servicios han asumido nuevos roles, en Colombia se han producido estos procesos, aquí nos ocuparemos de la descentralización fiscal y de los servicios, especialmente el educativo.

En este capítulo se abordan los debates sobre lo que se esperaba y sobre los resultados, se incluyen diversas experiencias mundiales, pero se toma en cuenta especialmente lo sucedido en los países de América latina (Latam).

La descentralización fiscal y de la gestión es vista como una transferencia de autonomía y responsabilidades financieras, administrativas y de gestión (en el caso educativo incluidas las pedagógicas) a las entidades territoriales de nivel inferior en forma permanente y que no puede ser revocada para luego otorgar autonomía a las unidades de servicio. La menor escala es en la salud la unidad de atención y en la educación, la escuela. En la experiencia mundial como veremos estos procesos se han dado en forma conjunta de diferente modo (Juma, Ramli, Suhaida bte Abd, Azimi, 2015).

No se trata de la desconcentración, ya que ésta no implica un cambio de poder sino simplemente asumir nuevos roles en la ejecución. La delegación es un intermedio, implica una transferencia de tareas o conjunto de tareas y sus recursos, es acotada y reversible. En este caso, los dirigentes del nivel inferior (por ejemplo, los directores) no parecen contar con todas sus posibilidades por lo limitado de su poder.

Según el enfoque más afín, el estado central debe seguir siendo responsable de cuestiones de estabilización y en el caso especialmente de las economías de escala, también de ciertos y limitados objetivos que tienen que ver con la equidad (BID, 2014). Y también se exige que la cantidad y calidad de un bien público sea definido por una sola institución para evitar distorsiones, por eso subsisten en muchos países centrales los seguros públicos de salud ${ }^{3} \mathrm{o}$ las cajas previsionales

\footnotetext{
${ }^{3}$ Puede verse al respecto Medina y Narodowski (2019
} 
de nivel nacional así como muchos programas compensatorios de educación (FMI, 2011).

Pero para esta bibliografía, cuánto más autonomía se transfiere y más se desciende en la escala en términos de incluso, incumbencias y regulaciones, más valen las supuestas bondades vinculadas a la simplificación, flexibilidad ante los cambios, acercamiento mayor entre oferta y demanda del servicio y la participación. Si se avanza menos, el accionar provincial/ municipal va a ser menos discrecional, va a generar menos heterogeneidad, pero va a tener más límites, por ejemplo, cuando el gobierno nacional se queda con ciertas incumbencias como las becas o transfiera los fondos para ellas y permita otorgarlas a los municipios o departamentos pero definiendo muy taxativamente el modo de elegir a los beneficiarios.

Esta idea de la descentralización y su relación íntima con la gestión surge de la teoría de la elección pública. Este enfoque que surge en los 70 s asume la existencia de fallas de mercado y reconoce las soluciones de segundo mejor, esto significa soluciones cooperativas entre individuos racionales que minimizan los costos de transacción generados por dichas fallas. En ese contexto asumen la existencia de asimetrías de información como causa de ineficiencias. El corolario central es que cuando ciertas actividades se realizan en la esfera pública (ya sea por su financiación como por la provisión), cómo pueden ser la salud y la educación, se deben establecer mecanismos que garanticen (al menos en parte) el autofinanciamiento, la competencia tanto del lado de la oferta como de la demanda incluso en una escala descentralizada (incluso del mercado laboral), así como incentivos para realizar esas soluciones cooperativas. A estos esquemas institucionales se los llama cuasi mercados, los mismos según el enfoque ayudan a reducir la asimetría de información y permiten que los agentes individuales puedan revelar sus preferencias y minimizar las ineficiencias que las decisiones políticas generan (McKenzie, 1999). 
Las críticas a esta concepción serán las que comúnmente se hacen a los enfoques neoclásicos a partir de la idea de que la asignación por parte del mercado puede generar más inequidad que la existente. De todos modos, hay una versión de la descentralización como empoderamiento de los sectores populares con un respaldo neoestructuralista que retomamos más delante. Boisier, Lira, Quiroga, Zurita y Rojas (1995) plantean la descentralización como una estrategia para lograr el perfeccionamiento del territorio y de la sociedad. La misma produce una distribución diferente del poder. Para eso Boisier (1998) afirma que se debe conceder autonomía. Entonces el gobierno regional pasa a ser conductor y animador, y su éxito depende de la capacidad endógena y ésta de la capacidad de canalizar la diversidad de intereses para transformarlos en relaciones en pos del desarrollo.

En la tesis seguiremos la propuesta de Medina y Narodowski (2019) que sostiene que ambos enfoques se han ido acercando y hoy se ha logrado en muchos países una síntesis razonable entre eficiencia y equidad, entre competencia y Estado y siempre con un fuerte empuje de la participación ciudadana.

En este enfoque intermedio, para que las ventajas se realicen, se plantea la necesidad de que las diversas unidades de gestión (en las diversas escalas, incluso en las unidades de gestión) cuenten (o sean fortalecidas para tener) las mismas capacidades y que logren (con el tiempo) un nivel de autofinanciamiento adecuado, como este parámetro se hace difícil, surgen diferentes formas de compensación a partir de diversos mix de gasto central, transferencias y recursos propios $^{4}$, a fin de asegurar potestades y capacidades. De este modo el Estado nacional asegura la equidad en función de los diferenciales efectivos de potencialidad recaudatoria y necesidades de gasto (Medina y Narodowski, 2019). Pero esto sólo de un modo temporal y observando que esos diferenciales

\footnotetext{
${ }^{4}$ Si la descentralización se da a nivel de escuela, se espera que estén garantizados los fondos mínimos para la gestión y para ellos hay diversas fórmulas, aunque también se habilita la recaudación propia estimulando el financiamiento directo de las familias (en el caso de la educación mediante el pago de aportes a la escuela si es pública o a escuelas privadas, la comercialización de espacios escolares, el sistema de sponsors).
} 
disminuyan debido a los esfuerzos de los gobiernos subnacionales y de las propias unidades de gestión (Porto, 2008). El tema central es la igualdad de oportunidades.

Naturalmente el mix de descentralización y competencia es consecuencia de las diversas presiones, de algunas regiones por hacerse de los recursos necesarios para llevar adelante su cometido cuando sus capacidades son inferiores y de otros por conservar o recuperar sus capacidades y no ceder parte de la riqueza, también de los actores que pueden constituirse en agentes del cambio en la gestión (Narodowski, 2020). Por eso Di Gropello (1999) dice no hay una dicotomía entre sistemas centralizados y descentralizados sino una variedad.

\section{Los problemas de la descentralización fiscal y de las reformas de la gestión en general}

El tema de la descentralización fiscal es central porque influirá notoriamente en las capacidades de los gobiernos locales y éstas impactan en las posibilidades de la gestión descentralizadas, además explica las asimetrías horizontales, entre departamentos o municipios. La evaluación de lo que sucedió en general es controvertida. Antes que nada, importa la dimensión actual del Estado. En ese sentido se debe decir que luego de diversos vaivenes, especialmente el estatalismo de posguerra y de una primera ofensiva privatista en los $80 \mathrm{~s}$, cada país parece haber llegado a una síntesis. Si se observa la carga tributaria total, en los países de la OCDE se estaba en 2017 en un promedio del 34.2\% del PBI, con Dinamarca, Islandia y Suecia por encima del 40\%; USA, España, Eslovaquia, Turquía y Japón cerca del $20 \%$. Cerca del promedio están Italia (29.5\%), Francia (29\%) y Canadá (28.4\%). En Latam el promedio es del $22.8 \%$; Colombia $29 \%$.Bolivia y Uruguay están cerca del $25 \%$. Brasil en $33 \%$ y Argentina $32 \%$ (Narodowski y Zugbi, 2020) 
En cuanto a recursos propios de OCDE (2018) éstos se ubican en el $43 \%$; sólo Austria había descentralizado menos. Canadá alcanza al $75 \%$ y USA al $52.6 \%$. Los países unitarios más descentralizados son Dinamarca, Japón y Suecia. Mucho menos han descentralizado ingresos Corea y Finlandia y en los últimos lugares están Grecia e Irlanda. Según BID (2017) muy poco centralizados están México con $14 \%$, Ecuador con $29 \%$, Argentina $40 \%$. Más descentralizados por los recursos está Colombia con $50 \%$ Bolivia. $57 \%$ Chile $65 \%$. Brasil es el más descentralizado con un $79 \%$ ). El agregado consolidado de Latam es $53 \%$. Las diferencias de recaudación propia entre gobiernos subnacionales son elevadas

Si observamos lo sucedido del lado del gasto, puede verse que en los países del OCDE erogaciones en promedio van de la mano de los recursos, pero hay países que han descentralizado el gasto más que la recaudación, son: Canadá, Alemania, Suiza, Islandia, Corea del Sur, Holanda, Nueva Zelanda, Noruega y Suecia. En Latam, Brasil, federal, gasta $40 \%$, menos de los ingresos propios, lo mismo Chile, unitario, que tiene un bajo grado de gasto subnacional. México va en sentido contrario, porque gasta localmente el $34 \%$, más que lo que recauda. Lo mismo, Colombia, Bolivia y Perú, países unitarios que muestran un alto nivel de descentralización del gasto local cercano al $30 \%$ pero éste es menor a los ingresos propios. En Argentina el gasto total realizado por las provincias y CABA asciende al 44\% mientras que la recaudación propia era del 40\% (BID; 2014 y 2018; OECD 2020).

La experiencia práctica tanto en países centrales como emergentes ha venido demostrando que debido a la heterogeneidad existente una parte del gasto que tenía que seguir siendo realizado a nivel nacional especialmente con fines compensatorios ( $y$ también para algunos con fines de control político) y lo mismo sucede con las transferencias para sostener una parte del gasto descentralizado. Los casos más descentralizados como por ejemplo Italia y España en Europa o Argentina, Brasil o México en América latina muestran que la estrategia puede 
contribuir a esa heterogeneidad si no se hacen los arreglos pertinentes (Medina y Narodowski, 2019)

En particular, para dar algún ejemplo, el modelo argentino tiene un fuerte sesgo de equidad que penaliza a las provincias con un PBI per cápita más alto aunque tengan iguales necesidades de gasto y por eso que a pesar del esfuerzo recaudatorio terminan teniendo un gasto per cápita menor a otras provincias. $Y$ además si bien el modelo de transferencias tiene un alto componente de equidad, las provincias menos favorecidas aun no pueden encontrar mecanismos de desarrollo endógenos (Granato, 2015).

Modelos como el español y el italiano presionados por regiones ricas que van en sentido inverso y el objetivo de la convergencia se aleja. Lo mismo sucede en todos los casos en que se valora población y esfuerzo contributivo. Las formas en que se han transferido competencias a los municipios son más heterogéneas pero siguen los mismos cánones (Batakis y Narodowski, 2021)

El caso colombiano va a estar entre los que han privilegiado la descentralización del gasto en los municipios, especialmente en salud y educación, pero ha descentralizado menos los recursos, y por eso los gastos centrales y las transferencias siguen siendo elevados. $Y$ en este contexto en qué además tiene mucha importancia los cálculos per cápita se beneficiaron los municipios grandes y ricos en detrimento de los más pobres que además de seguir dependiendo del Departamento, en el caso educativo, tienes niveles de gasto per cápita inferiores. Lo mismo sucede en las escuelas de barrios más vulnerables de los municipios certificados. Este tema será retomado en el capítulo 2.

Y si bien la descentralización fiscal debería empoderar las escalas inferiores y lograr una convergencia entre los territorios -sino, las asimetrías se consolidan, dificultando la gestión de los servicios y generando más inequidad- esto no ha sido tan así. Por ejemplo, para la Unión Europea, Maynou, Saez y Bacaria (2013) 
afirman que para el periodo 1990-2010, salvo raras excepciones como la de Cataluña en España o el centro norte en Italia, no existe convergencia. Arellano Garza (2006) dice que las regiones españolas convergieron en el periodo 19551979 y se alejaron desde 1979. Subirats (2007 y 2012) expone los pobres resultados observados por la descentralización pérdida de escalas y por el aumento de la gestión privada. A raíz de esto exige más que mecanismos compensatorios ${ }^{5}$.

En Latam la evaluación se realiza considerando ambos aspectos, la descentralización fiscal y las reformas en la gestión. Los organismos internacionales evalúan las reformas de los años 90s asumiendo que ha habido fuertes avances en cuanto a la eficiencia pero aún falta, especialmente porque los gobiernos centrales se quedaron con muchas incumbencias o los gobiernos locales no tenían las capacidades institucionales, fiscales y financieras necesarias (Gottret y Schieber, 2007; Galilea, Letelier y Ross, 2011; Ocde, 2012).

Kameshwara, Sandoval-Hernandez, Shields, Rai Dhanda (2020) plantean que es aun prematuro, que son programas que requieren de tiempo, que de a poco se irán creando las condiciones necesarias.

Mesa Lago (2005) puede ser un representante de la vasta literatura que dice que los efectos no han sido positivos, la descentralización y desregulación se realizó de forma precipitada e improvisada y no se resolvieron los problemas de fondo, la cuestión de los factores del desarrollo en general y las asimetrías regionales. Boisier (1998) y Alburquerque (1999) dicen que no se había comprendido la naturaleza de los cambios mundiales y se seguía apostando al ajuste fiscal. Albuquerque (2004), siendo el único que analiza el problema de manera general, sostiene que no puede haber transferencia de servicios sin un modelo de desarrollo económico que asegure la dotación de capital y capacidades - y no al contrario.

\footnotetext{
${ }^{5}$ También puede verse Moreno, del Pino, Marí-Klose, Moreno-Fuentes (2014) o Barros, Barry, Brand, Brouwer, De Maeseneer, Jönsson, Lamata, Lehtonen, Marušič, McKee, Ricciardi, Thomson (2015)
} 
Cortes y Vargas (2012) hacen una buena síntesis cuando dicen que los municipios más pobres y con menos capacidad de gestión, recaudan menos y dependen más de las transferencias del gobierno central, por eso tienen proyectos de inversión, pero además la poca capacidad institucional los expone más a capturas por grupos de poder, por eso el desempeño económico de largo plazo es menos eficiente. Es sumamente importante que el estado garantice una presencia en todo el territorio, buscando la eliminación de las desigualdades regionales, ante todo, la brecha existente en infraestructura, y luego abocarse a los problemas del desarrollo productivo, pero incluso concediéndoles autonomía ${ }^{6}$, sin esperar que se resuelvan rápidamente las asimetrías.

Y más allá de las cuestiones del formato del sistema de transferencias y el formato de la reforma de la gestión, se presenta como un problema central el hecho de que la participación de la comunidad en las decisiones sobre las distintas funciones de la provisión de servicios es baja y esto atenta contra los resultados (Alburquerque, 1999).

\section{Los debates generales sobre la descentralización y la reforma en la gestión educativa}

Ya mencionamos que la descentralización y reforma en la gestión educativa forma parte de la estrategia general y puede ser fundamentada de un modo similar. Como sucede también en la salud, desde el punto de vista de la responsabilidad político administrativa, la escala es regional, es decir la provincia o el departamento es el encargado, pero también puede ser el municipio. El primer caso se denomina provincialización y es lo sucedido por ejemplo en la educación de Argentina o los municipios no certificados de Colombia, también España e Italia; el otro ejemplo se denomina municipalización y es justamente el caso de los

\footnotetext{
${ }^{6}$ Lo mismo se reproducirá en los casos de autonomía escolar ya que en esta escala están esos diferenciales, los fondos propios potenciales y reales son menores en los barrios de menos poder adquisitivo, además en esos barrios los gastos requeridos pueden ser mayores y el gap se agranda.
} 
municipios certificados de Colombia. Si bien inicialmente parecía que este último modelo iba a ser el más utilizado en todo el mundo hay una variedad importante al respecto (Mcginn y Welsh, 1999). Además, como vimos, el origen de los fondos de las provincias o los municipios va a depender del nivel de descentralización del lado de los recursos, porque cómo surge de la experiencia analizada, la descentralización del gasto -por ejemplo del educativo- ha sido mayor que la de la recaudación.

Pero la gran innovación de las reformas educativas, como en la salud, es que se ha ido a modelos que transfieren la responsabilidad de un conjunto de cuestiones a la escuela y ésta pasa a ser la unidad de gestión. Para eso las escuelas tienen su propia personería aunque son financiadas, al menos en parte, por el Estado, como por ejemplo, Italia o Chile, EEUU e incluso como veremos Colombia ${ }^{7}$.

Italia implementó desde inicio de los 2000 la estrategia de la autonomía, en el marco de la descentralización regional, por la cual la escuela asume la administración con una conducción pedagógica y otra administrativa, con financiamiento estatal con una evaluación estricta de la cantidad de alumnos atendidos y posibilidades limitadas de autofinanciamiento. Hay un sistema de conducción con gran responsabilidad del rector pero apoyado en órganos colegiados representativos de la comunidad educativa. Es claro de todos modos que la estrategia está en continua revisión ${ }^{8}$. En Chile se tiene un modelo de oferta en el que son las familias las que dirigen el financiamiento de las escuelas. También está la tradicional escuela charter americana, en la que las familias abren sus propias escuelas, pero son financiadas por el Estado y la gestión es responsabilidad de la escuela bajo la conducción de la propia cooperativa (Chain y Narodowski, 2009)

\footnotetext{
6.En Juma, Ramli, Suhaida bte Abd, Azimi (2015) y Chain y Narodowski (2009) pueden verse diversos ejemplos mundiales

${ }^{8}$ Para más información, ver https://www.istruzione.it/archivio/web/istruzione/famiglie/autonomiascolastica.html
} 
En todos los casos la gestión es responsabilidad de la escuela, mediante formas de conducción colegiada (padres, docentes, alumnos). $Y$ se menciona la importancia del papel del director en este contexto y otras formas de gobierno escolar como los comités escolares.

Si bien se espera que la escuela pueda definir el equipo de trabajo, en la mayor parte de los países incluso con niveles diversos de descentralización se mantiene el estatuto docente nacional, en diversos casos, como Argentina, los salarios difieren entre entes territoriales. Por otro lado, en muchos casos se prevé la posibilidad de que el departamento, el municipio o la escuela con fondos transferidos o propios tengan un sistema de premios y castigos monetarios, de ascensos, etcétera que va generando con el tiempo otro tipo de diferenciales salariales. Según el enfoque que pugna por profundizar lo más posible la descentralización, esto hace que persistan rigideces importantes en el área de recursos humanos, que reducen mucho el grado de autonomía en la provisión del servicio (Di Gropello, 1999).

Mcginn y Welsh (1999) muestran que como acabamos de ver para la descentralización fiscal en general, hay una gran variedad de formas de distribuir la autoridad financiera y administrativa de la educación, algunas ya fueron mencionadas en párrafos anteriores. Los autores mencionan un estudio de 10 países, en la mitad las decisiones se toman en más de un nivel y hay diversos acuerdos para compartir las decisiones.

Otro estudio en 14 países de la OCDE citado por los autores encara la evaluación teniendo en cuenta dos grandes definiciones, la completa autonomía y la autonomía dentro de parámetros de un nivel superior o del más alto nivel. Se ve que las unidades intermedias de escala inferior se ocupan de cuestiones de asignación de recursos, los gobiernos centrales de las grandes estrategas y las escuelas tomaban la mayoría de las decisiones atinentes a la organización de la instrucción. Por otro lado, la autonomía absoluta se ve menos. Otro tema 
planteado por los autores muestra que las escuelas privadas son más autónomas, pero 47 países subsidiaban este segmento y mantenían fuertes sistemas de regulación y control.

Los resultados esperados en esta reforma en línea con los argumentos de la descentralización iban a ser la eficiencia técnica y económica en la producción del servicio, así como el control; pero la mayor capacidad de gestión además iba a permitir abordar estrategias positivas que redundarían en una mayor cobertura debido a que ayuda a la interacción entre la escuela y la comunidad; y redundaría en estrategias de capacitación, cambios curriculares, nuevas herramientas pedagógicas, etc. (Kameshwara, Sandoval-Hernandez, Shields, Rai Dhanda, 2020). En cuanto al primer punto, muchos opinan que la reforma se llevó a cabo en un contexto de ajuste fiscal basada en techos al gasto que atentó contra dicha eficiencia (Formichella, Krüger, Rojas, 2009; Diez-Gutierrez, 2018). En relación a la mayor cobertura se reconocen los progresos, como se verá para Colombia, pero la misma bibliografía citada dice que el impacto fue asimétrico debido a las diferentes posibilidades de los territorios. Para este tipo de opiniones esta inequidad es intrínseca al modelo, para los defensores del mismo, se trata de mejorar los instrumentos, generar compensaciones, etc.

En cuanto a la calidad de la educación, tema que no estamos abordando, según Kameshwara, Sandoval-Hernandez, Shields, Rai Dhanda, (2020) no hay correlación entre resultados de las pruebas y procesos de reforma, ellos dicen que las estrategias pedagógicas y su impacto, la participación ciudadana en los espacios como comités, tienen causas sistémicas y dependen de las diferentes intensidades de cada acción e importan las posibilidades del punto de partida. Estos temas volverán a ser tratados específicamente para el debate colombiano.

\section{Capítulo 2. Hitos de la descentralización del Estado y debates en Colombia}




\section{La normativa}

La Constitución Nacional de 1991 consagra el Derecho Fundamental de las personas a acceder a la Educación y con ello, le asigna al Estado la responsabilidad de garantizar el servicio educativo.

La misma Carta Política se compromete en un proceso de descentralización y mayor participación con el fin de aumentar la legitimidad y gobernabilidad, suponiendo que al acercar la toma de decisiones al ciudadano, este puede incidir sobre una mejor prestación de los servicios sociales por el rol que tendrán las entidades territoriales.

Según el artículo 287, 298 y 302 de la Carta las entidades territoriales (los departamentos, los distritos, los municipios y los territorios indígenas) tienen el derecho de gobernarse, administrar recursos, establecer ciertos tributos, realizar actividades que hasta el momento correspondían a la escala nacional, etc. para lo cual gozarán de autonomía (García largo, 2014). Luego se hace necesaria la segmentación de los municipios en distintas categorías - articulo 320-, seleccionadas a raíz de las características propias de cada uno de ellos.

En cuanto a los recursos nacionales, el artículo 356 indica que corresponde a la ley fijar los servicios a cargo de nación y de las entidades territoriales, además de determinar el porcentaje a ceder a los departamentos y distritos, y bajo qué criterios deben ser distribuidos los mismos. Adicionalmente, la ley debe establecer áreas prioritarias de inversión social y los criterios que se utilizaran para distribuir los recursos con los municipios - articulo 357-. El artículo 362 establece garantías para el uso de los que se originan endógenamente, en otras palabras, aquellos que son recaudados por las entidades territoriales, indicando que solamente podrán ser trasladados a nación en caso de guerra exterior (Soto, 2003). 
El proceso continúa con la ley 617 del 2000 que establece que los entes territoriales deberán hacer frente con sus recursos endógenos a los servicios que queden administrados por ellos. Y la Ley 715 de 2001 que dicta las normas en materia de recursos y competencias de los servicios de educación y salud, distribuyendo los recursos del monto total mediante la creación del Sistema General de Participaciones, reglamentando el Acto Legislativo 01 de 2001 (CGR, 2017).

La Contraloría General de la República (CGR, 2017) dice que la clave fue la unificación de todas las transferencias y la obligatoriedad del monto total que crecería según pautas preestablecidas. El valor iría ajustando por la variación promedio en los últimos 4 años del ICN a partir del 2008 porque previamente ajustaba transitoriamente por ICN más algún punto adicional. Este sistema desliga por completo el monto transferido como porcentaje del ICN, y garantiza el ajuste de los valores recibidos por las distintas jurisdicciones.

Los porcentajes son los siguientes: sector educativo $58,5 \%$, para salud $24,5 \%$ y gastos generales 17\%; el 4\% para Alimentación Escolar, Fondo Nacional de Pensiones de las entidades territoriales, Resguardos Indígenas y municipios ribereños del Rio Magdalena.

Los criterios de asignación de recursos del Sistema general de Participaciones (SGP) específicamente en educación se distribuyen en todos los departamentos, distritos y municipios certificados (salvo los departamentos creados por ley donde se reconocen las diferencias) según 4 tipologías y se brindan dos asignaciones adicionales para los cursos de adultos. Con esos recursos se pueden mejorar los ingresos de los docentes por ascensos en el escalafón.

Las tipologías están compuestas por los costos según nivel, zona y grupo; los docentes requeridos; el costo de los directivos; número de alumnos; gastos de 
personal administrativo y administración del servicio y por último la proporción destinada a financiar la canasta educativa (MEN, 2009).

\section{COMPOSICIÓN DE LA TIPOLOGÍA}

\begin{tabular}{|l|l|}
\hline COMPONENTE & \multicolumn{1}{|c|}{ DESCRIPCIÓN } \\
\hline Costo docente/ año & Costo promedio de acuerdo con el nivel, la zona y el grupo \\
\hline $\begin{array}{l}\text { Relación } \\
\text { docentes/grupo }\end{array}$ & $\begin{array}{l}\text { Docentes requeridos para un grupo de acuerdo con el nivel y } \\
\text { la especialidad. }\end{array}$ \\
\hline Directivos-docentes & $\begin{array}{l}\text { Proporción del costo promedio de los directivos docentes para } \\
\text { cada tipo de atención (nivel, zona, grupo). }\end{array}$ \\
\hline Tamaño de grupo & $\begin{array}{l}\text { Número de alumnos que debe atender cada docente según } \\
\text { nivel y zona. }\end{array}$ \\
\hline $\begin{array}{l}\text { Gastos } \\
\text { administrativos }\end{array}$ & $\begin{array}{l}\text { Proporción destinada a cubrir los costos de planta de personal } \\
\text { administrativo y gastos inherentes a la administración del }\end{array}$ \\
\hline Otros costos & $\begin{array}{l}\text { Proporción destinada a la financiación de la canasta educativa } \\
\text { (nfraestructura, dotación, mantenimiento, material didáctico, } \\
\text { etc.). }\end{array}$ \\
\hline
\end{tabular}

Fuente: Elaboración propia en base a Ministerio de Educación de Colombia MEN (2009)

Cuando observamos los valores para el 2009, vemos que efectivamente se otorga un plus para aquellas instituciones pertenecientes a zonas rurales, y además para aquellas instituciones de nuevos departamentos, como es el caso de Arauca y Casanare, Putumayo y San Andrés, Amazonas, Guainía, Guaviare, Vichada y Vaupés. Luego se aprecian las dos partidas correspondientes a los ciclos de adultos. 
Según la descripción de Zapata y Núñez (2017) la distribución de los recursos de propósito general a los municipios se reparte en un $17 \%$ para aquellos que tengan menos de 25.000 habitantes y el $83 \%$ para todos los municipios y distritos. En ambos casos se tienen en cuenta la pobreza relativa y población, en el caso del primer porcentaje se considera un $60 \%$ por pobreza relativa y $40 \%$ por población, y en el caso del segundo $40 \%$ para población y lo mismo por pobreza, pero además con dos componentes que expresan eficiencia administrativa y fiscal, dos criterios que buscan incentivar a aquellos municipios que cumplan con sus límites de gasto y que además incentiven el crecimiento de los ingresos propios.

Luego, estos recursos podrán ser utilizados de distintas maneras dependiendo de la categoría a la que pertenezca el municipio. Si hablamos de municipios de primera, segunda o tercera categoría, el $100 \%$ se destina a inversión con $8 \%$ a deporte, $6 \%$ a cultura, $10 \%$ al FONPET y los restantes a inversiones en otros rubros. En caso de tratarse de municipios de cuarta, quinta o sexta categoría, un $42 \%$ de los recursos son de libre destinación, lo restante se distribuye en un $8 \%$ para deporte, $6 \%$ cultura, 10\% FONPET, y los restantes de libre inversión.

La ley orgánica de ordenamiento territorial sufre diversas modificaciones pero es central la ley 1454 del 2011 porque pone énfasis en la descentralización al otorgar más instrumentos para que sean las entidades territoriales las que definan la distribución de competencias entre nación, entidades y demás esquemas asociativos. En este marco, en el año 2012 mediante la Ley 1530 se reformula la regulación sobre las distintas regalías declarándolas pertenecientes al Estado y no a una parte de este, y como consecuencia brinda a todas las entidades territoriales la participación sobre las regalías de manera equitativa. La norma, fue cuestionada pero la Corte entendió que ésta se trata de una prerrogativa del gobierno central. La Ley 1816 de 2015 fija un régimen mediante el cual la renta de monopolio proveniente de los licores destilados y las del alcohol debe destinarse en un $51 \%$ a salud y educación. 


\section{Los resultados y los debates}

Ante todo, el nivel del gasto per cápita como vimos en el capítulo anterior es bajo y eso condiciona el proceso general. Por otro lado, como se vio Colombia tiene un nivel algo inferior de descentralización fiscal cuando se la compara con los países de la OCDE, pero si se compara con países unitarios, el gasto público subnacional se encuentra más cercano al promedio que asciende al 29.1\% (por encima de Grecia, Turquía, Irlanda, Nueva Zelanda o Chile). Los municipios representan las dos terceras partes del total mientras que los Departamentos, la tercera restante. En América latina, junto con Perú son los dos países unitarios más descentralizados.

Zapata y Núñez (2017) muestran para el periodo 2002-2014 que los ingresos corrientes de los municipios per cápita y los ingresos tributarios per cápita crecen sostenidamente, y principalmente en los últimos años. $Y$ se observa un mayor crecimiento en los municipios de más de un millón de habitantes y en los menores a 25.000. Caso contrario aquellos municipios entre 25.000 y 100.000 habitantes que tuvieron un crecimiento discreto.

Los recursos de propósito general para el mismo periodo presentan una tendencia al crecimiento, los municipios de menos de 25.000 fueron los que más incremento tuvieron haciendo que la participación de estos se eleve en el total de recursos disponibles. Para el resto de los municipios la situación fue distinta ya que algunos vieron un leve crecimiento y otros hasta disminuyeron sus recursos de PG, teniendo como resultado que en todos ellos la participación de los mismos se redujera considerablemente.

CGR (2009) sin embargo, algo antes y con una clasificación más exhaustiva, permite ver que en 2009 no hay una correlación entre transferencias per cápita y niveles de pobreza, incluso se pueden ver notables incoherencias. Pero en 2014 la relación es mayor todavía se advierte que zonas con altísimo PBI per cápita reciben altos niveles de SGP. 
Esta hipótesis es sostenida también por OCDE (2016) que dice que en 7 municipios considerados de categoría especial el $60 \%$ de los ingresos provienen de recursos propios, mientras que en el $90 \%$ de los municipios de Colombia ese porcentaje se reduce a $15 \%$. Este problema se puede agravar si la descentralización continúa.

Ya dentro de los cuestionamientos "desde adentro" Soto (2003) plantea que el modelo es un hibrido entre federalismo fiscal y principal-agente, porque las entidades territoriales sacrificaron la posibilidad de gobernar a cambio de obtener - como agentes - una mayor porción de los recursos corrientes de la nación. Por eso no desaparece el clientelismo y tampoco el aparato burocrático. García Largo (2014), indica que, si bien se les da a los territorios la posibilidad de administrar los recursos, imponer tributos y el derecho a participar en los recursos nacionales, estos últimos quedan supeditados a decisiones centrales. También García Largo plantea la escasa autonomía mostrando los límites impuestos por las atribuciones del Congreso que explican el hecho de que la fuente exógena tenga tanta importancia. Las capacidades locales se configuran en un contexto unitario. Afirma que se ha presentado esta polémica toda vez que el gobierno central y el Congreso han limitado nuevamente funciones administrativas de los entes territoriales para devolverlas a la administración central.

El centralismo es el eje de las críticas de los gobernadores. Caldas (2020) recoge los discursos de un foro de la Federación Nacional de Departamentos en la que se hace hincapié en esta cuestión como un problema central de la falta de capacidades en las escalas inferiores, se plantea que más que una descentralización es una delegación acotada. El gobierno replica según la misma fuente que falta iniciativa

La cuestión sigue atravesada por el problema de la heterogeneidad. La estrategia general estaba basada en la confianza en el territorio, pero las asimetrías subsisten, Maldonado Copello (2011) mostraba para el período 1985 y 2005 con 
datos de DANE que el porcentaje de población pobre se había reducido, pero que la situación presentaba fuertes disparidades. Mencionaba que los departamentos de Vichada, Amazonas, La Guajira y Guainía incrementaron sus niveles de pobreza. En el censo 2005, de 33 departamentos 5 tenían niveles inferiores a $20 \%$; 13 entre $20 \%$ y $40 \%$; 11 entre $40 \%$ y $60 \%$; y por último 4 departamentos por encima del 60\%. En 2018 según DANE (2021) incluido Chocó bajaron a 3 los departamentos con un valor por encima del $60 \%$, se mantuvo en 11 entre $40 \%$ y $60 \%$ a 10 entre $20 \%$ y $40 \%$ y el valor de departamentos por debajo del $20 \%$ asciende a 18). La situación ha mejorado muy poco leída en estos términos. La Guajira aumentó su pobreza para el mismo periodo en un $13.7 \%$ y Chocó la redujo solamente un $3.6 \%$.

Cante y Jiménez (2020) muestra a través de un análisis de clusters que hay 403 municipios con alto nivel de pobreza multidimensional (IPM), bajos niveles de recaudación que requieren de apoyo del departamento y de nación. Otros 153, con un IPM mayor al anterior, pero con ciertos espacios más dinámicos, debe seguir recibiendo apoyo, pero además puede tener una política proactiva que el primer grupo no tenía. En mejores condiciones hay un cluster de 378 municipios con menos pobreza, población más urbana pero aun una vasta población del campo, son entes que pueden trabajar con más autonomía enfocándose en tanto en la pobreza urbana como rural. $Y$ hay un cluster de 164 que agrupa localidades más grandes y pobladas (ejemplo, las capitales de Departamento) que podrían asumir por completo las funciones asignadas a nivel local, debido al tamaño y la capacidad que poseen. Más allá de tratarse de entidades autosuficientes puede que el entorno regional las obligue a articularse con otras entidades de la misma clase o con aquellos entes circundantes mediante esquemas de asociatividad territorial.

Bonet Morón y Ayala García (2016) llegan a conclusiones similares a partir de una cuestión que se ha tratado en el apartado anterior de esta tesis, los diferenciales de necesidad de gasto por habitante en cada municipio y muestra la alta cantidad 
de entes locales y los pocos que se ubican en valores superiores. El Gini para esta variable fue de 0,34 , incluso superior al obtenido para la desigualdad social (de 0,29 ). Los autores muestran que el gasto municipal por habitante fue para 2014 de $\$ 1.542 .623$, mientras que la necesidad de gasto fue de $\$ 2.294 .114$. En esos cálculos, 787 municipios ejecutaron un gasto por debajo de la necesidad, mientras que 308 municipios tuvieron un gasto ejecutado por encima. Entonces, con el excedente de estos 308 se hubiera podido cubrir la necesidad de gasto de los entes deficitarios. Hubo un $48 \%$ de la población que no pudieron ver cubiertas sus necesidades. Y del lado de la capacidad fiscal surge lo mismo, que los municipios más desarrollados recaudaron un $57.6 \%$ del potencial, mientras que los menos desarrollados un $19.9 \%$, representando mayor disponibilidad de recursos para los primeros y mayores desigualdades en la capacidad de gasto. Es decir, que los recursos propios no logran compensar las mencionadas necesidades, sino que profundizan el problema.

OCDE (2016) hace ver la misma problemática en comparación con otros países. Colombia es el segundo país con Gini territorial más elevado, la sigue Chile y México. A raíz de esto la misma fuente pone en duda el SGP indicando que puede hacer una revisión de las formas en que se determinan las asignaciones, permitiendo mayor flexibilidad y nuevos parámetros que promuevan la solidaridad financiera (mecanismos de equiparación para apoyar a estas regiones). Se verá lo sucedido para la educación en cuanto a transferencias y equidad en el capítulo 3.

Al mismo tiempo OCDE (2016) pone el acento en la falencia que tienen los gobiernos subnacionales para recaudar, según sus cálculos del índice de evaluación de capacidades a nivel subnacional, 2/3 tienen baja capacidad y el $30 \%$ posee niveles intermedios o altos. Agrega que 672 municipios no han ejecutado más del $20 \%$ del presupuesto.

Entre los problemas de gestión, diversa según los municipios, se menciona el tamaño pequeño del sector público subnacional, alta rotación de personal, bajos 
salarios y perfiles ejecutivos políticos más que técnicos; escasa capacidad para el diseño de proyectos en las regiones rurales contribuye a las desigualdades territoriales. Menciona el hecho de que la norma limita los costos operativos de municipios con menos de 30.000 habitantes, pero no tiene en cuenta las necesidades de personal nuevo y con competencias acordes.

OCDE (2016) propone que deben mejorar los registros catastrales y prediales; racionalizar el portafolio de impuestos; disminuir los impuestos con destinos específicos; permitir instrumentos como peajes o cobros por congestión; promover mayor flexibilidad en gravámenes a usuarios y tarifas locales además de optimizar rentas por inmuebles. $Y$ especialmente fortalecer los sistemas administrativos y de control. Los diversos programas que brindan asistencia necesitan una mejor coordinación con especial énfasis en los municipios más débiles, focalizando en la fase de diseño de los proyectos, pero no de manera exclusiva. Finalmente la entidad supranacional plantea el tema de la corrupción local y regional como un problema de control, poniendo énfasis en la modificación del sistema de elección de contralores regionales, actualmente elegidos por asambleas regionales. Al mismo tiempo sostiene que Colombia ha establecido varios mecanismos para mejorar la participación de los grupos de interés en el diseño y la implementación de políticas pero que esta participación se ve limitada por la falta de recursos y competencias para los procesos participativos y en red de muchos gobiernos sub nacionales. Esta es una clave.

Por eso, lo más interesante de recalcar es que muchos autores, como el mismo DNP (2016) relacionan heterogeneidades, problemas de gestión y participación que debería plantearse junto a la redistribución del SGP. Plantea que el proceso de descentralización juega un papel básico en el fortalecimiento de las capacidades regionales y locales y que la situación de hoy comparada con la existente hace una o dos décadas, es mejor en la medida de que se elige democráticamente a los gobernadores y alcaldes, se impulsa al mejoramiento de la gestión, etc. Pero existen inconvenientes: lo más importante es la falta de 
reconocimiento de la heterogeneidad territorial, inequidad en los recursos, uniformidad de estrategias, poco desarrollo institucional, lo que ha generado que no ha habido progresos en el esfuerzo fiscal departamental y municipal y mayores beneficios a los centros urbanos con mayor costo de sus servicios. Entre las sugerencias aparece como central la de cuidar la heterogeneidad de lo municipio.

Restrepo y Nisimblat (2014) en el mismo sentido, valoran el proceso de descentralización de los 80 por las distintas instancias de participación que permitió e incluso lo consideran positivo en el proceso de paz, pero plantean que la misma no incluyó la descentralización del modelo de desarrollo y no fue capaz de conseguir resultados en términos de equidad. Así mismo, plantean el riesgo de que debido a las asimetrías aún existentes suceda una recentralización y ponen el acento en volver a utilizar instrumentos que permitan generar desarrollo y reemplazar las actividades ilegales fundamentalmente atrás de planes específicos superadores de los actuales planes de desarrollo social. También plantean darle un rol a los departamentos de coordinación e igualación de oportunidades para afrontar grandes inversiones de escala muy necesarias. Como un problema grave se dice que el malestar y la movilización van por otros canales mientras que la oferta institucional a veces no es utilizada y sostienen la necesidad de darle un mayor sesgo territorial y comunitario a las políticas sectoriales incluyendo asociaciones sectoriales y sindicatos ya que la descentralización fue más hacia prestadoras de servicios qué hacia las comunidades

Velázquez (1995) pone el acento en la falta de capacidad de gestión, especialmente los más pequeños, por otro lado dice que el modelo expuso más a los municipios que al clientelismo. Lo atribuye a que se han creado mecanismos de participación política como la Ley 134 de 1994 (iniciativa popular, referendo, consulta popular, cabildo abierto, revocatoria del mandato) pero la cuestión de los «pactos de poder» es estructural. Con las normas no alcanza. Debido a la importancia de los programas de inversión nacionales, las transferencias del gobierno central y el sistema de cofinanciación, las tensiones entre las escalas 
aumentan. Velázquez (2014) luego de muchos años y tratando de entender la cuestión de las regalías propone ampliar la participación ciudadana a partir de la ley de participación del 2012 para crear dispositivos particulares cómo pactos de gobernanza mesa de trabajo y un sistema de protocolos mientras los alcaldes y gobernadores tienen que disponer de fondos para estimular dicha participación.

Maldonado Copello (2011) va por el mismo camino, dice que la participación ciudadana no fue promovida por el gobierno nacional y las entidades territoriales, quedando solamente escritas, en las entidades territoriales la descentralización es absorbida por la lógica política local. La deficiencia de gestión se marca más en aquellos departamentos con menores ingresos sin embargo cuando aparece la voluntad política de llevar adelante un buen proceso de gestión para con la población, cualquier municipio logra buenos resultados. Parece el ejemplo de Sabaneta.

\section{Capítulo 3. Descentralización y reforma de la educación en Colombia}

\section{La normativa}

La descentralización y la reforma de la gestión que tiene un eje central en la autonomía, en Colombia van en paralelo a la descentralización general. En el año 1987 mediante el Decreto 077 se delega a los municipios el manejo de los planteles escolares; en el año 1988 mediante la Ley 24 se otorga a los departamentos las funciones administrativas para manejar las instituciones escolares; luego en 1989 se da a los municipios el manejo del personal (docente y administrativo) mediante la Ley 29. (Caballero Prieto, s/f).

Luego, la constitución de 1991 consagró la educación como derecho fundamental

y como servicio público que tiene una función social. Caballero Prieto (s/f) describe cómo la ley 60 de 1993 de competencias y recursos distribuye fondos en base a necesidades básicas insatisfechas, el ingreso per cápita territorial y la densidad 
poblacional y la Ley General de Educación 115 de 1994 que concedió autonomía a los colegios y a los gobiernos territoriales en la definición de currículos y textos, bajo los lineamientos del MEN.

En ella surgen los Consejos directivos y también la Junta Municipal de Educación (JUME). Los consejos fueron definidos a lo largo del tiempo, pero el decreto 0400 de 2001 establece centralmente el gobierno escolar y los mecanismos de participación de la comunidad educativa. En el vértice está la rectoría con la tarea de orientar el proyecto institucional y aplicar las decisiones. Pero es el Consejo directivo el encargado de tomar las decisiones en cuanto al funcionamiento de la institución, excepto las atinentes a la dirección administrativa de los privados. Los claustros están organizados del siguiente modo: el Consejo Académico, el Personero estudiantil en la gestión, el Cabildante estudiantil que debe velar por los derechos, deberes, el cuidado y fortalecimiento de lo público, la Contraloría estudiantil encargado del control del buen uso de los recursos del colegio. El Consejo estudiantil que elije anualmente a los representantes de los estudiantes por grado como representantes de grupos y el personero estudiantil del grado once, para representar a los estudiantes en las actividades escolares, el gobierno escolar y el consejo directivo, por mencionar algunos. Se eligen por voto popular (As.com, 2021). En cuanto al personero estudiantil, se elige a los 30 días iniciales del calendario escolar. Los postulantes se presentan mediante una campaña electoral y luego de una jornada de votación desarrollada dentro de cada institución se define el representante estudiantil. Quinceno-Botero, Rojas-Betancur y Hernandez-Quirama (2019) realizan esa descripción y llaman la atención acerca de maniobras -a veces apoyadas por los padres de los alumnos- para encaramar al hijo y también casos en que el acto es minimizado o sesgado en favor de un candidato ejemplar y en contra de los alumnos "problemáticos". Posteriormente puede suceder que la institución limita la acción política del personero a la esfera recreativa. No hemos encontrado trabajos con datos estadísticos sólidos. 
La JUME tiene el carácter de consultor permanente del municipio, conformada por el Alcalde, la Secretaria de Educación, el Director de Núcleo Educativo, un Representante del Concejo Municipal; dos Representantes de los educadores, uno de los cuales será directivo docente, un Representante de los padres de familia; un Representante de la comunidad campesina; un Representante de las instituciones educativas privadas del municipio. Entre las funciones está coordinar y asesorar a las instituciones educativas para la elaboración y desarrollo del currículo; proponer al departamento la planta de personal, emitir concepto previo para su traslado.

Es interesante resaltar que durante la segunda parte de los años 90 s se discute la forma de distribuir los fondos pasándose de a poco al modelo actual de demanda, dejando de lado la asignación por cantidad de maestros, y asumiendo como central los recursos por niños y jóvenes en edad escolar y al mismo tiempo el sistema de promoción de proyectos con fondos propios (Latinno, 2021).

Pero como vimos, es la ley 715 de 2001 que establece el nuevo modelo de transferencias. $Y$ en esa ley se definen las Entidades Territoriales Certificadas (ETC), como los entes regionales y locales de más de 100.000 habitantes que gozarán de mayor autonomía, desde el 2004 podrían entrar los municipios más pequeños cuando cumpliesen con los requisitos establecidos ${ }^{9}$ (Federdesarollo, 2018). El monto del SGP para educación surge de la Constitución pero su distribución entre las entidades territoriales, así como entre destinos (cobertura y calidad) se rige por la Ley 715 . El ministerio de educación se encarga de determinar la política nacional del sector, directrices, estándares, proteger derecho al acceso y seguimiento del servicio.

\footnotetext{
${ }^{9}$ La autonomía política y administrativa a las entidades territoriales tuvo un primer momento de corte departamental y posteriormente un segundo momento municipal, que tuvo dos fases, la primera para aquellos que tenían más de 100.000 habitantes y la segunda desde 2004 otros que quisiesen acogerse a la certificación y estuviesen en condiciones de hacerlo.
} 
Las ETC pueden administrar el servicio educativo en su jurisdicción, para eso reciben directamente los recursos a una cuenta maestra. En cambio aquellas entidades o municipios que no estén certificados deben coordinar con la secretaria de educación certificada (departamento) y directivos de establecimientos educativos de su jurisdicción, el uso de los fondos mediante el acceso a una bolsa común de recursos por medio de un convenio con una ETC., en general el departamento. En la actualidad existen 95 ETC, 32 departamentos y 63 municipios, y 1037 entidades municipales dependientes de su respectivo departamento (Forero y Moreno, 2019)

Según esta fuente que desarrolla todo el mecanismo y MEN (2018), el SGP para educación se distribuye de acuerdo a tres bolsas. Bolsa población atendida distribuidas entre las ETC para cubrir costos de prestación del servicio (mayoritariamente pago de nómina). Además, pueden destinarse a construcción y mantenimiento, pago de servicios públicos, necesidades educativas especiales y si sobran recursos, a transporte y alimentación escolar.

Luego la bolsa calidad-matrícula, para municipios certificados y no certificados, y las áreas no municipalizadas de Amazonas, Guainia y Vaupes pueden usarse en infraestructura educativa, la dotación de las instituciones, capacitación. También complementar transporte y la alimentación escolar ${ }^{10}$.

Por último la bolsa calidad-gratuidad educativa, distribuida en los distintos establecimientos educativos, cuyo objetivo es apoyar a los estudiantes, eliminar barreras de acceso, eximir del pago de derechos académicos, etc pueden usarse para becas, proyectos educativos productivos, arrendamientos, impresiones y publicaciones, seguros y transporte, etc. Al igual que los de calidad-matricula, son girados directamente a los municipios para luego trasladarse a los

\footnotetext{
${ }^{10}$ Los municipios no certificados como ETC, también reciben recursos para calidad que pueden ser utilizados para la prestación del servicio menos para gasto de nómina, y en la práctica son usados para capacitación de docentes, necesidades de los establecimientos educativos (transporte y mantenimiento de infraestructura).
} 
establecimientos. Adicionalmente un $1 \%$ es para cancelar prestaciones sociales del magisterio, y desde 2013 hay un porcentaje menor para conectividad.

La ley 715 del 2001 establece un criterio de transferencia de recursos por niño atendido, buscando estimular la ampliación de la cobertura y la retención de los niños en las escuelas, estrategia que parece haber dado resultado. También se tiene en cuenta las necesidades educativas especiales, internados y establecimientos con jornadas únicas. $Y$ toda entidad territorial que brinde servicio con su capacidad oficial a la población que ingresa al Sistema de Responsabilidad Penal para Adolescentes recibirá un 20\% adicional (MEN, 2018; Forero y Moreno, 2019).

Según estas fuentes, los recursos del SGP destinados a la nómina docente y directiva, incluyen la asignación básica (valor mensual básico por cargo sin considerar otros factores), los auxilios de movilización, auxilios de transporte, bonificaciones por zonas de difícil acceso, recargos nocturnos, ascensos en el Escalafón Nacional Docente, Sobresueldo de Directivos Docentes (asignaciones adicionales determinadas anualmente para los servidores públicos directivos), horas extras (con previa reglamentación dictada por la Secretaria de Educación). Además, se abonan las indemnizaciones por vacaciones (para aquellas personas que no hicieron uso de los días de vacaciones asignados por año académico), otros gastos por servicios personales, subsidio de alimentación, prima de servicio (el Decreto 1545 de 2013 establece el pago de 15 días de remuneración al 30 de junio), prima de vacaciones ( $50 \%$ del sueldo mensual), prima de navidad ( 1 mes de salario al 30 de noviembre), entre otras.

Por otro lado, de la misma fuente surge que hay transferencias destinadas a sostener planes y programas específicos, por ejemplo, la adición de recursos para saldar la diferencia entre los aportes patronales del personal docente y directivo; el 
Programa de Alimentación Escolar, el Programa Nacional de alfabetización para jóvenes y adultos, etc. En todos los casos se exige a cambio de los recursos una serie de lineamientos administrativos y estándares mínimos del programa, la movilización necesaria, la participación del rector, la infraestructura necesaria, según el caso.

En el caso de los ingresos por regalías, en el 2017 se definieron etapas y procedimientos que deben cumplir las inversiones realizadas con esas fuentes obligando a los municipios y departamentos a presentar los proyectos ante el área correspondiente del gobierno nacional.

Los fondos propios del municipio pueden provenir de su presupuesto y también desde el decreto 2880 de 2004 puede recibir recursos de instituciones solidarias, que dejan de pagar el impuesto a la renta siempre que lo donado sea esté un $20 \%$ por encima de su resultado. Los destinos pueden ser cupos educativos del proyecto ACCES-ICETEX u otros proyectos con previa aprobación del Ministerio de Educación Nacional.

Este esquema hace que el modelo sea un mix de proporción y focalización, que no permite a los entes aumentar las plantas docentes o administrativas por encima de los recursos asignados, además de limitar los aumentos por ascensos o cualquier otro gasto adicional que supere el límite de los recursos disponibles en el SGP. En línea con esto, la Ley 1176 del 2007 establece el porcentaje de los recursos provenientes por población atendida que podrán ser destinados para gastos administrativos con estos recursos, la diferencia debe ser afrontada por el ente.

La responsabilidad de las Entidades Territoriales Certificadas (ETC) incluye administrar la planta docente y directiva, y los ascensos. En cuanto a la primera 
administra la planta de su jurisdicción, pero no selecciona docentes ya que se hace por concurso (los traslados si pueden realizarse pero por acto administrativo). Luego ascensos de aquellos docentes que se financian con cargo al SGP si son administrados por las ETC, siguiendo criterios tales como tiempo de permanencia y estudios de posgrado, agregando el nuevo estatuto una evaluación de desempeño. Por otro lado, las ETC están autorizadas a contratar entidades no estatales con cargo al SGP si se demuestra el déficit estatal y pueden pagar la planta del personal administrativo de las escuelas también con cargo al SGP.

El Fondo de Servicios Educativos, es el mecanismo que le permite a los establecimientos educativos controlar un conjunto de ingresos y gastos. Los prerrequisitos para que el establecimiento pueda crear este fondo es que tenga el consejo directivo organizado, y además que cuente o contrate el personal necesario.

En los establecimientos son los rectores los encargados de administrar los Fondos de Servicio Educativo (FSE), destinados a gastos de funcionamiento distintos a los de personal. Los mismos son recibidos por el concepto de "gratuidad". Los FSE se reciben por otros conceptos (distintos a los de población atendida y población por atender) y comprenden también los recursos propios de los municipios.

Los fundamentos de certificación educativa según la LEY 715 están en la búsqueda del acrecentamiento de la cobertura y la calidad, así como la eficiencia en la utilización de los recursos que le son transferidos a los entes territoriales, también la equidad territorial, la democracia representativa y participativa, el esfuerzo fiscal y el mejoramiento de la capacidad de gestión administrativa, directiva, académica y comunitaria. Estos objetivos serán logrados bajo la hipótesis de que tales propósitos se alcanzan al estar más cerca de las necesidades de los usuarios, siempre que el gobierno territorial cuente con la 
capacidad técnica, administrativa y financiera, en lo que hace a la planificación y la gestión. En el capítulo 5 veremos cómo funcionó en general y para Sabaneta.

En cuanto a la evolución normativa del SGP, un acto legislativo del 2002 establece tasas de crecimiento para el mismo: $2 \%$ por año entre 2002 y 2005 , y del $2.5 \%$ entre 2006 y 2008.

En el 2007 ocurre algo similar (acto legislativo 04): $4 \%$ en 2008 y 2009 , del $3.5 \%$ en 2010 y del 3\% entre 2011 y 2016 ... Estableció también un crecimiento adicional para la participación del sector educación del $1.3 \%$ en 2008 y 2009, 1.6\% en 2010 , y $1.8 \%$ entre 2011 y 2016 . El monto del SGP crecerá a partir de 2017 de acuerdo con el incremento promedio de los ingresos corrientes de la nación en los últimos cuatro años. A su vez el Ministerio de Educación, mediante el decreto 3020/ 2002, especifica ciertas condiciones para el proceso que hacen al plan de desarroll, los establecimientos educativos, la planta de personal, número adecuado de estudiantes por aula de acuerdo según capacidad física, un plan de gestión, sistemas de información, certificación de los procesos, vigilancia y control.

En 2002, mediante decreto $1278^{11}$ se modifica el Estatuto Docente del decreto 2277 de 1979, con nuevos criterios de ingreso, ascenso y retiro, con una estructura de tres grados con cuatro niveles salariales, con evaluaciones de desempeño y aptitud para otorgar ascensos.

Se establece que los directivos desempeñan las actividades de dirección, planeación, coordinación, administración y son responsables del funcionamiento de la organización escolar. Las funciones del Rector incluyen todo lo concerniente al proyecto educativo institucional y las decisiones del gobierno escolar; también el

\footnotetext{
${ }^{11}$ Este enfoque se completó con diversos decretos posteriores, por ejemplo, el decreto 3783 de 2007 que establece protocolos que deben cumplirse a la hora de efectuar las evaluaciones.
} 
aprovisionamiento de los recursos necesarios. Rosales-Yepes, Montes-Miranday Figueroa-Gutiérrez (2020) sostienen que lo que se pretendió es fortalecer el liderazgo de los directivos docentes porque así se iba a elevar la calidad educativa de las instituciones ${ }^{12}$. Las funciones de los docentes se desarrollan frente a los alumnos con una batería similar de procedimientos.

Según la síntesis de Bayona Rodríguez (2017) el decreto 1278 permite que los docentes cobren más, generando por ende una brecha entre docentes privados y públicos. Por otro lado, se abandonaron los ascensos por la vía de los puntajes tradicionales prestándose atención a las evaluaciones de otro tipo, según el autor hay una mejora, aunque aún no se logra evidenciar al máximo capacidades relacionadas con proceso. Además, la periodicidad es limitada. Pero igualmente la evaluación del desempeño define los ascensos con evaluaciones y luego también las mejoras salariales. Por último, menciona que hay salarios distintos diferenciando por formación, pero no se viabiliza la posibilidad de acceder a la misma mediante financiamiento masivo de posgrados. Sabaneta avanzó por su cuenta en ese sentido.

En el 2011 con el decreto 4807 la gratuidad se parametriza a partir de condiciones de aplicabilidad, esto con el fin de garantizar el acceso a la educación toda la población, exonerándolo de cualquier pago para derechos académicos. En el artículo 85 de la ley del Plan Nacional de Desarrollo 2014-2018 se establece la jornada única para mantener a los estudiantes más tiempo en los establecimientos, reforzando áreas básicas a través de estrategias como el juego o metodologías diversas y así tener mejor calidad educativa. Se define para el gobierno nacional y entidades territoriales certificadas, un tiempo máximo de aplicación que no debe superar el año 2030.

\footnotetext{
${ }^{12}$ En este mismo sentido de fortalecer el rol directivo es que se conformó después el I programa Rectores Lideres Transformadores.
} 
Ese mismo 2011 se da el traspaso del PAE (Programa de Alimentación Escolar) desde el Instituto Colombiano de Bienestar Familiar hacia el Ministerio de Educación Nacional. Este como estrategia de permanencia escolar y también para garantizar la implementación de la Jornada Única.

\section{Resultados y debates}

El proceso general ha tenido ciertas limitantes y características. Colombia es uno de los paises que menos invierte en Educación. De todos modos ha aumentado del $2,7 \%$ del PBI en $1985,4.75 \%$ en $2005,4,49 \%$. Se evidencia en el grafico que el aumento fuerte en el gasto público como porcentaje del PBI se da en la década del 90 (Federdesarrollo, 2018). La apuesta parece ser a la eficiencia (Cano, 2018).

Según OCDE on line, el gasto promedio de todos los paises que componen el grupo es de US\$10.182 al año por estudiante, cifra para las personas que están desde primaria hasta secundaria y Colombia tan solo destina para cada alumno al año US\$3.245. "En Colombia no se gasta ni $10 \%$ o $20 \%$ de lo que se invierte en otros territorios de la Ocde" (El País.com, 2017). Sólo si se analiza el gasto educativo por alumno al año, pero como proporción del Producto Interno Bruto (PIB) éste no es bajo comparado con otros países. Federdesarrollo (2018) muestra que es superada por Bolivia, Brasil, Argentina y Ecuador mientras Perú, México y Chile registran porcentajes menores. En el caso del nivel primario está por encima de varios países de América latina y en el nivel secundario se ubica por debajo.

Forero y Moreno (2019) muestra dos métodos, para el año 2015, el nivel de gasto público está por debajo del de países como Argentina, México, Brasil y Chile. Analizando con el segundo método se posiciona por encima de Chile, sin embargo sigue estando por debajo de los otros 3 países. Dado el nivel descrito el gasto en educación se destina en gran medida al pago a docentes y administrativos) de 
primaria y secundaria ( $86 \%$ y $90 \%$ respectivamente), dato que, si bien está en línea con los países latinoamericanos, se encuentra muy por encima de los países de la OCDE ( $77 \%$ y $78 \%$ respectivamente).

En cuanto al SGP hay una caída del $81 \%$ del 2002 al $60 \%$ del 2014 y un aumento de los recursos provenientes del MEN (10 a 18\%, mismo periodo). De ese presupuesto, 33\% (2.4 billones) corresponde a al Programa de alimentación escolar, $31 \%$ orientado a aumentar la cobertura educativa, y $18,9 \%$ la calidad educativa. Se suma a esto los recursos destinados al Fomag, para el pago de pensiones y demás prestaciones para los maestros (5.6 billones). En cuanto a la financiación de las entidades territoriales, si bien experimentan una mejora (menos del $9 \%$ en 2002 a $12.8 \%$ en 2014) comparados con los países de la OCDE sigue siendo extremadamente baja ya que en Colombia el $84 \%$ de los recursos provienen de nación mientras que en los países de la OCDE este valor disminuye a $52 \%$. Por último, el financiamiento proveniente de otras entidades públicas se ubica por encima del anterior, alcanzando un $5.8 \%$ en 2014 , mostrando mejoras para el periodo (en 2002 casi $0 \%$ ). Estos datos pueden resultar positivos a quienes esperan la tarea compensatoria del Estado central y negativos para quienes piden más autonomía (Forero y Moreno, 2019).

Como es sabido también, existe una gran disparidad entre distintas entidades territoriales y el uso de recursos propios para financiar el gasto en educación. Los departamentos y municipios grandes (Bogotá, Cali y Medellín), los que asignan recursos propios y significativos para este fin. Según Forero y Moreno (2019) los principales departamentos y los municipios mencionados seguidos de un segundo grupo (Barranquilla y Cartagena) van a la cabeza. Ciudades como Envigado y Sabaneta tienen recursos propios que representan más del $30 \%$ de los gastos totales. En función de esta heterogeneidad es que el MEN trata de incentivar el gasto con recursos propios de las ETC, especialmente con mecanismos de cofinanciación. 


\section{PARTICIPACIÓN DE LOS RECURSOS PROPIOS EN EL TOTAL POR DEPARTAMENTO}

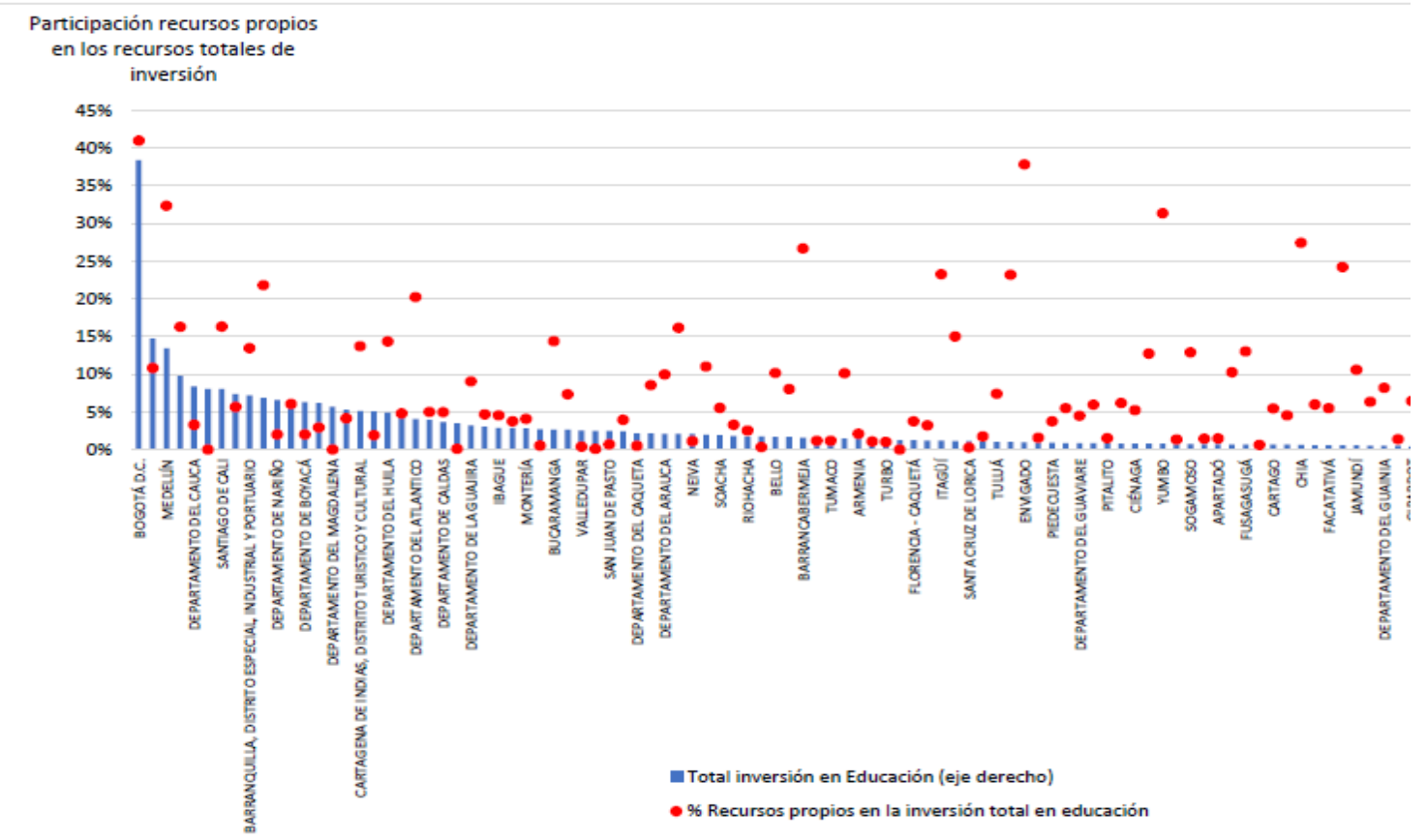

Fuente: Forero y Moreno (2019)

Si se observan las matrículas, por año, desde el 2005 al 2019 hay una tendencia alcista tanto para el nivel medio como secundario -más leve para este último-, un $25 \%$ y $10 \%$ respectivamente. En el nivel medio los aumentos más notables fueron los presentados por los departamentos de Chocó (74\%), Córdoba $(54 \%)$ y Cundinamarca $(40 \%)$.

A nivel nacional las matriculas del nivel primario disminuyeron un $20 \%$. Dentro de los departamentos con caídas más significativas encontramos a Sucre $(-24 \%)$, Antioquia (-22\%) y Córdoba (-19\%). Lo mismo ocurrió con las matriculas del nivel transición, que a nivel nacional disminuyeron un 13\%. 


\section{CANTIDAD DE MATRÍCULAS POR NIVEL EDUCATIVO Y DEPARTAMENTO (INCLUIDO TOTAL NACIONAL). ÍNDICE BASE=2005.}
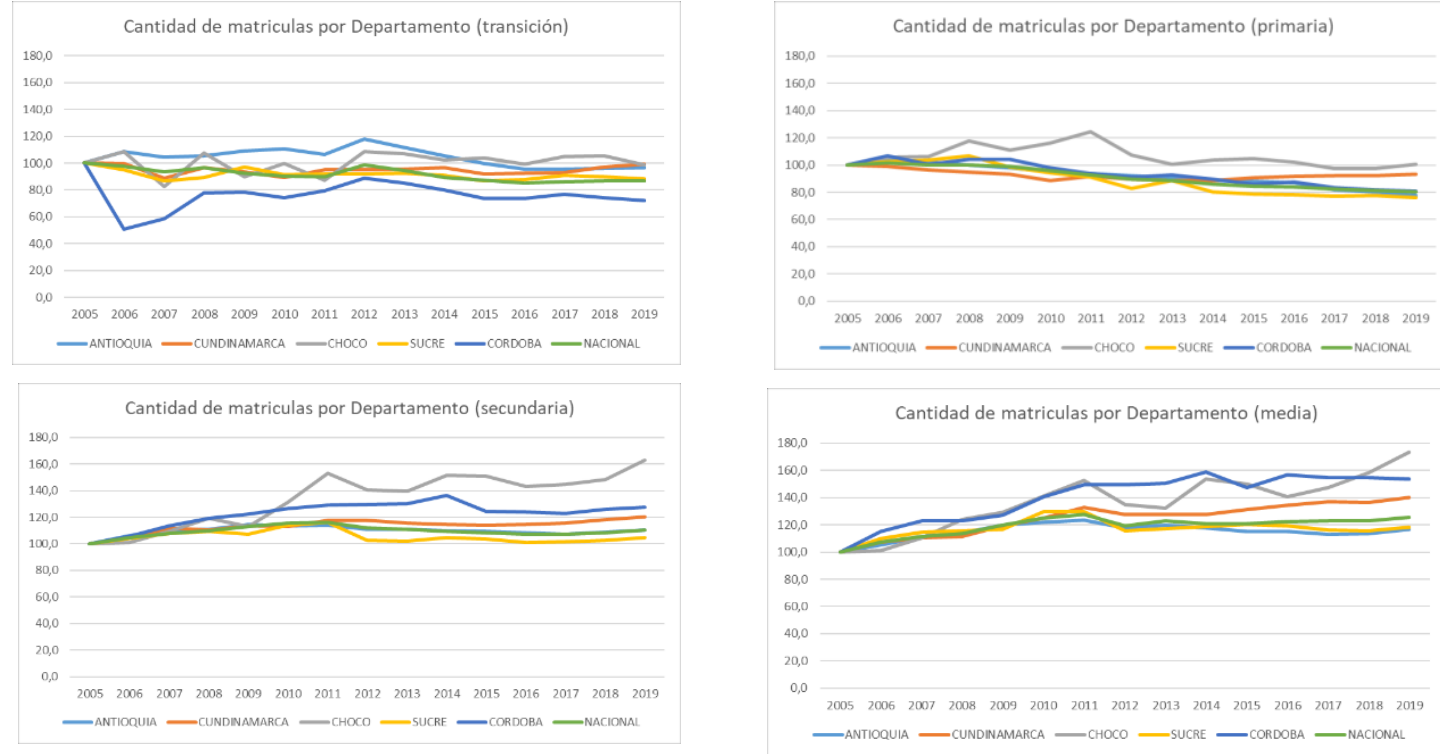

Fuente:http://bi.mineducacion.gov.co:8380/eportal/web/planeacionbasica/matricula

En cuanto a la metodología para medir la tasa de cobertura se usarán dos indicadores: bruta y neta. La tasa bruta de cobertura (TBC), mide el número de niños que están asistiendo a un nivel educativo determinado (sin importar su edad) respecto a la población total que integra el grupo de edad al que teóricamente corresponde ese nivel. Por esta razón las tasas brutas pueden ser mayores al $100 \%$ pues la población que asiste a un nivel determinado, puede ser mayor que la de la edad en la que debería asistir a ese nivel, término que en Colombia se conoce como extraedad. La TBC también puede sobrepasar el 100\% por muchas otras razones, una de ellas es la atención en el municipio de Sabaneta de estudiantes que no son del municipio, sino de otros cercanos, que por multiplicidad de razones deciden matricularse en esta municipalidad.

La Tasa Neta de Cobertura es una tasación de cuánta población en las edades ideales para asistir a educación preescolar, básica y media se matricula en las 
instituciones educativas. Para interpretar correctamente este indicador, se debe tener presente que la edad del alumno juega un papel fundamental.

La Tasa de Cobertura Bruta, ascendió de un 62\% en el 2005 a un $72 \%$ en 2017. Son notables los incrementos en las tasas de cobertura para todos los departamentos en los niveles, secundario y medio. Hemos tomado algunos casos: en el nivel secundario Cundinamarca alcanza el $82 \%$; Sucre $76 \%$; Antioquia $74 \%$; Córdoba $73 \%$; Chocó $49 \%$. Por el lado del nivel media la tasa nacional sigue siendo baja. En el nivel primario se pasa de un $91 \%$ en 2005 a un $83 \%$ en 2017 a nivel nacional. Las caídas más significativas dentro de estos 5 departamentos se presentan en Antioquia (94\% a $83 \%$ ) y Córdoba (95\% a $84 \%$ ). Para el caso del nivel transición se da una situación similar a la anterior. A nivel nacional la tasa de cobertura pasa de un $62 \%$ a un $55 \%$. Y salvo el departamento de Chocó (de $40 \%$ en 2005 a $54 \%$ en 2017) acercándose al promedio nacional, todos los departamentos analizados disminuyeron su tasa de cobertura, con casos significativos como el de Córdoba que cayó de un $83 \%$ a un $54 \%$.

\section{TASA DE COBERTURA BRUTA DIVERSOS NIVELES EDUCATIVOS}
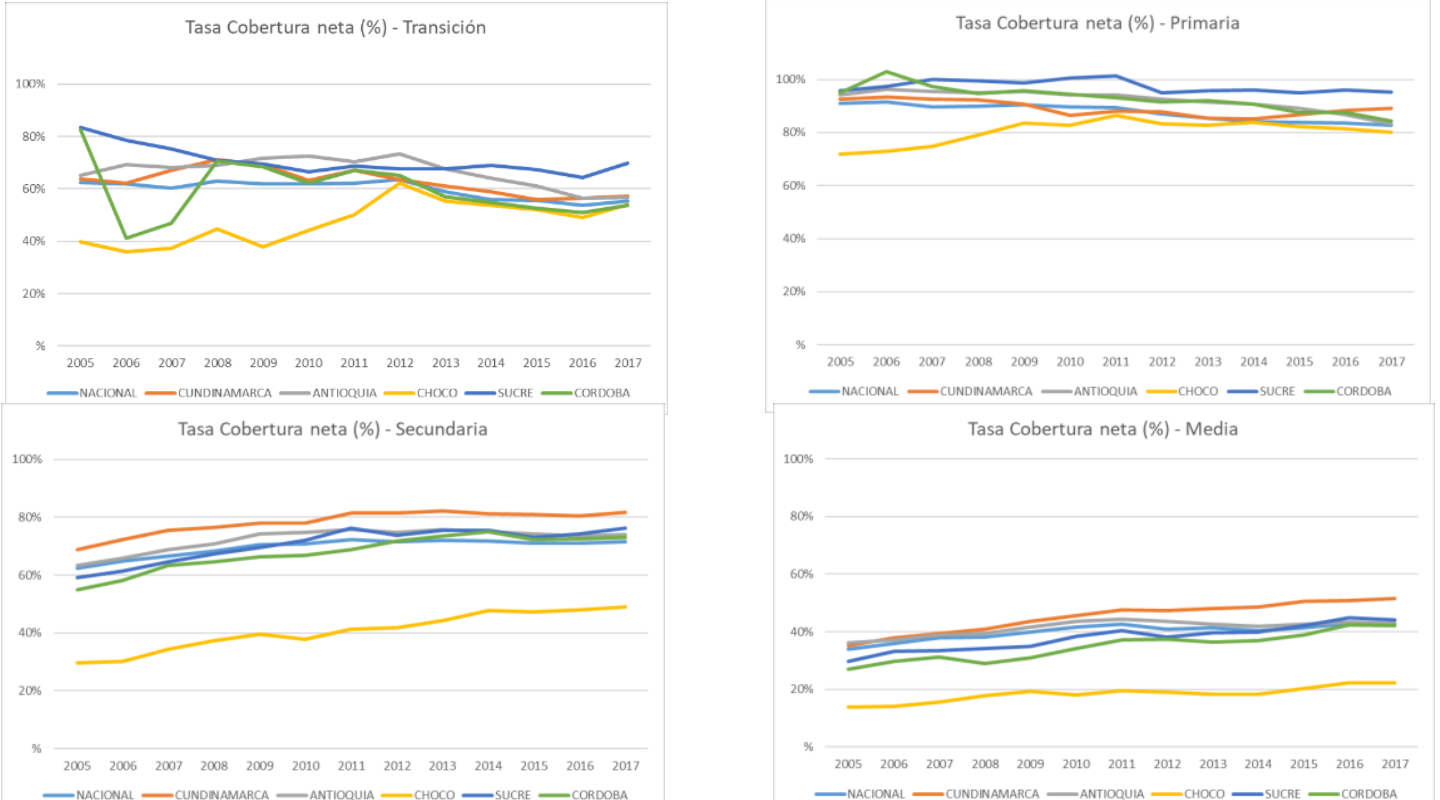

Fuente:

http://bi.mineducacion.gov.co:8380/eportal/web/planeacionbasica/tasa-de-cobertura-neta-x-departamento 
A nivel nacional los establecimientos oficiales disminuyeron un $38 \%$, pasando de 15.735 establecimientos en el año 2005 a 9.788 establecimientos en 2019.

De los departamentos analizados, el que más redujo sus establecimientos oficiales es Antioquia (-75\%, de 3.839 a 976 establecimientos oficiales) y seguido por Sucre (-57\%, de 710 a 303 establecimientos oficiales). El departamento de Chocó (en línea con el resto de los indicadores), es el único que incrementó los establecimientos oficiales para el periodo analizado pasando de 177 en 2005 a 208 en 2019 (18\%), sin variar los establecimientos no oficiales. En cuanto a los establecimientos no oficiales, a nivel nacional disminuyeron un 7\% (de 10.551 a 9.836 establecimientos no oficiales) en el periodo analizado. De los departamentos analizados los únicos que presentaron aumentos en estos fueron Córdoba (34\%) y Cundinamarca (31\%).

\section{ESTABLECIMIENTOS OFICIALES Y NO OFICIALES (EN CANTIDAD POR MUNICIPIO), PARA EL AÑO 2006 Y 2019.}

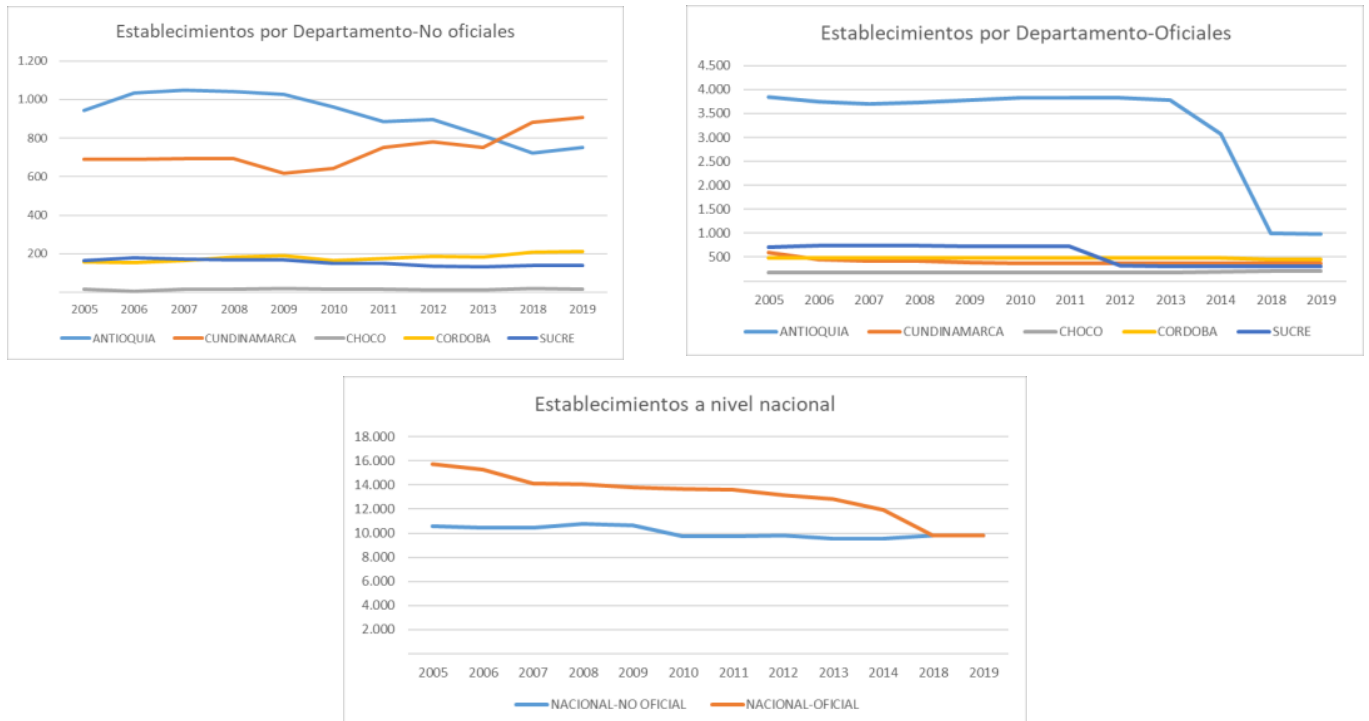

Fuente:http://bi.mineducacion.gov.co:8380/eportal/web/planeacionbasica/establecimientos-educativos 
El texto citado del Ministerio (MEN, 2018) reconoce que Colombia sigue teniendo cobertura baja en comparación con los países de la región. Además, se evidencia una tasa de "repitencia" y de deserción aún muy marcadas, en este caso, 30.1 en secundaria y 11.7 en primaria. Esto da muestras de que el sistema no ha podido garantizar la culminación del ciclo, principalmente en las áreas rurales. Si bien no abundaremos en este aspecto, las comparaciones internacionales ubican desfavorablemente a Colombia en materia de calidad educativa, aunque de a poco aparecen mejoras en las pruebas.

En cuanto a los debates suscitados "desde adentro", Caballero Prieto (s/f) plantea que especialmente al inicio que el modelo está limitado porque no otorga una verdadera autoridad para el manejo del plantel docente y administrativo, cuestión que se agrava cuando se observa que la participación ciudadana no funciona como corresponde pese a las herramientas otorgadas y no ejerce el rol de revisor, y al observar que no existe una fuente de información correcta. Y que el $80 \%$ de los recursos van destinados al pago de los docentes y los recursos se asignan por oferta y no a partir del resultado logrado. En el fondo, la transferencia de responsabilidades es mínima. En ese sentido propone la delegación plena del manejo, distribuir recursos considerando los resultados, responsabilizar a los departamentos para que hagan los controles pertinentes sobre los municipios.

Desde el punto de vista de los que exigen más autonomía, especialmente gobernadores y alcaldes de municipios fuertes, se presta atención a la inflexibilidad que presentan los criterios de asignación que no tienen en cuenta los diferenciales de costos existentes entre las distintas regiones, y que no crean incentivos para promover la eficiencia y la calidad, además de no promover la generación de más recursos propios que se complementen con los nacionales. Los alcaldes piensan que son sólo canales para esos recursos, pero que no deciden cómo se usan, por eso no les interesa ni mejorar ni aportar recursos propios. Esto parece cierto para municipios débiles y no tanto, pero es indiscutible 
según este enfoque para municipios fuertes e institucionalmente maduros. A su vez se dice que las fórmulas de distribución son impredecibles y es muy el lento el proceso de certificación y el aumento de los fondos del MEN para enfrentar la alta heterogeneidad en las ETC, hace que haya una responsabilidad compartida entre MEN y ETC, que hacen todo más complejo. Galvis (2015) muestra la diferencia en la eficiencia de las entidades territoriales en cuanto al uso de los recursos, dice que si bien el MEN ha hecho esfuerzos por fortalecer la capacidad de las ETC y sus secretarias de educación, no ha logrado continuarlos quizás por falta de colaboración de las ETC, el Proyecto de Modernización de las Secretarías de Educación iniciado en 2004 se terminó en el 2014 y sólo había colaborado la mitad de las ETC.

Otros enfoques ponen el acento en que el criterio de transferencia basado en niño atendido no es inequitativo y que las necesidades básicas insatisfechas eran un componente interesante. Caballero Prieto (s/f) propone dos tipos de transferencias, una que se formule con una lógica de equidad y redistribución que permita igualar las condiciones territoriales, y otra que incentive los cambios de gerencia y gestión mediante premios por buenos resultados. Para su implementación plantea la necesidad de un acuerdo con las asociaciones gremiales de maestros, claro que esto es algo difícil por el esquema mismo propuesto. Además, el intento de incluir parámetros asociados a costos diferenciales, complejizaron el tema sin resolverlo (Federdesarrollo, 2018).

En lo que hace al nuevo estatuto docente, se valora el avance en hacer más directa la conexión entre concursos y evaluación de desempeño, junto con los ascensos, que luego tienen una implicación directa en salarios, pero la normativa nacional obtura esta estrategia ya que se nivelan los salarios para cerrar la brecha con otras profesiones, pero los aumentos generalizados perjudican el avance de la política de ascensos y salarios basada en la evaluación y el desempeño. 
Ya entre las críticas se plantea, como lo hace la docente con participación sindical entrevistada, que el riesgo de la certificación es que la escuela sea convertida en empresa y los rectores olviden la pedagogía y la esencia misma de la escuela, igual puede pasar con la sociedad que lo permita, que no haya políticas públicas que amparen los avances significativos en materia educativa y social y que las administraciones de turno cambien sus prioridades. En este tipo de enfoques se enfatiza la poca inversión educativa, sigue siendo un talón de Aquiles para nuestros escenarios educativos, la masificación en las aulas, las limitantes para proteger la salud mental de los educadores, la limitación de formar para el pensamiento y la constante insistencia de formar para la obediencia. Los proyectos de calidad de vida que dignifiquen la labor docente y ante todo la defensa de la educación pública como tesoro de los que deben ser incluidos en una sociedad justa y equitativa.

En la misma línea de los párrafos anteriores, la Federación Colombiana de educadores (FECODE) ve el proceso como la disputa entre el Estado Colombiano y su proyecto de mercantilización de la educación, la competencia, la contratación privada y la federación sindical, con una defensa del Estado como reaseguro del derecho constitucional a la educación gratuita y de calidad (Giraldo-Paredes y De La Cruz-Giraldo, 2016).

Según este autor, por un lado, estaban los que decían que la inversión pública en educación debía bajar para dar paso al sector privado. FECODE proponía un aumento del gasto estatal, dar estabilidad al docente junto a una mayor autonomía curricular y pedagógica, reducir el número de alumnos por aula, construir escuelas. Mientras el gobierno proponía las políticas de descentralización, FECODE según la fuente planteaba mantener el control administrativo de la educación a nivel nacional. Al mismo tiempo reducir el poder de los rectores y la cantidad de cargos directivos. Esta organización había propiciado el Foro Nacional por la Defensa de la Educación Pública en 1984, y el Congreso Pedagógico 
Nacional en 1987 desde donde se impulsaban políticas alternativas que fueron presentadas como propuestas en la Asamblea Nacional Constituyente de 1991.

Como síntesis FECODE consideraba que la propuesta original fue modificada como consecuencia de la negociación con el Gobierno nacional luego de una huelga, pero el resultado fue el aumento del rol del sector privado y las ONG con lo cual la autoridad avanzó en su objetivo de disciplinamiento social. La federación sostiene que, en vez de generar democracia local, creció el autoritarismo en un contexto municipal que en muchos casos ha sido desfinanciado.

De todos modos, es claro que el sistema mantendrá la orientación general y puede ir enfrentando las críticas mencionadas, incluso los sindicatos han sido fundamentales para balancear el modelo.

\section{Capítulo 4. Sabaneta y su sistema educativo}

\section{Antioquia, Área Metropolitana Valle de Aburra y Sabaneta}

El departamento de Antioquia tiene una extensión territorial que ocupa el $5.57 \%$ de Colombia, la población representa el $13.26 \%$ del país (viene después de Bogotá) alcanzando una densidad promedio que duplica a la nacional. Está dividido en 9 sub regiones y tiene 125 municipios. La del Valle de Aburra está formada por 3 zonas: Zona Norte (municipios de Barbosa, Girardota, Copacabana y Bello), Zona Centro (Municipio de Medellín) y Zona sur (Itagüí, Envigado, La Estrella, Sabaneta

y Caldas). En total suman los 1158 Km2 constituyendo el Área Metropolitana. La misma es una suerte de cañón limitado por altiplanos (AMA, 2020). 


\section{ÁREA METROPOLITANA DEL VALLE DE ABURRA}

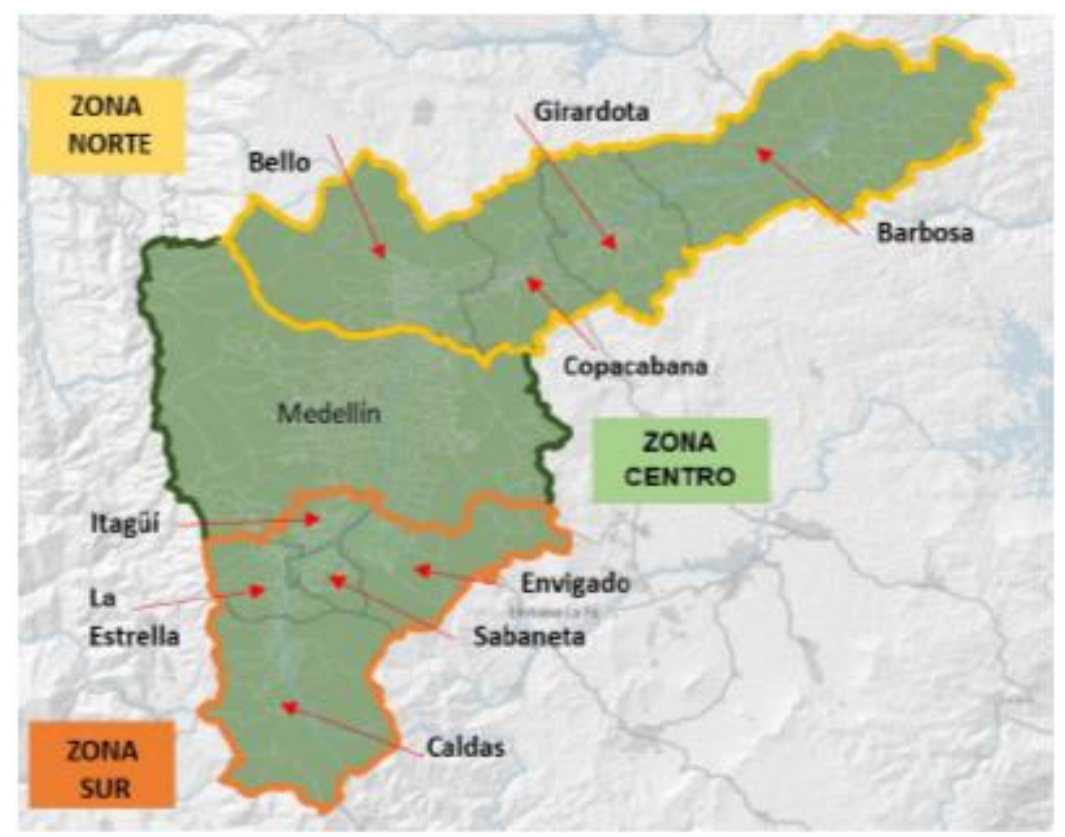

Fuente: AMA (2020)

Al 2020 se contaban 4.055 .296 habitantes, esto representa el $60.73 \%$ de toda la población del Departamento. El Valle se ha ocupado de forma extendida generándose problemas típicos de esa forma urbana. Los municipios con más densidad de población son Itagüí con 17.058,5 hab/Km2, Medellín $(6.546,3)$, Sabaneta $(5.865,4)$, Envigado $(4.749)$ y Bello $(3.656,6)$.

Para el periodo 1964-1993 observamos que Bello es el municipio con mayor tasa de crecimiento demográfico alcanzando un valor de $215.26 \%$, mientras que para 1993-2020 Sabaneta se posiciona en primer lugar alcanzando una tasa de 194.55\%, luego vienen Envigado con un 95.41\%, Bello (87.91\%), La Estrella (81.57\%), Girardota $(74.66 \%)$, Copacabana $(64.80 \%)$, Barbosa $(55.34 \%)$, Itagüí $(47.68 \%)$ y Caldas $(47.68 \%)$. Alejado, Medellín presento un $38.07 \%$. Este elemento es fundamental para analizar este municipio bajo estudio. Dentro de la zona sur, La Estrella es el municipio con menor cantidad de habitantes y el segundo con menor densidad poblacional al alcanzar un valor de 2157 hab/km2. 


\section{CRECIMIENTO DEMOGRÁFICO SUBREGIÓN VALLE DE ABURRA}

\begin{tabular}{|l|cr|}
\hline \multirow{2}{*}{ Escala Territorial } & \multicolumn{2}{c|}{ \% Crecimiento Demografico } \\
\cline { 2 - 3 } & $\mathbf{1 9 6 4 - 1 9 9 3}$ & \multicolumn{2}{c|}{ 1993-2020 } \\
\hline ANTIOQUIA & $\mathbf{9 8 , 5 9}$ & $\mathbf{3 5 , 7 4}$ \\
Subregión Valle de Aburrá & $\mathbf{1 4 7 , 9 9}$ & $\mathbf{5 0 , 7 7}$ \\
\hline Medellín & 137,41 & 38,07 \\
Barbosa & 129,53 & 55,34 \\
Bello & 215,26 & 87,91 \\
Copacabana & 155,88 & 64,8 \\
Girardota & 144,86 & $\mathbf{7 4 , 6 6}$ \\
Caldas & 125,22 & 47,68 \\
Envigado & 101,38 & 95,41 \\
Itagüí & 184,02 & 49,96 \\
La Estrella & 152,39 & 81,57 \\
Sabaneta & & 194,55 \\
\hline
\end{tabular}

Fuente: AMA (2020)

Si se analizan los municipios por el valor agregado por habitante, primero está Envigado (36 millones de pesos), le sigue Girardota (34 millones de pesos), Sabaneta con 33 millones de pesos (todos por encima de los 9 mil dólares mientras que el de todo Colombia y del Departamento, cerca de 6 mil), por encima de La Estrella y Medellín con 22 y 20 millones muy cercanos al promedio del departamento y el nacional.

\section{PBI SUBREGIÓN VALLE DE ABURRA}

\begin{tabular}{|l|rrr|}
\hline $\begin{array}{l}\text { NOMBRE DEI } \\
\text { TERRITORIO }\end{array}$ & $\begin{array}{l}\text { VALOR AGREGADO } \\
\text { 2019 (MILES DE } \\
\text { MILLONES DE } \\
\text { PESOS) }\end{array}$ & $\begin{array}{l}\text { POBLACIÓN } \\
\text { (PROYECCIÓN DANEA A A POR HABITANTE } \\
\text { 30-06-2020) }\end{array}$ & $\begin{array}{l}\text { VALOR AGREGADO } \\
\text { (MILES DE PESOS) }\end{array}$ \\
\hline DEPARTAMENTO & $\mathbf{1 2 0 . 7 0 9 , 5 0}$ & $\mathbf{6 . 6 7 7 . 9 3 0}$ & $\mathbf{1 8 . 0 7 6}$ \\
DE ANTIOQUIA & $51.534,50$ & 2.533 .424 & 20.342 \\
Medellín & 832 & 54.347 & 15.309 \\
Barbosa & $5.060,40$ & 552.154 & 9165 \\
Bello & $1.074,10$ & 81.820 & 13.128 \\
Copacabana & $1.866,50$ & 54.439 & 34.286 \\
Girardota & 999 & 83.423 & 11.975 \\
Caldas & $8.753,70$ & 242.197 & 36.143 \\
Envigado & $7.246,90$ & 289.994 & 24.990 \\
Itagüí & $1.680,00$ & 75.517 & 22.247 \\
La Estrella & $2.928,50$ & 87.981 & 33.286 \\
Sabaneta & &
\end{tabular}

Fuente: AMA (2020)

En la zona sur del área se encuentran los tres municipios con menor porcentaje de pobreza, Sabaneta presenta el valor más bajo con $4.5 \%$ seguido por Envigado 
$4.9 \%$ y La Estrella con $9.2 \%$. De toda el área, Barbosa es el que mayor al presentar un $22.2 \%$, cercano al promedio nacional. Medellín tiene un $12.8 \%$, con una población de 310.673 en esas condiciones. Se debe tener en cuenta que Colombia utiliza una canasta muy baja, de 90 dólares mensuales por persona.

\section{ÍNDICE DE POBREZA MULTIDIMENSIONAL VALLE DE ABURRA}

\begin{tabular}{|c|c|c|c|c|c|}
\hline \multirow[t]{2}{*}{$\begin{array}{l}\text { NOMBRE } \\
\text { MUNICIPIO }\end{array}$} & \multicolumn{3}{|c|}{ TOTAL } & \multicolumn{2}{|c|}{$\begin{array}{l}\text { \% POBREZA } \\
\text { MULTIDIMENSIONAL - } 2018 \text { - } \\
\text { DANE }\end{array}$} \\
\hline & 2018 & 2019 & 2020 & $\%$ & POBL. POBRE \\
\hline Medellín & 2.427 .129 & 2.483 .545 & 2.533 .424 & 12,8 & 310.673 \\
\hline Barbosa & 51.969 & 53.242 & 54.347 & 22,2 & 11.537 \\
\hline Bello & 522.264 & 538.527 & 552.154 & 14,2 & 74.161 \\
\hline Caldas & 79.638 & 81.658 & 83.423 & 16,0 & 12.742 \\
\hline Copacabana & 77.884 & 80.000 & 81.820 & 11,6 & 9035 \\
\hline Envigado & 228.848 & 236.114 & 242.197 & 4,9 & 11.214 \\
\hline Girardota & 51.662 & 53.162 & 54.439 & 13,9 & 7181 \\
\hline Itagūi & 276.744 & 283.794 & 289.994 & 10,9 & 30.165 \\
\hline La Estrella & 71.545 & 73.696 & 75.517 & 9,2 & 6582 \\
\hline \multirow[t]{2}{*}{ Sabaneta } & 82.375 & 85.484 & 87.981 & 4,5 & 3707 \\
\hline & 3.870 .058 & 3.971 .241 & 4.055 .296 & 12,3 & 476.996 \\
\hline
\end{tabular}

Fuente: AMA (2020)

En cuanto a la cobertura de los distintos servicios, en agua potable, alcantarillado, energía eléctrica, y recolección de residuos, Sabaneta va primero por encima del 99\% de cobertura. Para el primero, Envigado y Medellín se presentan en segundo y tercer lugar con un valor de $97.17 \%$ y $97.02 \%$ respectivamente, mientras que en el segundo servicio es seguido por Itagüí con un 99.01\% y nuevamente Envigado con $97.34 \%$. También en gas e internet Sabaneta se posiciona en primer lugar en valores de $91.92 \%$ y $86.86 \%$, mientras que el promedio del Valle asciende a $76.03 \%$ y $66.41 \%$ respectivamente. Si comparamos esta situación con La Estrella, este último presenta sus peores indicadores de cobertura al alcanzar un $71.04 \%$ y $68.57 \%$ para los servicios indicados anteriormente. 


\section{COBERTURA SERVICIOS VALLE DE ABURRA}

\begin{tabular}{|c|c|c|c|c|c|c|}
\hline $\begin{array}{l}\text { DEPARTAMENTO, } \\
\text { SUBREGIONES Y } \\
\text { MUNICIPIOS }\end{array}$ & $\begin{array}{c}\text { COBERTURA DE AGUA } \\
\text { POTABLE (\%) }\end{array}$ & $\begin{array}{c}\text { COBERTURA } \\
\text { RESIDENCIAL DE } \\
\text { ALCANTARILLADO } \\
\text { (\%) }\end{array}$ & $\begin{array}{c}\text { COBERTURA } \\
\text { RESIDENCIAL DE } \\
\text { ENERGÍA } \\
\text { ELÉCTRICA (\%) }\end{array}$ & \begin{tabular}{|l|} 
COBERTURA \\
RESIDENCIAL DE \\
ASEO (\%), \\
RECOLECCIÓN \\
DE DESECHOS \\
SÓLIDOS)
\end{tabular} & $\begin{array}{c}\text { COBERTURA DE } \\
\text { GAS POR RED } \\
(\%)\end{array}$ & $\begin{array}{l}\text { COBERTURA } \\
\text { RESIDENCIAL } \\
\text { DE INTERNET } \\
(\%)\end{array}$ \\
\hline Medellín & 97,02 & 97,15 & 99,52 & 98,9 & 75,65 & 66,25 \\
\hline Barbosa & 46,38 & 53,03 & 99,48 & 78,17 & 37,79 & 31,78 \\
\hline Bello & 91,77 & 92,62 & 99,15 & 96,99 & 75,46 & 62,74 \\
\hline Caldas & 75,7 & 88,44 & 99,71 & 97,11 & 66,59 & 63,2 \\
\hline Copacabana & 95,91 & 83,45 & 99,62 & 95,54 & 71,31 & 66,21 \\
\hline Envigado & 97,17 & 97,34 & 99,85 & 99,67 & 88,75 & 86,78 \\
\hline Girardota & 63,27 & 70,84 & 99,74 & 90,04 & 63,02 & 54,27 \\
\hline Itagüí & 89,73 & 99,01 & 99,5 & 99,11 & 80,32 & 71,7 \\
\hline La Estrella & 85,78 & 93,72 & 99,74 & 96,19 & 71,04 & 68,57 \\
\hline Sabaneta & 99,75 & 99,58 & 99,9 & 99,79 & 91,92 & 86,86 \\
\hline
\end{tabular}

Fuente: AMA (2020)

\section{Sabaneta y su territorio}

Sabaneta es el municipio más pequeño de Colombia tiene una extensión de 15 $\mathrm{Km} 2$, como acabamos de ver, forma parte del área metropolitana del Valle de Aburra, y está a 14 kilómetros de Medellín. Las vías de acceso son rápidas y sencillas. Vimos que en os últimos 20 años se produce el crecimiento más fuerte de su población.

En la zona urbana dentro de los 13 barrios más poblados se concentra casi el $60 \%$ de la población (Entre Amigos, Calle Larga, Santa Ana, entre otros). La cabecera municipal tuvo su mayor incremento en el periodo 1973-1985 con una tasa de $5.58 \%$.

Las zonas rurales (Las lomitas, Cañaveralejo, San José, Pan de azúcar y María Auxiliadora) presentan una concentración aun mayor de la población en sus principales barrios, concentración que ronda entre el $85 \%$ y $87 \%$.

Este aumento es consecuencia de la oferta de lotes para construcción de edificios en el boom inmobiliario y la renuencia de otros municipios para habilitar tierras 
para el desarrollo de proyectos urbanísticos. MS (2009) valoraba el hecho de que si bien Sabaneta no ofrecía grandes cantidades de tierras, las mismas se presentaban con buenas condiciones de suelo, normativas, de infraestructura para llevar adelante proyectos de construcción apuntados a estratos altos con capacidad de compra. Se terminó constituyendo en el primer municipio según la fuente por el mayor atractivo para realizar desarrollos habitacionales, con 17 puntos sobre 18, seguido por Medellín, Envigado y Bello.

Según DANE (2007) con datos de 2005, si se analiza si las personas asisten a un establecimiento ubicado en el mismo municipio de su vivienda, Medellín alcanzaba un $97.6 \%$ y el caso opuesto era Sabaneta con el valor más bajo del Valle de Aburra, con un $69.3 \%$, el $17 \%$ iba a Medellín y casi un $8 \%$ a Envigado. Seguido de Sabaneta encontramos a La Estrella donde el porcentaje ascendía al $74.3 \%$. Lamentablemente no hemos encontrado datos actuales. Si se observa la concentración del trabajo en el mismo municipio de la vivienda, Medellín es el que mayor porcentaje registra. El valor más bajo lo presenta La Estrella con el 45\%. Sabaneta tiene un $53 \%$ que se desempeña localmente y un $28 \%$ que se traslada a Medellín.

Al mismo tiempo el Municipio mostraba la cobertura de servicios públicos incluso en la zona rural y la rural dispersa, cuyos porcentajes de cobertura alcanzan como se vio un alto porcentaje. No obstante, aun en las veredas de María Auxiliadora, Pan de Azúcar, San José y, en las Brisas y Playas Placer las aguas residuales se desechan a campo abierto.

El municipio cuenta con dos instituciones de salud ubicadas en los barrios Virgen del Carmen (CES) y Prados de Sabaneta (Hospital Venancio Díaz), el primero abocado al ámbito metropolitano y el segundo al municipal.

En cuanto a la actividad industrial, de tamaño mediano, la hayamos ubicada en las carreras 48 y 49 , algunas también sobre las carreras 43 en el barrio Las Casitas y 
Restrepo Naranjo, debido a las ventajas de conectividad que presenta. Algunas industrias también cuentan con acceso al ferrocarril lo que en algún momento brindaba una ventaja en el traslado de materias primas y mercancías. Entre las industrias más importantes encontramos a Cerámica Sabaneta, Plastiquimica, Ramo y Cronch, que por su tamaño también presentan un riesgo ambiental para la zona por la industria.

La actividad comercial y de servicios se da sobre las vías principales, encontramos el sector central caracterizado por comercios como graneros, supermercados, centros comerciales, etc., y cuando se analiza específicamente en los barrios se observa que la escala de comercio es mucho más pequeña y dispersa, por lo general almacenes ubicadas en las viviendas de las personas.

En la zona rural había frijoles, plátanos, pero la ruralidad va desapareciendo.

Ese crecimiento de manera vertiginosa el hecho de que inicialmente haya sido el lugar del urbanístico, el hecho de que muchos pobladores originales han tenido que irse del municipio por el nivel tan costoso de vida desde todas sus perspectivas, que muchos se hayan quedado representando a sectores rezagados y que hoy sea el "mejor vividero de Colombia" como dijo una entrevistada. Los habitantes del municipio ponen entre sus principales preocupaciones el problema del transporte $(27.3 \%)$ por las escasas rutas para desplazarse y el excesivo crecimiento urbano hacia el interior (16.7\%). Esto y la necesidad de corregirlo ha sido muy bien planteado el en Plan de desarrollo 2016-2019 (SPM, 2016) pero no queda tan claro en el de 2019 (SPM; 2019).

Esto hace que haya una preocupación sobre la identidad, una filosofía que enmarque los valores, partiendo de su historia, en caso contrario es probable que traiga grandes riesgos sociales, culturales, ambientales y educativos (problemas futuros de abastecimiento de agua, peso excesivo de construcción sobre una 
superficie que tuvo muchas lagunas, al menos hasta 2016, dificultad en vías de acceso, población vulnerable poco atendida).

Este modelo de crecimiento condiciona al sistema educativo ya que puede generar una fuerte presión hacia la segmentación entre lo privado y lo público y entre sectores sociales, por eso el rol del Municipio puede ser fundamental en este contexto.

\section{El sistema educativo de este municipio y las políticas de los últimos años}

Sabaneta cuenta con 32 establecimientos educativos, lo que representa un aumento de 6 desde 2005, fundamentalmente debido a los establecimientos no oficiales. La Estrella los aumenta casi en igual forma y en Medellín los establecimientos totales caen, explicado por una gran reducción de los no oficiales mientras que los establecimientos oficiales se incrementan muy levemente (de 227 a 231).

\section{ESTABLECIMIENTOS OFICIALES Y NO OFICIALES (EN CANTIDAD POR MUNICIPIO), PARA EL AÑO 2006 Y 2019.}
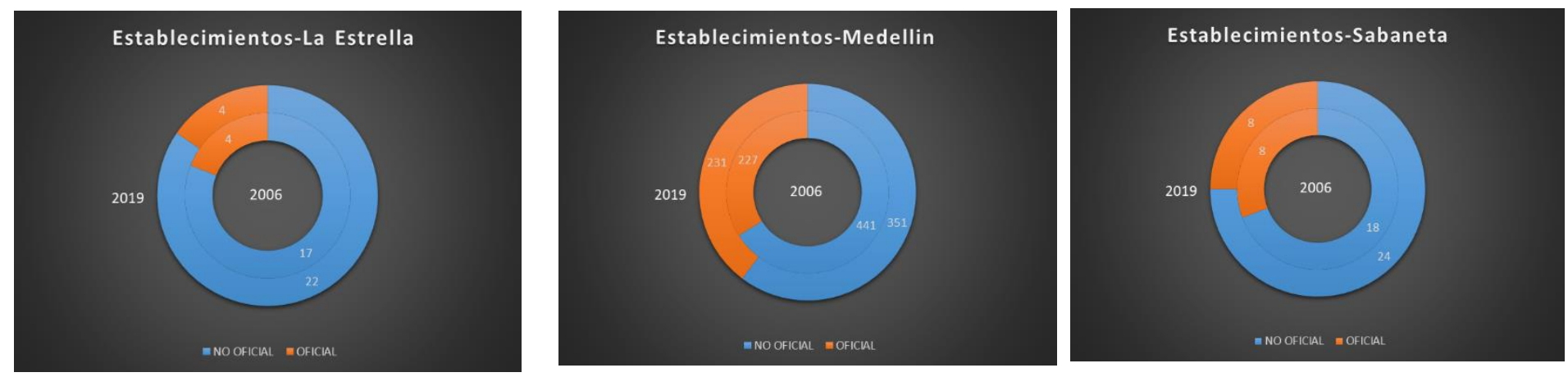

Fuente:http://bi.mineducacion.gov.co:8380/eportal/web/planeacion-

basica/establecimientos-educativos 
El Colombiano (2016) decía que el municipio cuenta con excelente oferta de centros educativos para todos los niveles, de carácter público y privado, esta es la imagen del municipio.

La matrícula por niveles de preescolar, basica y media para el año 2018 en las 8 IE oficiales, 8 colegios privados y preescolares del municipio es asi:

\section{MATRÍCULA ESCOLAR SABANETA}

\begin{tabular}{|l|r|r|r|}
\hline \multicolumn{4}{|c|}{ Matrícula 2018} \\
\hline $\begin{array}{c}\text { Nivel } \\
\text { educativo }\end{array}$ & Urbano & \multicolumn{1}{c|}{ Rural } & \multicolumn{1}{c|}{ Total } \\
\hline Preescolar & 574 & 302 & 876 \\
\hline Primaria & 5.263 & 1.908 & 7.171 \\
\hline Secundaria & 3.362 & 1.196 & 4.558 \\
\hline Media & 1.401 & 418 & 1.819 \\
\hline Total & 10.600 & 3.824 & 14.424 \\
\hline
\end{tabular}

Fuente: SPM (2020)

Desde el Plan de desarrollo 2008 se plantea garantizar la cobertura con el fin de formar ciudadanos competitivos y con capacidades de construir sociedad incluyente y participativa (MS, 2008).

En el Programa educación para Todos del Plan de desarrollo (SPM, 2016) se nota que se le iba a dar un fuerte impulso al tema educativo, a partir de la premisa que la población valoraba en primer lugar esta cuestión, junto con la presencia de buenos espacios para mejorarlos y potenciarlos y el turismo. La gestión planteaba en el Plan mencionado que había encontrado algunos proyectos cofinanciados, que habían sido iniciados durante la gestión anterior y a los cuales se les daría continuidad. Por ejemplo, la nueva sede de la Institución Educativa María Auxiliadora, el coliseo de la I.E. Adelaida Correa y la Biblioteca Municipal.

Pero especialmente se apunta a que Sabaneta sea una ciudad "educadora", un centro educativo conectado al mundo. Para ello se afirma que es importante garantizar buenas condiciones de infraestructura, promover una mejor 
capacitación de la planta docente a través de post grados, promover el intercambio de estudiantes, y establecer una educación que abarque problemas formales, informales, culturales, que incluya artes, todas cuestiones que van a lograr una mejor inserción del alumno en los puestos de trabajo mejor remunerados.

Se identifica en ese Plan_que hay una débil apropiación social de la educación (desde todas sus aristas) en el municipio. Las causas de esto se encuentran en que no hay una política específica para la ciencia, tecnología e innovación ${ }^{13}$, no hay articulación con empresas, incentivos a la investigación austeros, docentes y estudiantes no capacitados para realizar investigaciones, poca participación del municipio en el ámbito académico, y una orientación vocacional inoportuna. Esto concluye en una baja calidad educativa, en poco incentivo para realizar investigaciones, pérdida de competitividad del municipio, deserción del sistema educativo, desarticulación del sistema municipal con el departamental y nacional, poca participación y consecuentemente apropiación en trabajos de divulgación, ausencia de redes de investigación, desmotivación de la comunidad educativa, etcétera.

Se admite que la tasa de deserción es baja y se propone llevar adelante planes que enfrenten esta problemática, y que además el municipio no debe confiarse en los datos nacionales porque la población realmente es superior a la estimada por el DANE, y probablemente los indicadores educativos estén mostrando una situación mejor de la que existe en la realidad. Los principales productos esperados, como indicadores en el Plan de Desarrollo Sabaneta de Todos 2016 2019 (SPM, 2016), con incidencia en los resultados de educación, se relacionan con objetivos como ampliar la cobertura, disminuir la carga laboral docente a través de la creación de nuevas plazas, implementar la jornada única, tener infraestructura adecuada y con todo esto mejorar también la calidad educativa y

\footnotetext{
${ }^{13}$ Se crea el proyecto de Acuerdo 16 para la ciencia la tecnología y la investigación de 2016
} 
de vida del Municipio al complementar también el ciclo educativo con la educación terciaria a través de proyectos como la zona franca de educación e innovación. Dichos productos siguen siendo generales.

Analizando en el Plan un eje clave para el municipio como es la participación ciudadana, el gobierno local encuentra que existían más de 300 organizaciones sociales pero que sin embargo, hay una débil organización social y comunitaria dentro del municipio. Por esto, se lanza el programa "Participación Ciudadana de Todos" que tiene como objetivo fortalecer las organizaciones y los mecanismos e instancias de participación. Como metas propone brindar apoyo y capacitación al $50 \%$ de las organizaciones, asistencia técnica a 24 organizaciones, control y vigilancia de las JAC, intervenir espacios de infraestructura comunal, abrir 4 escuelas de liderazgo, capacitación en mecanismos de participación, entre otras (SPM, 2016).

El Plan educativo 2019 (MS, 2019) que va en línea con el Plan del 2016 se propone abocarse a buscar una integralidad en el sistema, y principalmente tiene que reconocer y validar los campus de las instituciones de educación superior. Lo hace a partir de la opinión de los propios habitantes (incluidos estudiantes) constituyendo diversas vías. Por un lado una estrategia denominada "Estudiantes motivados y Docentes preparados", que pone el acento en capacitar a los docentes en el uso de Tics y aprendizaje learning by doing; también fomentar el aprendizaje por fuera de la escuela; todo esto mediante una capacitación didáctica permanente sobre el cuerpo docente tanto de los oficiales como privados y planes de proyectos escolares anuales.

En segundo lugar, la estrategia denominada "Integración interinstitucional", que tal como lo dice su título busca fomentar la integración entre las distintas instituciones a través de la firma de distintos convenios bajo la Secretaria de Educación y Cultura. Y la de "Internacionalización de la educación de Sabaneta" busca integrar el sistema educativo del municipio con el de otros municipios a nivel nacional y 
fomentar el aprendizaje de inglés. Entre sus acciones contempla fomentar la figura de los tutores extranjeros, becas a docentes para el aprendizaje, actividades públicas en segunda lengua y fortalecer el currículo de inglés en las instituciones. Lo modos de implementar esto sería mediante organismos de cooperación y becas anuales.

"Sabaneta en el aula" busca desarrollar espacios de aprendizaje por fuera del aula y luego estimular actividades curriculares y extracurriculares. Para esto se propone brindar espacios públicos adecuados que permitan llevar adelante diferentes tipos de actividades. Frente a la demanda creciente de hacer cada vez más inclusivos los espacios de aprendizaje, "Sabaneta incluyente" se propone incluir en el currículo, contenidos que expresen diversidad en muchos aspectos.

La estrategia "Despertando Talentos: humanización de la educación", busca mediante la firma de convenios estimular distintos emprendimientos, acompañar a esos proyectos, y mediante concursos calificar a los mejores. En línea con esto, pero por fuera de los emprendimientos, se busca destacar a los mayores logros deportivos, artísticos y creativos, para estimular los jóvenes talentos del municipio. Por último "Aprendizaje toda la vida" busca asegurar que todas las personas, independientemente de su edad puedan acceder a los procesos de aprendizaje mediante un programa de capacitación intergeneracional.

En el Plan de desarrollo 2020 (SPM, 2020) si bien no está puesto el mismo énfasis en la educación y en las mismas temáticas el sendero de trabajo es similar. Algunas diferencias que vale la pena marcar pero que no pueden ser evaluadas en la práctica porque la gestión empezó recientemente y están relacionadas a la focalización que se hacen maestros y profesores, pero la propuesta tiene un nivel de generalidad muy alto. 


\section{Capítulo 5. Cambios desde la certificación en los procesos educativos en el municipio de Sabaneta}

\section{Principales cambios institucionales y presupuestarios}

El municipio de Sabaneta fue certificado por parte del Ministerio de Educación Nacional como autoridad para administrar el servicio educativo en su territorio, mediante la Resolución 9067 del 17 de marzo de 2010 (MEN, 2010). El municipio según la evaluación realizada, cumplía con los requisitos establecidos enumerados en el capítulo anterior.

En el proceso de certificación del municipio de Sabaneta, se contó con el apoyo de diversas instituciones entre ellas las universidades, pero de todas las entrevistas surge que el gran impulsor fue el Municipio. Por otro lado es el único que impulsa fuertemente el proceso en todos los documentos, varios ya descritos.

La docente con participación sindical entrevistada manifiesta que el sindicato hasta el 2016 no fue convocado. Luego si lo hicieron, pero esta organización, como su federación nacional desconfió desde el inicio y tuvo una postura crítica, aunque de negociación. Un punto central de desacuerdo, según la entrevistada, es el fuerte rol de las universidades privadas. Otras demandas que se plantearon son la falta de un proyecto de vivienda para los docentes, la poca inversión en salud, el freno al proyecto de la casa del maestro.

Por otro lado, la misma entrevistada dice que Sabaneta era muy lineal con las políticas educativas que se impartían desde el MEN, pero se fueron consolidando antes de la certificación mesas de trabajo, que permitieron una reflexión del colectivo docente municipal sobre una mirada y postura crítica ante los proyectos educativos vigente y como se podían mejorar desde la experticia de los docentes y la práctica pedagógica, trabajo que se quedó en pausa desde que se certifica 
Sabaneta. Por eso "la investigación y la divulgación de las prácticas significativas son muy frágiles, escasean las políticas públicas para mantener en el tiempo los avances y proyectos que han permitido administraciones con conciencia social" (Docente con participación sindical).

Según un tríptico que hemos podido ver (Municipio de Sabaneta, 2018), la Junta de Sabaneta participó en el período 2016 y 2019 de la toma de decisiones vinculadas a la mayoría de los temas al mismo tiempo pudimos ver en las redes una actividad relativamente dinámica pero naturalmente la conformación de la misma no nos asegura su representatividad

En este proceso, el gasto global de la Secretaria de Educación y Cultura en el 2015 se ubicaba en U\$\$8.303.460, y de manera sostenida creció un 53\% en el periodo 2015-2018, alcanzando un valor de U\$\$12.680.859 para este último año. En el 2019, sumando la caída en pesos colombianos del mismo (3\% con respecto a 2018) y la gran devaluación sufrida, el gasto cayó un $13 \%$ en dólares, ubicándose igual por encima del año que hemos tomado como base, en U\$S11.055.940. Si le sumáramos el promedio de los últimos años de servicios personales del área Secretario que no figuran, la suma daría algo por encima del 2018 (línea punteada verde en el gráfico).

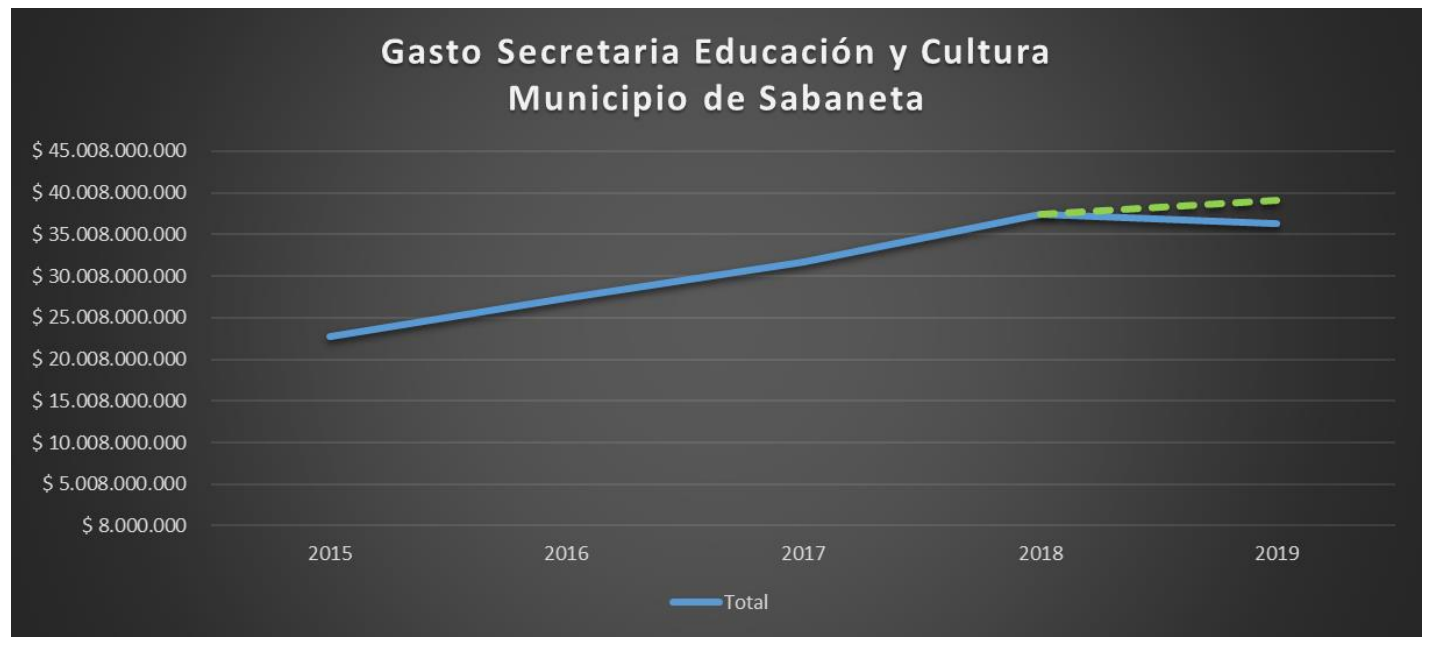

Fuente: Elaboración propia en base a Presupuestos de Ingresos Disponibles del Municipio de Sabaneta 2015-2019. 

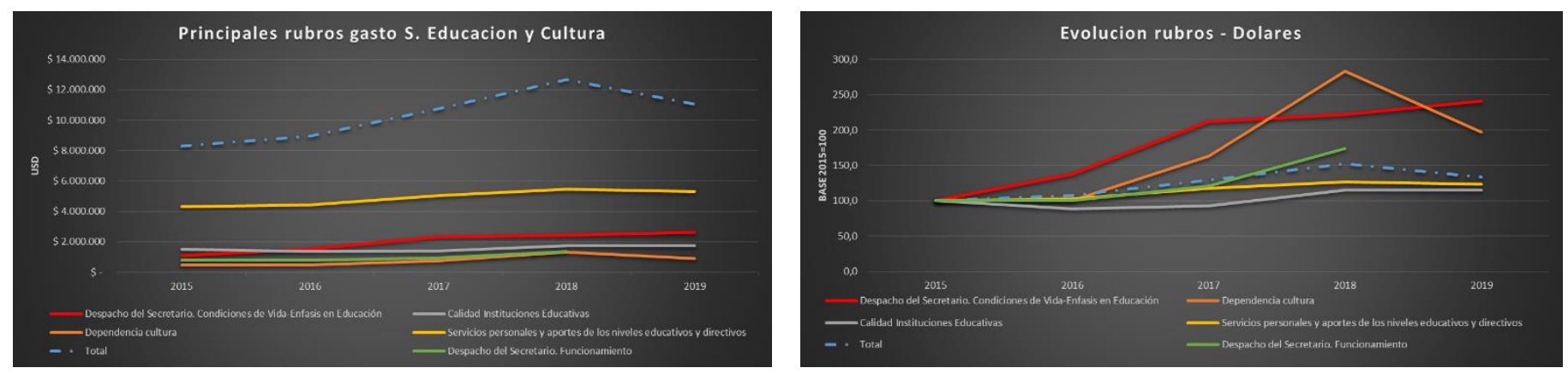

Fuente: Elaboración propia en base a Presupuestos de Ingresos Disponibles del Municipio de Sabaneta 2015-2019.

Naturalmente el gasto en educación es el de mayor importancia. Si tenemos en cuenta los gastos realizados mediante "Condiciones de vida - Énfasis en educación", "Calidad de instituciones educativas-Inversión", y la suma del pago al plantel docente en todos los niveles para definir el gasto total en educación, concluimos que al 2019 representa el $88 \%$ del total gastado por la Secretaria. Por otro lado, Cultura representa el $8 \%$.

Con el objetivo de desagregar los distintos rubros por fuera de los destinados a cubrir las plantas docentes, se debe distinguir el periodo 2015-2019 en dos debido a los cambios programáticos existentes, en primer lugar el periodo 2015-2016. En el primer año analizado en Condiciones de Vida aparecen como centrales los fondos para apoyo de los establecimientos y las becas. En 2016 ya se ve la descentralización del concepto de alimentación escolar, que representa el $22 \%$ del gasto total. Este año desaparece el apoyo a las escuelas y caen un $28 \%$ las becas y el Fondo de Crédito Educativo pero aumenta el apoyo a la población vulnerable. Algo común para ambos años son los bajos recursos destinados a incentivar la continuidad de los alumnos en la educación superior (U\$\$7.260,41 y U\$\$3.969,32 respectivamente). 
ITEM CONDICIONES DE VIDA-ÉNFASIS EN EDUCACIÓN. VALORES EN DÓLARES 2015-2016.

\begin{tabular}{|c|c|c|}
\hline Descripcion & \multicolumn{2}{|c|}{2015} \\
\hline Apoyo para Operación de IEIQD & $330.377,51$ & - \\
\hline Becas Mejores BachilleresI.E Públ IQD & $323.458,16$ & $231.509,29$ \\
\hline Fondo de Orédito Educativo IQD & 182561,12 & $91.393,37$ \\
\hline Atención Población con Necesidades Educativas IaD & $77.897,04$ & $87.979,56$ \\
\hline Acceso y Permanencia Educativa IQD & $55.596,99$ & \\
\hline Continuidad en Educacion Superior IaD & $7.260,41$ & $3.969,32$ \\
\hline Servicio de Alimentacion Escolar (mixto) & $\$$ & $699.996,38$ \\
\hline Total programas seleccionados & $\$ 977.151,22$ & $\$ 1.114 .847,93$ \\
\hline Total programas del presupuesto & $\$ 1.097 .122,92$ & $\$ 1.505 .600,99$ \\
\hline
\end{tabular}

Fuente: Elaboración propia en base a Presupuestos de Ingresos Disponibles del Municipio de Sabaneta 2015-2019

En Calidad de las Instituciones, los fondos destinados a la gratuidad fueron los más importantes del 2015 y disminuyeron al 2016 en un $6 \%$ en dólares, el destino es la gestión de los establecimientos educativos. Los fondos están reguladas por el acuerdo de 2012 por el municipio en relación y concordancia con la normativa de fondos de servicios educativos nacionales. En el decreto se establece el modo en qué se define los ingresos ya sea por venta de productos por explotación de bienes y otros ingresos y se establece la posibilidad de gastar en funcionamiento inversiones y también se aclaran las partidas que no pueden ser destinadas fundamentalmente relativas al personal.

Siempre según los Presupuestos de Ingresos Disponibles del Municipio de Sabaneta 2015-2019, se observa en 2015 una proporción importante destinada a estrategias pedagógicas cuyo monto asciende a U\$\$188.928, para el 2016 esta cuenta no presenta gastos, sólo está El plan Saber por un monto muy bajo (51.000 dólares). Algo común para ambos años son los bajos recursos destinados a incentivar la continuidad de los alumnos en la educación superior. En 2016 tiene importancia la construcción de aulas por la partida de transferencias asignada para Jornada única. Este segundo año parece haber una mayor tendencia a financiar proyectos educativos de diverso tipo. 


\section{ITEM CALIDAD INSTITUCIONES EDUCATIVAS. VALORES EN DÓLARES}

2015-2016.

\begin{tabular}{|c|c|c|}
\hline Descripcion & \multicolumn{2}{|l|}{2015} \\
\hline Gratuidad en la Educación IdD & 310.86432 & 292957,17 \\
\hline Gratuidad en la Educación SGP & $199.265,46$ & $188.336,62$ \\
\hline Estrategias Pedagógicas EducativasId D & $188.928,25$ & - \\
\hline Contruccion de Aulas para Jornada Uhica R日MNSGP EUC & - & 251.13463 \\
\hline Formacion Personal Docentes Remanentes SGP 2012 & $153.185,06$ & - \\
\hline Fortalec Programa Extracurriculares IaD & 112867,00 & - \\
\hline Fortalecimiento de Jornadas Escolares Complementarias IaD & - & 74881,23 \\
\hline Apoyosen transporte escolar IQD & - & $49.095,74$ \\
\hline Proyectos educativostransversalesId D & & $67.416,96$ \\
\hline Implementacion de PlanesEducativos Institucionales IQD & & 44186,16 \\
\hline Total programas seleccionados & $\$ 965.110,09$ & $\$ 968.008,51$ \\
\hline Total programas del presupuesto & $\$ 1.518 .114,59$ & $\$ 1.351 .335,93$ \\
\hline
\end{tabular}

Fuente: Elaboración propia en base a Presupuestos de Ingresos Disponibles del Municipio de Sabaneta 2015-2019

Luego, enfocándonos en el periodo 2017-2019 queda muy claro la importancia que tiene el gasto en alimentación, consecuencia del desarrollo del PAE, representando aproximadamente un $24 \%$ de todo el gasto en educación para ese año.

\section{ITEM CONDICIONES DE VIDA-ÉNFASIS EN EDUCACIÓN. VALORES EN DÓLARES 2017-2019.}

\begin{tabular}{|c|c|c|c|c|c|c|}
\hline Descripcion & \multicolumn{3}{|c|}{2017} & \multicolumn{2}{|l|}{2018} & 2019 \\
\hline Atencion restaurantes escolaresIQD-SGP-MENPAE & $\$$ & $961.056,47$ & $\$$ & $995.225,72$ & $\$$ & $1.070 .801,54$ \\
\hline M TALENIOM FUTROAcceso a la Educación Terciaria IQD & $\$$ & 482332,91 & $\$$ & 27249446 & - & \\
\hline Presencia de I.E superior para la zona franca IQ D & $\$$ & $187.747,27$ & $\$$ & $107.564,48$ & $\$$ & $63.483,43$ \\
\hline Fortalecimiento met. Rex. Pobl vulnerable y extra edad IQD-SGP & $\$$ & $157.888,57$ & $\$$ & $333.420,70$ & $\$$ & 342185,05 \\
\hline Implementación de đencia, Tecnole Imov. para la zona franca IQD & $\$$ & $70.478,11$ & $\$$ & $25.680,26$ & $\$$ & $141.403,56$ \\
\hline Fortalecimiento de las bibliotecasfísicasy virtuales escolares IaD & $\$$ & 54310,84 & $\$$ & $81.815,35$ & $\$$ & $81.739,18$ \\
\hline EventoseducativosIaD & & & $\$$ & 22219,50 & $\$$ & $121.899,62$ \\
\hline Total programas seleccionados & $\$$ & 1.913 .81417 & $\$$ & $1.838 .420,47$ & $\$$ & $1.821 .512,39$ \\
\hline Total programas del presupuesto & $\$$ & $2327.233,90$ & $\$$ & $2438.270,80$ & $\$$ & $2643.618,54$ \\
\hline
\end{tabular}

Fuente: Elaboración propia en base a presupuestos del Municipio.

En el gráfico adjunto puede verse el aumento desde el 2016 al 2019, casi un 60\%, partiendo de 550 millones de dólares y alcanzando en este último año U\$S 1.070.801. Téngase en cuenta que se trata ésta de una transferencia del gobierno nacional con ese destino. 


\section{GASTOS EN GRATUIDAD Y ALIMENTACIÓN}

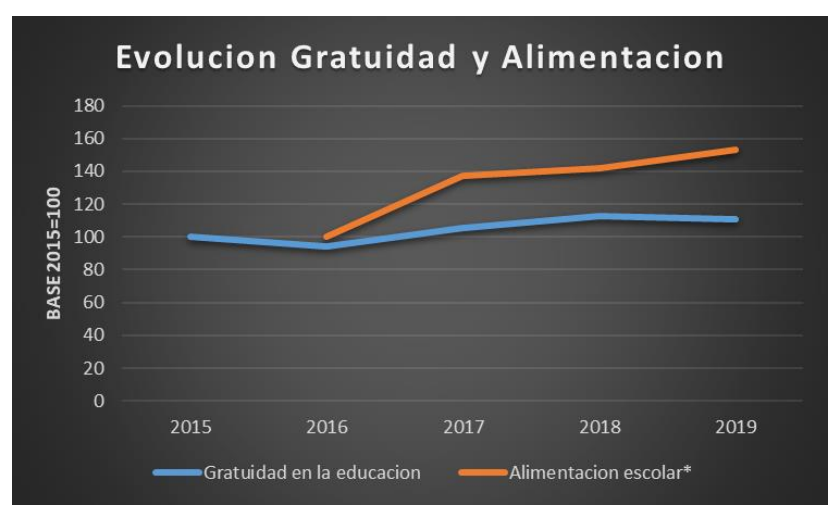

Fuente: Elaboración propia en base a presupuestos del Municipio. Alimentación escolar base $2016=100$.

Observamos un fuerte énfasis en las metodologías flexibles de enseñanzas para población vulnerable y extra edad, durante el año 2018 y 2019. Para el 2017 el monto destinado ascendía a U\$S157.888, sin embargo en el año 2018 se incrementó un 111\% (U\$S333.420), alcanzando los U\$S342.185.05 durante el año 2019.

Por otro lado, se aprecia un fuerte impulso a la educación superior en los presupuestos del año 2017 y 2018, mediante el plan "Mi Talento, Mi Futuro" y el incentivo a la presencia de instituciones de educación superior en las zonas francas

Específicamente en el primer caso, durante el 2017 y 2018, se destinaron U\$S482.332 y para el segundo U\$S 272.494 , lo cual representó un $13 \%$ y $7 \%$ sobre el gasto total en educación respectivamente. También se presta atención a los eventos afines a estos proyectos.

En Calidad de las Instituciones, nos encontramos con que la única cuenta que es posible trazar la continuidad desde el 2015 al 2019 es "Gratuidad en la Educación" porque naturalmente se trata de los fondos para los establecimientos. En el año 2017 incrementa su monto con respecto al 2016 en un 12\% (superando al 2015) 
para luego encontrar su pico en el año 2018, un $12.5 \%$ por encima del 2015 . Esto es debido a la incorporación de fondos propios. La situación del año 2019 sigue la tendencia del gasto general y disminuye un $1.6 \%$ con respecto al 2018.

Hay aumentos significativos en los diversos programas pedagógicos nuevos (eventos académicos, jornadas complementarias, segundo idioma, capacitación a docentes). Ésta última cae desde 2018. Es evidente el fortalecimiento de las jornadas complementarias, cuyo monto creció un 50\% representando un $11 \%$ sobre cada categoría de presupuesto anual.

\section{ITEM CALIDAD INSTITUCIONES EDUCATIVAS. VALORES EN DÓLARES} 2017-2019.

\begin{tabular}{|c|c|c|c|}
\hline Descripcion & 2017 & 2018 & 2019 \\
\hline Gratuidad en la Educación IQD-SGP & $\$ 519.499,09$ & $\$ 519.836,28$ & $\$ 498.53475$ \\
\hline Apoyos en transporte escolar IQD & $\$ 119.566,84$ & $\$ 147.390,54$ & $\$ \quad 179.801,94$ \\
\hline Eventos académicos en la educación EXSTIIQD & $\$ \quad 160.947,61$ & $\$ \quad 161.611,08$ & $\$ 149.327,04$ \\
\hline Fortalecimiento de JornadasEscolares Complementarias IQD & $\$ \quad 96.45421$ & $\$ 122585,10$ & $\$ 184428,64$ \\
\hline Mantenimiento a las Instituciones EducativasEXST.IOD & $\$ \quad 71.450,48$ & $\$ 163.419,88$ & $\$ 169.226,29$ \\
\hline Fortalecimiento del segundo idioma IAD & $8.157,50$ & $\$ 54002,45$ & $\$ \quad 60.980,90$ \\
\hline Capacitación a docentesy directivos docentesIQD & $\$ \quad 83.350,20$ & $\$ \quad 32132,26$ & $\$ \quad 60.949,81$ \\
\hline Total programas seleccionados & $\$ 1.059 .425,93$ & $\$ 1.200 .977,59$ & $\$ 1.303 .249,38$ \\
\hline Total programas del presupuesto & $\$ 1.402449,90$ & $\$ 1.749 .598,34$ & $\$ 1.750 .286,93$ \\
\hline
\end{tabular}

Fuente: Elaboración propia en base a Presupuestos de Ingresos Disponibles del Municipio de Sabaneta 2015-2019

En el año 2019 el presupuesto de educación fuera del gasto en servicios personales se descompone del siguiente modo. Tal como se mencionó en la sección anterior, el gasto destinado a cubrir las necesidades alimentarias de los estudiantes fue creciendo constantemente dentro del gasto en educación, convirtiéndose en el más representativo de todos. Le sigue Gratuidad de la Educación y el apoyo a población vulnerable, luego Operación del sistema Local ${ }^{14}$. Mantenimiento de IE representa el $4 \%$ al igual que Transporte, Jornadas

\footnotetext{
${ }^{14}$ Se trata de un proyecto de manejo de datos educativos y georeferencxiación. Puede verse en https://www.observatoriosabaneta.org/educacion-y-ciudadania-cultural/\#educacion
} 
Complementarias y Zonas Francas. La Capacitación, las becas y el apoyo para la continuidad se van desdibujando.

\section{GASTOS DE EDUCACIÓN SIN SERVICIOS PERSONALES}

\begin{tabular}{|c|c|c|c|}
\hline Descripcion & \multicolumn{2}{|c|}{ Monto 2019} & Representacion \\
\hline Atencion restaurantes escolares IQD-SGP-MENPAE & & $1.070 .801,54$ & $24 \%$ \\
\hline Gratuidad en la Educación IQD-SGP & $\$$ & $498.534,75$ & $11 \%$ \\
\hline Fortalecimiento metodologías flexibles poblac. vulnerable y extra edad IQD-SGP & $\$$ & 342185 & $8 \%$ \\
\hline Operación del Sistema Local de EducaciónIQD & $\$$ & 296.862 & $7 \%$ \\
\hline Fortalecimiento de Jornadas Escolares Complementarias IQD & $\$$ & 184429 & $4 \%$ \\
\hline Apoyosen transporte escolar IQD & $\$$ & 179.802 & $4 \%$ \\
\hline Mantenimiento a las Instituciones Educativas EXSTIIQD & $\Phi$ & 169.226 & $4 \%$ \\
\hline Presencia instituciones educación superior zonaf & $\$$ & 157.807 & $4 \%$ \\
\hline Eventosacadémicos en la educación EXST.IQD & $\Phi$ & 149.327 & $3 \%$ \\
\hline Implementación de đencia, Tecnole Imov. para la zona franca IQD & $\Phi$ & 141.404 & $3 \%$ \\
\hline Eventoseducativos IQD & $\$$ & 121.900 & $3 \%$ \\
\hline Otros & $\Phi$ & 1.147 .504 & $26 \%$ \\
\hline Total programas seleccionados & & $3.312277,48$ & \\
\hline Total programas del presupuesto & $\$$ & 4393.905,47 & \\
\hline
\end{tabular}

Fuente: Elaboración propia en base a Presupuesto de Ingresos Disponibles del Municipio de Sabaneta 2019

Por otro lado, el gasto en cultura fue uno de los más promovidos al experimentar un crecimiento para el periodo $2015-2018$ de $183 \%$, pasando de representar el $6 \%$ en 2015 (U\$S465.106) al 10\% en 2018, con un monto total de U\$S1.317.270. Notamos allí un fuerte impulso a la biblioteca municipal, cuyo gasto ascendió a U\$\$369.879, representando un $28 \%$ del gasto total de este rubro. Luego, se destinaron recursos al fortalecimiento de las escuelas de arte y música, cuya representación en el total gastado fue de $25 \%$ y $9 \%$ respectivamente. El gasto destinado a la proyección artística y cultural también tuvo una importancia considerable, al gastarse $U \$ \$ 235.655$, lo que representa un $18 \%$ del presupuesto cultural. 
DEPENDENCIA CULTURA AÑO 2018. VALORES EN DÓLARES.

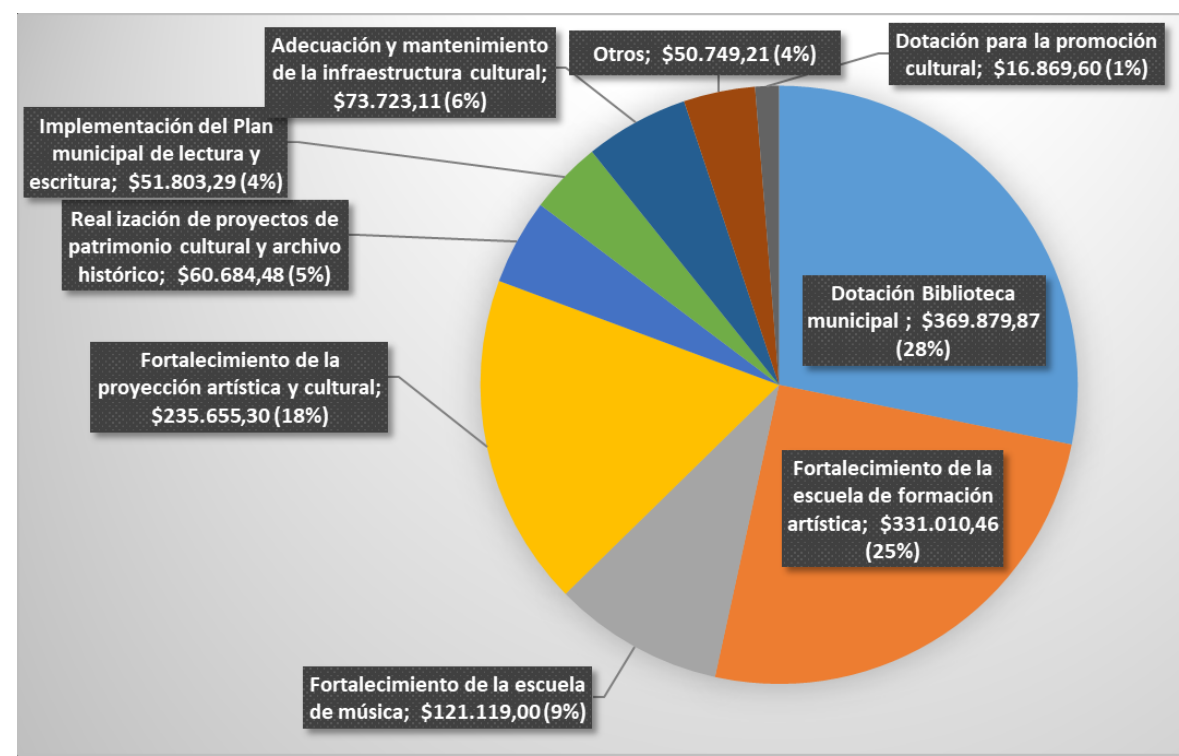

Fuente: Elaboración propia en base a Presupuesto de Ingresos Disponibles del Municipio de Sabaneta 2018

Por último, es importante analizar el origen de los fondos. El mismo se compone de Ingresos de libre disponibilidad, SGP y recursos del Ministerio de Educación Nacional bajo el Programa de Alimentación Escolar. También tenemos recursos mixtos, en los que los proyectos deben ser desarrollados con recursos del SGP e ICLD y algunos tan claros que solo se pueden pagar con los recursos del SGP como la nómina y las prestaciones sociales de los docentes.

Observamos como los ingresos corrientes de libre disponibilidad (ICLD) mantienen una importante participación sobre el total de recursos, al representar un $42 \%$ sobre el total gastado por la Secretaria para ese año. Si no tenemos en cuenta los recursos destinados a gastos administrativos y docentes, que provienen por completo del Sistema General de Participaciones (SGP), el porcentaje de ICLD se eleva a $74 \%$, lo cual muestra una gran importancia de estos fondos. Estos ingresos mantienen una supremacía a lo largo de todas las categorías que no forman parte del gasto docente y administrativo, que contienen la inversión (ya sea infraestructura o planes) en educación y cultura. Demuestra la capacidad del 
municipio para recaudar y disponer una parte para la educación, alternativa que los no certificados no tienen.

Naturalmente siguen teniendo gran importancia de los recursos provenientes del SGP, pero principalmente enfocados a los gastos administrativos y docentes, ya que cuando son considerados estos gastos los recursos representan el $48,2 \%$ del total, pero cuando no se consideran los gastos el porcentaje disminuye al $9 \%$.

Los recursos del PAE, que aparecen dentro de la categoría Condiciones de VidaÉnfasis en Educación, representan un 6,6\% de los recursos utilizados bajo esa categoría, y un $1,3 \%$ del total utilizado por la Secretaria.

\section{DISTRIBUCIÓN DEL PRESUPUESTO POR ORIGEN DE LOS FONDOS. AÑO}

\section{8}

\begin{tabular}{|c|c|c|c|c|c|c|c|c|c|}
\hline \multirow{2}{*}{ Categoria } & \multirow{2}{*}{ Total 2018} & \multirow{2}{*}{ ICLD } & \multicolumn{6}{|c|}{ Mixto } & \multirow{2}{*}{$\%$ ICLD } \\
\hline & & & SGP & PAE & FONPET & ICDE & FOMAG-SSF & MINCULTURA & \\
\hline SERVICIOS PERSONALES & $\$ 1.020 .508$ & $\$ 1.020 .508$ & - & - & - & - & - & - & $100 \%$ \\
\hline GASTOS GENERALES & 5.581 & 5.581 & - & - & - & - & - & - & $100 \%$ \\
\hline TRANSFERENCIAS & 323.472 & - & - & - & - & - & $\$ 323.472$ & - & - \\
\hline Despacho del Secretario. Condiciones de Vida-Enfasis en Educación & $\$ 2.438 .271$ & $\$ 2.154 .515$ & $\$ 123.958$ & $\$ 159.797$ & - & - & - & - & $88 \%$ \\
\hline Calidad Instituciones Educativas & $\$ 1.749 .598$ & $\$ 1.252 .801$ & $\$ 437.977$ & - & $\$ 58.820$ & - & - & - & $72 \%$ \\
\hline Dependencia cultura & $\$ 1.317 .270$ & $\$ 529.388$ & 90.593 & - & $\$ 369.880$ & $\$ 319.629$ & - & 7.780 & $40 \%$ \\
\hline Centro de Orienta y Gest para el Trabajo & 371.818 & $\$ 371.818$ & - & - & - & - & - & - & $100 \%$ \\
\hline Gastos Admon.Establecimientos I.E. & 564.686 & - & $\$ 564.686$ & - & - & - & - & - & - \\
\hline Preescolar I.E. & $\$ \quad 240.145$ & - & $\$ 240.145$ & - & - & - & - & - & - \\
\hline Básica Primaria I.E. & $\$ 1.576 .954$ & - & $\$ 1.576 .954$ & - & - & - & - & - & - \\
\hline Básica Secundaria y Media I.E. & $\$ 2.490 .418$ & - & $\$ 2.490 .418$ & - & - & - & - & - & - \\
\hline Directivo Docente & $\$ \quad 582.137$ & - & $\$ \quad 582.137$ & - & - & - & - & - & - \\
\hline Total & $\$ 12.680 .859$ & $\$ 5.334 .611$ & $\$ 6.106 .869$ & $\$ 159.797$ & $\$ 428.700$ & $\$ 319.629$ & $\$ 323.472$ & 7.780 & $42 \%$ \\
\hline Total sin gastos administrativos y docentes & $\$ 7.226 .518$ & $\$ 5.334 .611$ & $\$ 652.528$ & $\$ 159.797$ & $\$ 428.700$ & $\$ 319.629$ & $\$ 323.472$ & 7.780 & $74 \%$ \\
\hline
\end{tabular}

Fuente: Elaboración propia en base a Presupuesto de Ingresos Disponibles del Municipio de Sabaneta 2018

\section{La oferta actual y la cobertura}

Un objetivo central de la certificación era la evolución de la cobertura, la información al respecto surge del Ministerio de Educación on line y se refleja en los gráficos sucesivos. En el periodo analizado, se observa que en el nivel secundario y medio la tasa de cobertura neta (según edad) se eleva levemente para los tres municipios, pero el municipio que mayor tasa de cobertura presenta 
al 2017 es Sabaneta en los tres niveles, en el medio con un 73\%, en el secundario con el $120 \%$ y en el primario en un $128 \%$. Esto es importante porque la tendencia nacional es otra y este municipio cubría primaria sólo $116 \%$ en el 2005 . En este nivel Medellín y La Estrella disminuyen su tasa de cobertura ubicándose muy por debajo ( $98 \%$ y $99 \%$ respectivamente). El segundo como ya hemos dicho no ha sido aún certificado.

En el nivel transición, es muy notable el aumento en la cobertura presentada por La Estrella que alcanza los 20 puntos (48\% año 2005; 68\% año 2017). Pero lo central es la evolución de la cobertura. En el periodo analizado, se observa que en el nivel secundario y medio la tasa de cobertura se eleva levemente para los tres municipios. En el nivel medio, en promedio los tres municipios pasan de un $54 \%$ a un $61 \%$, guiados por mayores incrementos en La Estrella ( $45 \%$ a $56 \%$ ) y Medellín ( $47 \%$ a $54 \%$ ). No obstante, el municipio que mayor tasa de cobertura presenta al 2017 es Sabaneta con un 73\%. Por otro lado, la tasa de cobertura en el nivel secundario promedio para los tres municipios alcanza el $99 \%$ en el 2017 , cuando en el 2005 era del $86 \%$.

En el resto de los niveles educativos la situación se presenta diversa. En el nivel primario, con un quiebre para el año 2014, Medellín y La Estrella disminuyen su tasa de cobertura sin embargo se mantienen cerca del 100\% (98\% y 99\% respectivamente). El caso de Sabaneta es interesante ya que a pesar de estar en un $116 \%$ en el 2005, para el año 2017 incrementa su tasa alcanzando un $128 \%$. En el nivel transición, de nuevo es muy notable el caso de Sabaneta que se acerca al $100 \%$ mientras La Estrella que logró un aumento está por debajo del $70 \%$. 


\section{TASA DE COBERTURA NETA (POR MUNICIPIO)}
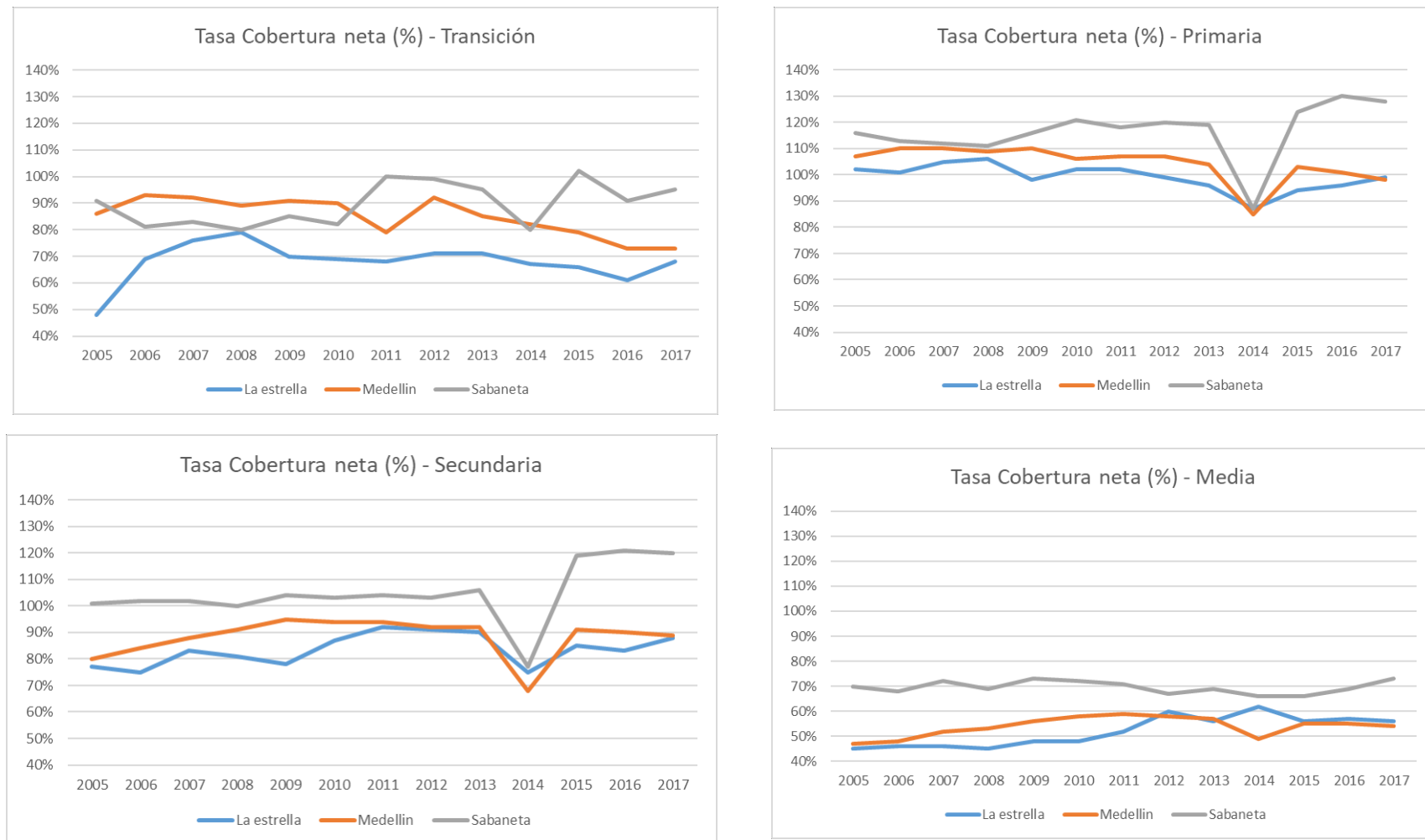

Fuente:

http://bi.mineducacion.gov.co:8380/eportal/web/planeacionbasica/tasa-de-cobertura-neta-x-departamento

Los resultados de la estrategia pueden verse en la TCB, (Tasa de Cobertura Bruta) que define la población matriculada en la educación escolar sin importar la edad.

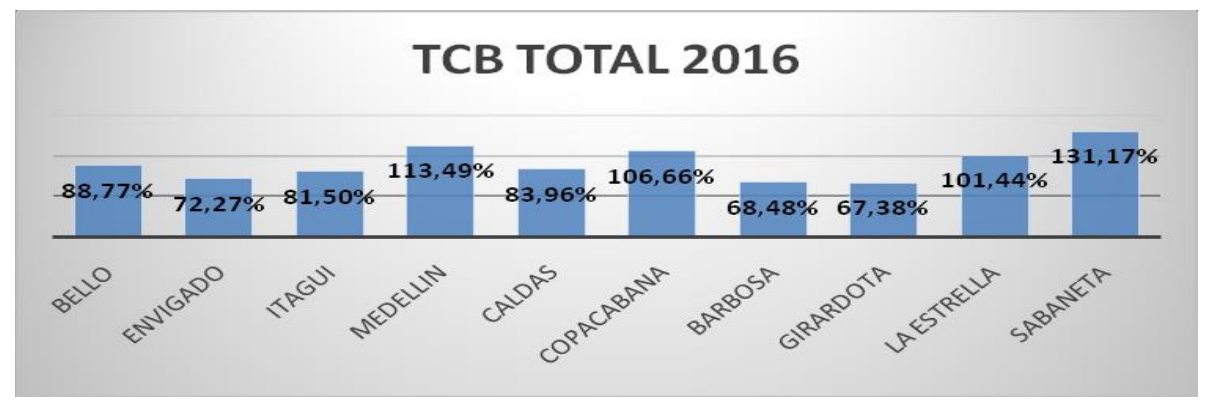

Fuente:

http://bi.mineducacion.gov.co:8380/eportal/web/planeacionbasica/tasa-de-cobertura-neta-x-departamento 
Es el municipio con mayor cobertura en educación en comparación con los demás municipios del valle de Aburra, como puede verse en la gráfica anterior.

Como hemos visto, para el nivel de básica primaria se observó un aumento significativo en el crecimiento de la Tasa de Cobertura, el municipio tiene una alta demanda en este nivel educativo, por la calidad de la formación y la gran oferta de instituciones académicas, con relación a los demás municipios de Antioquia.

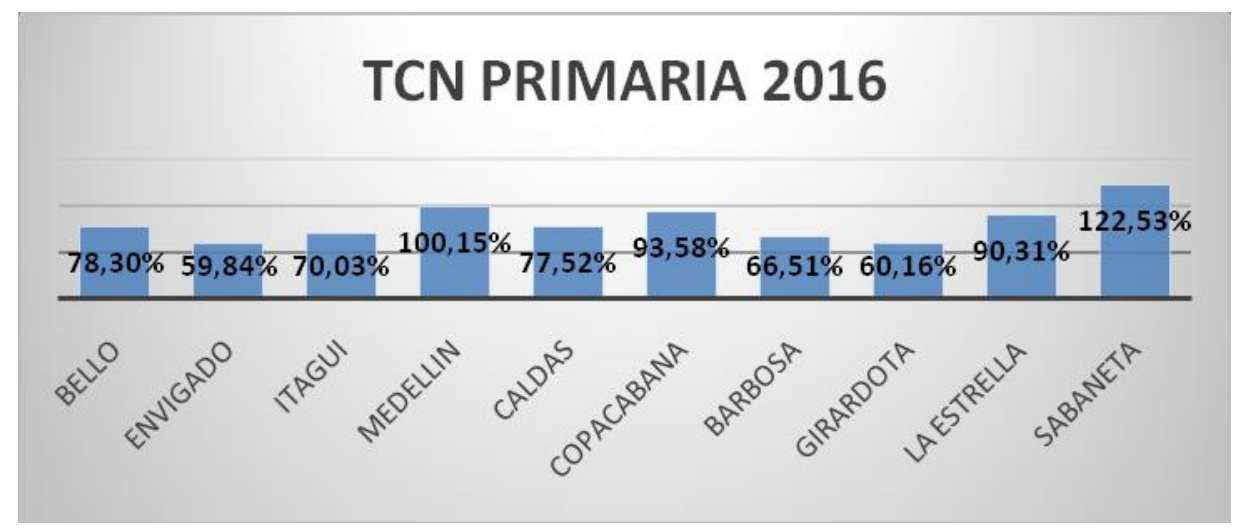

Fuente:

http://bi.mineducacion.gov.co:8380/eportal/web/planeacionbasica/tasa-de-cobertura-neta-x-departamento

La deserción es un factor que mide el MEN al identificar estudiantes que abandonan el sistema educativo, retirandose de una institucion y no volviendo a matricular en el año lectivo, este seguimiento se hace a través del Sistema de Matricula SIMAT (sistema de información a nivel nacional) En el gráfico puede verse que Sabaneta ha visto una interesante reducción y a su vez está mejor posicionado que el promedio nacional.

TASE DE DESERCIÓN INTRA-ANUAL DEL SECTOR OFICIAL

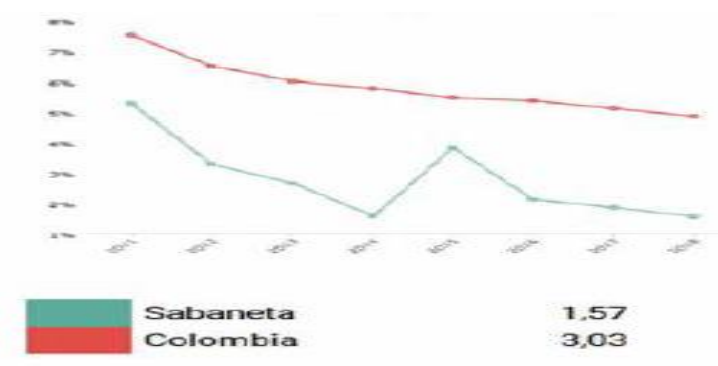

Fuente: SPM (2020) 
En relación a las exigencias de la normativa se evidencia que para el nivel Preescolar, se cumplen las relaciones técnicas; el número de profesor por alumno es adecuado. Las relaciones técnicas para el nivel de Básica Primaria se ven mejor estructuradas, y estan por encima de los promedios aceptados ya que por cada grupo existe un maestro. En secundaria no se cumplen las exigencias por el tamaño de las aulas que no es el adecuado para la cantidad de alumnos, debido a la alta demanda que se tiene para este nivel. Aunque se tiene una buena oferta de los centros educativos, no todos cumplen las exigencias.

\section{RELACIONES TÉCNICAS DIVERSOS NIVELES EDUCATIVOS SABANETA}

\begin{tabular}{|l|r|r|r|r|r|r|r|r|r|}
\hline \multirow{3}{*}{ INSTITUCIONES EDUCATIVAS } & \multicolumn{9}{|c|}{ Preescolar } \\
\cline { 2 - 10 } & \multicolumn{2}{|c|}{ Alumnos } & \multicolumn{1}{c|}{ Grupos } & \multicolumn{2}{c|}{ Docentes } & \multicolumn{2}{c|}{ Relación AVD } \\
\cline { 2 - 10 } & \multicolumn{1}{|c|}{$\mathrm{R}$} & $\mathrm{U}$ & $\mathrm{R}$ & $\mathrm{U}$ & $\mathrm{R}$ & $\mathrm{U}$ & $\mathrm{R}$ & $\mathrm{U}$ \\
\hline MARIA MEDIADORA & 0 & 35 & 0 & 1 & 0 & 1 & & 35,0 \\
\hline ADELAIDA CORREA ESTRADA & 0 & 66 & 0 & 2 & 0 & 2 & & 33,0 \\
\hline $\begin{array}{l}\text { CONCEJO DE SABANETA JOSE } \\
\text { MARIA CEBALLOS BOTERO }\end{array}$ & & & & & & & & \\
\hline JOSE FELIX DE RESTREPO VELEZ & 0 & 65 & 0 & 1 & 0 & 1 & & 35,0 \\
\hline MARIA AUXILIADORA & 23 & 0 & 1 & 0 & 0 & 2 & & 33,0 \\
\hline PRESBITERO ANTONIO BAENA & & & & & & & & \\
SALAZAR & 60 & 0 & 2 & 0 & 2 & 0 & 30,0 & \\
\hline PRIMITIVO LEAL LA DOCTORA & 61 & 0 & 2 & 0 & 2 & 0 & 30,5 & \\
\hline RAFAEL J. MEJIA & 0 & 91 & 0 & 3 & 0 & 3 & & 30,3 \\
\hline & 144 & 293 & 5 & 9 & 5 & 9 & 28,8 & 32,6 \\
\hline
\end{tabular}

\begin{tabular}{|c|c|c|c|c|c|c|c|c|}
\hline \multirow{3}{*}{ INSTITUCIONES EDUCATIVAS } & \multicolumn{8}{|c|}{ Primaria } \\
\hline & \multicolumn{2}{|c|}{ Alumnos } & \multicolumn{2}{|c|}{ Grupos } & \multicolumn{2}{|c|}{ Docentes } & \multicolumn{2}{|c|}{ Relación AID } \\
\hline & $R$ & U & $\mathrm{R}$ & U & $\mathrm{R}$ & U & $\mathrm{R}$ & U \\
\hline MARIA MEDIADORA & 0 & 203 & 0 & 5 & 0 & 5 & & 40,6 \\
\hline ADELAIDA CORREA ESTRADA & 0 & 365 & 0 & 11 & 0 & 11 & & 33,2 \\
\hline $\begin{array}{l}\text { CONCEJO DE SABANETA JOSE MARIA } \\
\text { CEBALLOS BOTERO }\end{array}$ & 0 & 229 & 0 & 5 & 0 & 5 & & 45,8 \\
\hline JOSE FELIX DE RESTREPO VELEZ & 0 & 532 & 0 & 15 & 0 & 15 & & 35,5 \\
\hline MARIA AUXILIADORA & 160 & 0 & 5 & 0 & 5 & 0 & 32,0 & \\
\hline $\begin{array}{l}\text { PRESBITERO ANTONIO BAENA } \\
\text { SALAZAR }\end{array}$ & 342 & 0 & 10 & 0 & 10 & 0 & 34,2 & \\
\hline PRIMITIVO LEAL LA DOCTORA & 399 & 0 & 11 & 0 & 11 & 0 & 36,3 & \\
\hline \multirow[t]{2}{*}{ RAFAEL J. MEJIA } & 0 & 612 & 0 & 15 & 0 & 15 & & 40,8 \\
\hline & 901 & 1941 & 26 & 51 & 26 & 51 & 34,7 & 38,1 \\
\hline
\end{tabular}

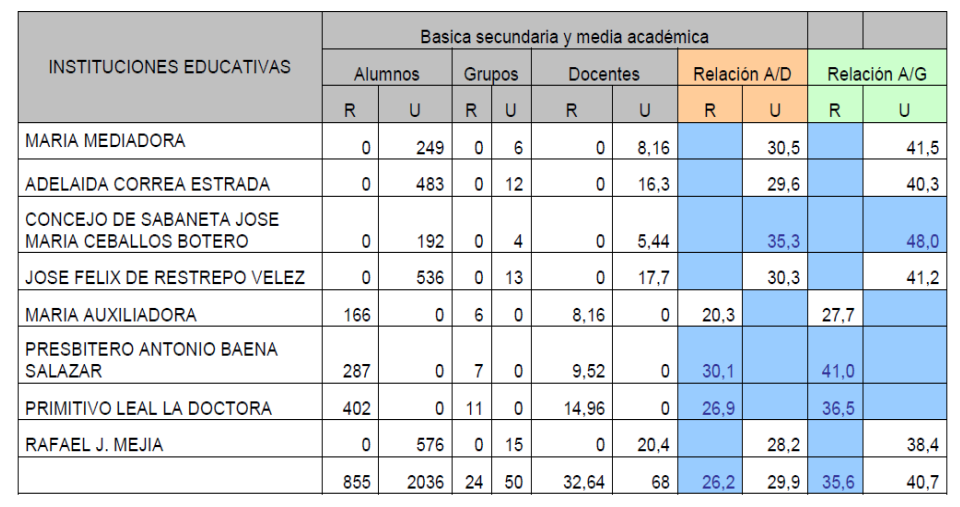

\section{Fuente: Municipio de Sabaneta (2019)}

El resultado está en línea con nuestras hipótesis, si vemos el trabajo de Moreno Montes (2017), para educación primaria, los municipios certificados se ubican en el rango cobertura muy alta (93\% del total). Para 2011 , el $100 \%$ de los municipios certificados tienen buenos resultados en cobertura educativa; esto demuestra el 
esfuerzo de los municipios certificados por llevar más estudiantes a los establecimientos educativos. Este dato es similar para municipios no certificados en 2005 pero cae al $89 \%$ para 2008. En secundaria y media, los municipios certificados alcanzan un $92 \%$ para 2011 en cobertura muy alta. La gran mayoría de municipios no certificados se agrupan en cobertura media y alta, aunque decrecen luego del 2005. En realidad, éstos son contextos en que la pobreza, el índice de desarrollo municipal, el índice de desempeño y el índice de profesionalidad docente (las variables que mas inciden en el modelo presentado por el autor) juegan en contra. El caso Sabaneta es el inverso, y las políticas permitidas en este municipio por el modelo y las concidiones institucionales en el último período han potenciado los resultados. Esos municipios con desventajas no han podido gozar de estas alternativas.

\section{Rectoría, profesión docente y apoyo a los estudiantes}

A continuación, se analizan los aspectos que hacen a la gestión en un municipio certificado en el marco del sistema descentralizado colombiano. En primer lugar, nos interesa abordar el hecho de que se trata de un modelo que otorga gran responsabilidad a los rectores, sobre todo, pero especialmente en el control del presupuesto del FSD, este aspecto así como la estrategia de conducción escolar es conferido también en los municipios no certificados, pero según opinión del directivo entrevistado de La Estrella, sin otras prerrogativas pierde eficacia.

El rector, además de estar administrando un presupuesto, rinde cuentas al Consejo directivo, soluciona la falta de un docente, con poca autonomía de contratar quien reemplace esta función, problemas de presupuesto para mantenimiento, la relación con la aseadora o el vigilante, etc. $Y$ al mismo tiempo se reconoce que se trata de una tarea para la que no se prepararon. El tema central que surge es que estas actividades invaden la elaboración y luego la ejecución del Proyecto Educativo Institucional y la estrategia pedagógica. De todos modos los rectores han logrado empoderarse y ese era un objetivo. 
El sindicato se focaliza, como vimos en la posición de Fecode y en la entrevista a la docente del sindicato, en la fuerza que va tomando el núcleo de rectores de las escuelas públicas como un actor empoderado a partir de las posibilidades que las certificaciones ofrecen. También temen que el proceso siga encausado por un fuerte acento en lo técnico administrativo.

Lo mismo sucede alrededor del Consejo directivo, para algunos no muy activo más allá de la lógica formal. Por lo tanto se cuestiona el escaso sesgo hacia lo pedagógico, que el modelo pone énfasis en el control de los fondos y al mismo tiempo en la cobertura, por eso lo pedagógico pierde peso.

Pero una entrevistada, estudiante que había participado del gobierno escolar valoraba la experiencia, reconocía que muchos compañeros no daban importancia a la actividad, pero al mismo tiempo le parecía un reto "llegarle a las personas que no piensan igual" (Estudiante que había estado en el gobierno escolar). Cuestionaba la distancia generacional que advertía con la rectora en ciertos temas, como el rechazo a los cortes de cabello o portar pircing, también algunas trabas en el Consejo, especialmente cuando llega una persona con ideas críticas. Planteaba que por eso muchas personas le tienen miedo a la rectora y a las posibles represarías que ella tomara ante estudiantes y maestros.

Para una ex rectora por encargo y actual docente puede ser que haya algún manejo tendiente a controlar los consejos directivos, pero la reforma generó ámbitos de participación interesantes y en la mayor parte de los casos los directivos intentan formas de conciliación. En muchas conversaciones se menciona claramente el punto de vista diverso del sindicato y su influencia allí donde hay afiliados. Una funcionaria decía que, salvo algunos rectores imponentes, en su gran mayoría son los consejos directivos quienes aprueban. Valoraba el hecho de que se deben rendir informes públicamente, mediante carteleras. También nos manifestaba que el proceso fue mejorando. 
Además, en las entrevistas a los docentes surge inquietud sobre el elevado número de estudiantes por aula, a veces de más de 40 estudiantes. Y se suele mencionar la aparición de problemas relativos al bienestar, diferentes síntomas y signos que no son compatibles con los 3 días de incapacidad, 5 hasta 15, renovables automáticamente después del vencimiento de estas. Por otro lado el sistema solo permite reemplazar incapacidades mayores a 30 días. Sucede que en ocasiones estas incapacidades de tan solo 3 días duran años, por eso en la escuela puede haber al mismo tiempo 5 o 6 grupos de más de 40 estudiante sin docente.

En cuanto al salario, ésta es una variable exógena pero los municipios pueden generar un sistema de premios o estímulos y también se puede ser más expeditivo para determinar las suplencias, en el presupuesto hemos visto que ha habido algún esfuerzo en ese sentido. Por otro lado está la oportunidad de realizar mejoras en los procesos de ascenso, con la formación docente y el beneficio de maestrías y doctorados que incrementa el escalafón docente y por ende su salario.

En el caso de las suplencias, se puede reemplazar un maestro con una incapacidad con los recursos de SGP si la incapacidad es de 30 días o más, si el municipio está certificado se puede hacer por horas extras, sin que el maestro reemplazante supere las 25 horas al mes. En el municipio con el programa de maestros por Jornadas complementarias trataba de cubrir las incapacidades, para ello se contaba con 16 profesores que atienden sus programas y a demás tenían unas horas disponibles para reemplazos. El directivo de La Estrella planteó esto como un tema central.

Después de la certificación del municipio de Sabaneta, hay una forma de evaluación de desempeño que se complejizó pues la opinión del rector frente al desempeño de los docentes era definitiva para acceder a los demás procesos de ascenso, si era mal evaluado por el rector pocas esperanzas se daban para 
seguir las otras opciones, los docentes empezaron a exigir el compromiso de las administraciones de turno para que al administrar los recursos designados para la educación fueran visibilizados, el sindicato intercedió positivamente. Dicho sindicato a nivel nacional FECODE a través de paros y pliegos de peticiones logra negociar con la administración central y llegar a acuerdos que benefician la labor docente.

Las capacitaciones mencionadas en las entrevistas a directivos y docentes son por un lado las de Unidad de Atención Integral que se realizan anualmente para los docentes y clasificación de niños con necesidades educativas y a su vez estrategias para el trabajo dentro del aula. Se menciona el foro municipal del 2018 con fuerte participación docente desde la organización con la Secretaría municipal, $\mathrm{y}$ foros de menor magnitud se siguen realizando.

También se debe mencionar porque la han valorado todos los entrevistados, una modalidad que representa una forma de interrelación superadora que es la de las Experiencias significativas en la que el docente desarrolla un tema que ha preparado y qué impulsa algún tipo de debate. En algunos casos se presentan didácticas innovadoras que permitirían ampliar los temas del foro educativo, de cada IE debe haber mínimo una propuesta. En la IE de una entrevistada hubo 9 propuestas innovadoras entre 22 maestros.

Muchas de estas estrategias han sido mencionadas por el directivo de La Estrella, aunque él plantea que el municipio ha iniciado el proceso de certificación porque la dependencia con el departamento es una limitante grande. Dice que la mayor parte de los entes territoriales municipales, incluso los más humildes tratarían de certificarse si les fuera posible.

Una docente entrevistada valoró enormemente el Programa Formación en Rectores líderes transformadores, de 2 años de duración a partir de la necesidad de mejorar la comunicación y el trabajo en equipo de los directivos de las IE. Era 
un encuentro cada 2 meses durante una semana. Se contrató para ello la fundación Empresarios por la Educación, por convenio. Estos talleres se planteaban en un comunicado de prensa del Municipio como un espacio para fortalecer las competencias pedagógicas, administrativas y comunitarias.

En el primer encuentro se trabajó "en el autoconocimiento y la valoración del otro para destacar cualidades individuales y grupales, empoderar y fortalecer su rol dentro de la institución, generar trabajo colaborativo y responsabilidad compartida" (Fundación Empresarios por la Educación, 2017). En el informe realizado, recién citado por se evalúa el módulo 1 "El valor de ser y de ser con otros" se dice que al inicio había un grupo heterogéneo disconforme y que de a poco se fue avanzando a una mayor cohesión sobre la base de asumirse como líderes trascendiendo el interés personal al interés institucional. También se hace un perfil de cada rector.

Luego se desarrollan las actividades realizadas entre ellas buzón del afecto, construcción de acuerdos, el reloj, mapa de coherencia personal, mapa de mi vida en la escuela, mándala, rueda de roles, lluvia de ideas, propósito de vida, modelo de responsabilidad personal, conversaciones transformadoras y retroalimentación efectiva. $Y$ se realiza una introducción a las redes de liderazgo para que los directivos participen de esta red más amplia. Al final se hace una nueva evaluación de los directivos en función de las actividades realizadas.

Como nos mencionó la rectora entrevistada, en un segundo encuentro el programa se enfocaba en "los retos en torno a la formación y el fortalecimiento del liderazgo, en el reconocimiento del contexto educativo y en la definición de sueños institucionales, para configurar estrategias de mejoramiento e innovación" (Rectora entrevistada).

Por otro lado, de las entrevistas con directivos surgen las jornadas pedagógicas, que también son obligatorias por ley, mensuales o de carácter extraordinario, y normalmente duran una jornada de 6 horas, en pandemia se hacen virtual. Se 
tratan temas como Comisiones de evaluaciones y promoción, y también casos de aspecto psicosocial. Otro tema que se suele abordar en las Jornadas pedagógicas son los ajustes de las programaciones, aclaración sobre conceptos o informar a los maestros sobre debilidades de plan de área.

Si bien no surgen de las entrevistas aun grandes innovaciones en el rubro capacitación interna, debe decirse que antes las mismas dependían de la Secretaria de educación del departamento de Antioquia, que mandaban los cursos sin intervención alguna del municipio ni de las escuelas. Por otro lado, naturalmente este es un proceso que recién empieza.

En cuanto a estudios formales, se han desarrollado actividades para promover especializaciones, maestrías, doctorados, dentro del esquema de Todos a la $U$ que veremos luego. En cuanto a las becas, en las entrevistas se menciona el proceso atravesado por 19 docentes en total que fueron financiados para realizar el doctorado y se propone para periodos sucesivos una mayor relación entre los temas y los proyectos escolares. La oferta de apoyo para esto está muy bien vistas porque de otro modo no se da la oportunidad para formación en educación superior para maestros, por lo costosos de esos programas.

También se mencionan los congresos y los viajes que han dejado un recuerdo positivo. Particularmente importante fueron para todos los entrevistados sin excepción los 4 Congresos de Política Educativa en América Latina, con la participación de gran cantidad de maestros, aunque los mismos no fueron un espacio de presentación de trabajos y participación fuerte, podrían significar un paso adelante. Las temáticas fueron: Innovación, Gubernamentalidad y educación, Pedagogías latinoamericanas, invenciones y legados; Educación desde América Latina: paradigmas, experiencias e innovaciones

También recogió muy buenas opiniones la participación en el IV Encuentro Internacional de Directivos Docentes en Barcelona, que giró alrededor del tema 
"Influencia de las redes sociales en la educación". Además de las actividades del evento se organizaron diversas visitas a instituciones educativas de Barcelona. La actividad fue similar a la anterior conceptualmente, pero en este caso se planteaba una apertura a un intercambio más efectivo con las experiencias educativas de España. La misma dio lugar a diversas actividades en Sabaneta divulgando estos aprendizajes.

Una política particular que ha desarrollado el ultimo alcalde fue la de lograr la aprobación por parte del Ministerio de Industria, Comercio y Turismo de una Zona Franca de Educación e Innovación (Zfei). Esta normativa permite ofrecer la tasa del $20 \%$ del impuesto sobre la renta, hasta por 30 años contra el 35\% habitual siempre que se demuestre la inversión, generación de innovaciones y creación de empleo (al menos 500). Además, un conjunto de insumos queda exentos de IVA. Al mismo tiempo están exentos de los impuestos aduaneros y gozan de arancel 0 para toda exportación (El Colombiano, 2019). Los documentos del municipio mencionan el acompañamiento de la Fundación Colombo Canadiense, Cámara de Comercio Aburra Sur, Corporación empresarial PROSUR, Aso comunal, etc. La misma se financia con el item presupuestario "Condiciones de vida - Énfasis en educación"

Entre los principales objetivos de corto mediano plazo se incluía la formalización de convenios para estimular la presencia de instituciones de educación superior nacionales e internacionales, el acondicionamiento de espacios para la oferta de servicios educativos terciarios, eventos de difusión y apropiación de la ciencia como ferias, estimular proyectos de producción de conocimiento, entre ellos nanotecnología, biotecnología. En la práctica sólo se llegó a organizar eventos de promoción.

Los entrevistados más consustanciados con el modelo nos han mostrado su conformidad, desde el sindicato se plantea que "hay una gran población que necesita otras miradas de capacitación distintas, en realidad se sabe poco sobre 
las necesidades sentidas de capacitación para los docentes porque se carecen de trabajo sistemático para conocerlas e intervenirlas".

Comparado con otros modelos educativos de Latam no parece haber grandes diferencias. Sin embargo, parece cierto que los docentes pasan por un período de recambio asignado por la pérdida de importancia de las escuelas pedagógicas y el aumento de los profesores con un origen en una carrera profesional y con una capacitación en pedagogía realizada posteriormente, este perfil puede dar un sentido profesional a la enseñanza, pero también puede ser una forma de pérdida de mística.

De todos modos, hemos encontrado tanto alumnos como padres y rectores muy satisfechos en cuanto al compromiso, la forma de dar clase, las evaluaciones. Otros puntos de vista responden a personas que reflejan debates más teóricos al respecto.

Respecto a los currículums la metodología de las de los primeros años giraban en torno a las mesas de trabajo, pero las mismas fueron suspendidas, trataron de ser establecidas en el 2016 sin éxito. Se cuestionaba desde el sindicato la coordinación de una universidad privada Ceipa, que desconoce el sector público, no propone una investigación que se contextualice y que responde a la idea de la competitividad. Pero especialmente se cuestiona la falta de participación de los docentes en la organización y en la interacción, no se socializan las propuestas con las bases de maestros y luego pasan las propuestas al concejo sin un debate con las comunidades educativas. Desde entonces los cambios curriculares son mínimos e informales.

Finalmente, de las entrevistas surge que hay pocas actividades extraescolares, se puede mencionar la formación de Comfenalco para enfrentar entrevistas laborales, manejo de emociones, hacer hoja de vida. También se han mencionado capacitaciones sobre economía y de emprendimientos. 
En cuanto a la indagación sobre los procesos pedagógicos colectivos, tratando de resumir, los entrevistados vinculados a la rectoría puntualizan que antes de la certificación no existía de manera significativa la evaluación institucional, actualmente las instituciones constantemente hacen su proceso de evaluación institucional anual, con participación de los diferentes agentes de la comunidad educativa, pero otros plantean que los modelos pedagógicos no son contextualizados: “¿cómo puede Colombia hablar de modelos educativos propios si está extraviada en su propio territorio?" (Docente con participación sindical).

En relación a los estudiantes, como hemos dicho, el modelo propone programa de inversión social para cierto porcentaje de estudiantes con buenos desempeños académicos. El más importante es Todos a la U. Este programa surge en el 2009 con el acuerdo 06 que a su vez es mejorado con el Acuerdo Municipal No 8 de 2018 con fondos propios. Se compone de 4 sub cuentas distintas: "Mi Talento, Mi Futuro", estimula a los mejores estudiantes del Bachillerato oficial del Municipio de Sabaneta; "Educación Superior para Todos" otorga financiación mediante créditos preferenciales o condonables; "Sabaneta en el Mundo" financia estudios en el exterior o fuera del departamento con créditos no condonables; "Fondo Conjunto Municipio de Sabaneta - ICETEX" mediante créditos financia a docentes y directivos la realización de Especializaciones, Maestrías y Doctorados (CMS, 2018).

En la norma se crea un Comité Técnico Operativo entre otros conformado por un integrante de la JUME y un Personero de las Instituciones de Educación Publicas del Municipio de Sabaneta con el fin de establecer criterios de selección, condiciones del apoyo y alcances.

Es interesante ver cómo define la norma los cupos para los 29 mejores bachilleres de las Instituciones Educativas: 2 mejores graduados por cada Institución Oficial; 2 mejores de la IE Oficial "José María Ceballos Botero" del programa extra edad y adultos mayores; 9 graduados de Instituciones Oficiales con mejor promedio en 
los grados 9, 10 y 11, y en la prueba SABER 11 (y no pertenezcan al grupo A); 1 estudiante destacado en deporte; y 1 destacado en Arte.

También se sumaron otras instituciones del municipio que becan estudiantes. $Y$ Finalmente el municipio comenzó a pagar el pin que es el derecho a rendir el examen de ingreso a la universidad a los estudiantes que no pueden hacerlo. Esto surge del Acuerdo Municipal Nro. 5 del 2018 y se incluye alumnos del grado 11 de las instituciones públicas y de los CLEl.

Entonces, se entrega por única vez el PIN a estos estudiantes que cumplan con las condiciones establecidas por el acuerdo, con el objetivo de cumplir con el requisito de acceso a Instituciones Públicas de Educación Superior para rendir examen de ingreso, comprometiéndose la Secretaria de Educación y Cultura a brindar el acompañamiento necesario a los estudiantes con el objetivo de definir su proyecto de vida, orientación profesional y el ingreso a la Educación Superior (CMS, 2018)

Una entrevistada que pasó todo el proceso y obtuvo una beca contó que debía ser la mejor, tener el mejor promedio en los grados 9 a 11 y así pasar como la mejor bachiller de la institución, el estudiante que queda en el segundo puesto también es beneficiario de la beca y el tercero participa por unos cupos generales del municipio. Nos manifestó que no sentía que este proceso generaba competencia porque se habían ayudado entre varios. Valoró que haya otros beneficios como Todos a la $U$, el pago de pin y otros temas. Y está orgullosa de que su beca cubre el $100 \%$ y ella estudia en EAFIT, "la mejor universidad en Colombia" ya que la beca de mejor bachiller no pone límite de precios. Aunque reconoce que "somos muchos quienes queremos estudiar, y aquí las oportunidades son muy bajas", en Colombia entrar a una universidad pública se está volviendo muy complejo y triste, en mi caso de 45 graduados solo 10 estamos estudiando" (Estudiante que participó del gobierno escolar). 
Una funcionaria de la secretaría decía que es una gran oportunidad para los jóvenes que no tienen recursos para dar continuidad a sus estudios y proyectos de vida personal y profesional, que no se la gana cualquiera y que luchan por años por obtenerla.

Por último, las posibilidades que brinda la certificación se tradujeron en pruebas internas diseñadas por los docentes desde sus áreas para los estudiantes, simulacros pruebas ICFES, acorde a las disposiciones del MEN, para mejorar luego los "entrenamientos" en el desarrollo de las pruebas del estado. El preicfes, se realiza después de clase en la jornada contraria, con un profesor externo, con una entidad que se llama Proasedu, según documentos oficiales, un proyecto de inversión del municipio para mejor la calidad educativa y las oportunidades de los estudiantes para el acceso a la educación superior.

Muchos estudiantes, según la rectora entrevistada valoran los simulacros y las pruebas de estado, porque son útiles para prepararse para la Universidad. Para una funcionaria entrevistada los Exámenes de estado sirven como requisito para pasar a la Universidad pero que en Sabaneta se ha intentado con los simulacros ayudar a los estudiantes y realizar una innovación local. En ese sentido valora el programa "Jugando aprendo" como una estrategia para dar cumplimento a los temas puestos en el currículum pero como una forma diferente.

En este sentido se debe decir que el Municipio quedó con el mejor desempeño en las pruebas nacionales Saber 11 de todo el Departamento con un puntaje promedio de 286, 32 y consolidándose entre los mejores resultados a nivel nacional (Municipio de Sabaneta, 2016) ${ }^{15}$. Las críticas a esto provienen más bien

\footnotetext{
${ }^{15}$ Esto va en línea con MEN (2018) que muestra que los resultados de la prueba Saber, son más satisfactorios en las entidades territoriales certificadas, donde el porcentaje de maestros con posgrados es mayor. De todo modos menciona que el desempeño fue mejor para las escuelas que participaron del Plan Todos a Aprender (PTA), donde se destinaron $\$ 130.000$ millones en promedio con 94 formadores y 4500 tutores y que brindó formación a casi 100.000 maestros.
} 
de la bibliografía en relación a si este tipo de pruebas estandarizadas ayudan al proceso de aprendizaje.

\section{Conclusiones}

Las estrategias de gestión que ha establecido el Municipio de Sabaneta, han propiciado mejoras significativas en la cobertura principalmente, en básica primaria y secundaria.

Es evidente que el sistema le ha dado la posibilidad a Sabaneta de aprovechar su capacidad económica para obtener recursos y destinarlos a educación y ha logrado como contrapartida un aumento sustancial de la cobertura. Esta oportunidad la han tenido muy parcialmente los municipios que no pudieron sumarse a la certificación como surge de las normas y las estadísticas analizadas y lo manifiesta el entrevistado de la Estrella.

Sabaneta se ha posicionado como líder en educación, viene cumpliendo los procesos de gestión y adecuado uso de los recursos económicos en función del plan de desarrollo territorial. Probablemente debido a esa confrontación implícita con el sindicato y también a la trayectoria docente del anterior alcalde es que el proceso en general no ha recibido críticas sustanciales más allá de algunos cuestionamientos a los presupuestos manejados por los rectores.

Como contrapartida, debido al bajo gasto per cápita a nivel nacional hay problemas que se observan fundamentalmente en las aun escasas actividades didácticas de cierta complejidad, extracurriculares, viajes etc. y fundamentalmente esto se observa en el acceso a la universidad dado lo limitado del esquema de becas nacionales y lo poco que -pese al esfuerzo realizado puede hacer en este sentido el municipio. 
Otro elemento limitante ha sido la elevada carga burocrática y administrativa que soportan los rectores qué es la contracara de su nuevo poder contractual pero qué embarga buena parte de su actividad a costa de su atención en las actividades estrictamente pedagógicas. Esto sucede por el espíritu de la reforma pero también por la velocidad con que los municipios han debido asumir funciones para los cuales no estaban preparados y al mismo tiempo por las restricciones que tienen en cuanto a rodearse de personal capacitado en esta área, algo que es coherente porque, sino el personal administrativo terminaría superando al docente. Es que tal vez la escuela sea una escala ineficiente para toda esa carga.

De todos modos, probablemente el municipio inicialmente no estaba preparado para el cambio, y muchas veces no hubo una lectura novedosa y local de la política educativa nacional, de a poco se ha ido consolidando un equipo en la Secretaria y en las IE que van pudiendo administrar mejor la autonomía y abordando cuestiones pedagógicas más profundas en las que los municipios no certificados dependen del Departamento.

Finalmente se podría decir que la reforma cubrió al sistema educativo de una identidad "eficientista" que muchos teóricos y enfoques de los sistemas educativos del mundo, sobre todo el europeo continental, cuestionarían, pero eso es el reflejo del modelo de desarrollo elegido por el país, es parte de otro debate.

\section{Bibliografía}

Acosta P., Serrano C. (2011) El proceso de descentralización en Colombia. Proyecto de gobernanza subnacional para el desarrollo territorial en los Andes. RIMISP. Centro Latinoamericano para el Desarrollo Rural. Recuperado de: https://www.rimisp.org/wp-content/files mf/135965783013.pdf.

Albuquerque, F. (2004) "Desarrollo económico local y descentralización en América Latina". Revista de la CEPAL Nro 82, abril. Recuperado de: 
http://saludpublica.bvsp.org.bo/textocompleto/bvsp/boxp68/desarrollodescentralizacion.pdf

Alburquerque, F. (1999), "Cambio estructural, globalización y desarrollo económico local", Comercio exterior, Banco Nacional de Comercio Exterior, México, Vol. 49, Num. 8.

Alcaldía de sabaneta. (22 de abril de 2014). Icontec certifica a la secretaría de educación y cultura de sabaneta. Obtenido de

http://www.sabaneta.gov.co/salaprensa/paginas/certificacion .aspx

Área Metropolitana Valle de Aburrá AMA (2020) Plan Integral de Desarrollo Metropolitano Aburrá 2021 - 2032: Consolidación de la Región Metropolitana. Recuperado de:

https://www.metropol.gov.co/planeacion/PIDMformulacion/PIDM version1 conceja les Enviar.pdf

Arellano Garza, M. (2006) "la convergencia regional en España y las causas de convergencia del PIB per cápita en Cataluña" en Ensayos- Volumen XXV, num 2, noviembre 2006, pp.57-80.

As.com (2021) Gobierno escolar: órganos, funciones y cómo se decide quiénes lo conforman. 6 de abril. Recuperado de:

https://colombia.as.com/colombia/2021/04/07/actualidad/1617748592 705293.html

Barros P, Barry M, Brand H, Brouwer W, De Maeseneer J, Jönsson B, Lamata F, Lehtonen F, Marušič D, McKee M, Ricciardi W, Thomson S (2015). Access to health services in the European Union- Preliminary opinion. European Commission. Recuperado de:

https://ec.europa.eu/health/expert panel/sites/expertpanel/files/010 access health care en.pdf

Batakis S y Narodowski P (2021) Argentina: las dificultades para avanzar en la agenda metropolitana. Costa M, Lui L, Tavares Rebello S. Governança 
Metropolitana na América Latina: um panorama das experiências contemporâneas sob uma mirada comparativa. Cepal e Ipea. Recuperado de: https://repositorio.cepal.org/bitstream/handle/11362/46908/S2100303 pt.pdf?sequ $\underline{\text { ence }=1}$

Bayona Rodríguez H (2017) La imposibilidad que tienen los docentes de ascender: la realidad del 1278. Red de la Educación, 24 de julio. Recuperado de: https://lasillavacia.com/silla-llena/red-de-la-educacion/historia/la-imposibilidad-quetienen-los-docentes-de-ascender-la

BID (2016) "Descentralizando los ingresos fiscales en América Latina: por qué y cómo"

BID (2017) "Descentralización fiscal y disparidades regionales en América Latina: el potencial de las transferencias de igualación"

BID 2014 y 2018

Boisier, S. (1998), "Post-scriptum sobre desarrollo regional: modelos reales y modelos mentales", Anales de geografía de la Universidad Complutense, $\mathrm{N}^{\circ} 18$, Madrid, pp. 13-35.

Boisier, S., Lira, L. Quiroga B., Rojas, C. y Zurita, G. (1995), "Sociedad civil, actores sociales y desarrollo regional, Dirección de políticas y planificación regionales", Documento 95/14, Serie Investigación, Chile, Instituto Latinoamericano y del Caribe de Planificación Económica y Social (ILPES).

Bonet Morón J., Ayala García J. (2016) La brecha fiscal territorial en Colombia. Documento de trabajo sobre economía regional. Banco de la Republica. CEER. Recuperado de:

https://www.banrep.gov.co/sites/default/files/publicaciones/archivos/dtser 235.pdf.

Borja J (2004) Barcelona y su urbanismo. Éxitos pasados, desafíos presentes, oportunidades futuras. Zirma, año 3- número 21 - julio. Recuperado de: https://cafedelasciudades.com.ar/politica 21.htm 
Borja J y Carrión F (2016) Ciudades resistentes, ciudades posibles. En Borja J, Carrión F y Corti M Ciudades para cambiar la vida. Una respuesta a Hábitat III, Café de las Ciudades.

Caballero Prieto (s/f) La descentralización educativa en Colombia: perspectivas y realidad (Versión preliminar). Recuperado de:

\section{http://decon.edu.uy/network/M00/caballer.pdf}

Caldas N (2020) ¿Cómo avanza la descentralización del país? 30 de junio. Recuperado de https://www.eltiempo.com/politica/gobierno/como-avanza-ladescentralizacion-del-pais-512620

Cano, c. M. (12 de agosto de 2018). Con aumento en la inversión, sabaneta fortalece educación. Obtenido de El Tiempo:

https://www.eltiempo.com/colombia/medellin/con-aumento-en-la-inversionsabaneta-fortalece-educacion-254470

Cante D., Jiménez E. M. (2020) Descentralización administrativa y categorización municipal en Colombia. Revista Brasileira de Gestão e Desenvolvimento Regional. Recuperado de:

https://www.rbgdr.net/revista/index.php/rbgdr/article/view/5879/980.

Chain L y Narodowski P (2009) Economía y Educación. Dos disciplinas que van de la mano. Aulas y Andamios. Recuperado de:

https://periferiaactiva.wordpress.com/bibliografia-y-papers/uocral

CGR (2017) Efecto redistributivo del Sistema General de Participaciones. Resultados y perspectivas en los sectores de Salud y Educación. Contraloría General de la República

Comisión del Gasto y la Inversión Pública-Federdesarrollo (2018), Informe Final, diciembre de 2017. Recuperado de:

https://www.fedesarrollo.org.co/sites/default/files/LIB2017COMISION.pdf 
Consejo Municipal de Sabaneta CMS (2018) Acuerdo Municipal No 5 (17 de abril del 2018) "Por el cual se crea una estrategia de acceso a la Educación Superior Pública que consiste en entregar el PIN, para los estudiantes del grado 11 de las Instituciones Educativas Públicas y de los ciclos Lectivos Educativos Integrados (CLEI) del Municipio de Sabaneta". Recuperado de:

\section{https://concejodesabaneta.gov.co/files/acuerdos/2018/05.pdf}

Consejo Municipal de Sabaneta CMS (2018) Acuerdo Municipal No 8 (16 de julio del 2018) "Por el cual se crea el Fondo Municipal para la financiación de la educación superior " Todos a la U" y se derogan los Acuerdos Municipales Nros. 022 de 1999, 06 de 2009 y 25 de 2016". Recuperado de:

\section{https://concejodesabaneta.gov.co/files/acuerdos/2018/08.pdf}

Cortes D. y Vargas F. (2012) Inequidad Regional en Colombia. Serie documentos de trabajo No. 127. Universidad del Rosario. Recuperado de:

\section{https://www.urosario.edu.co/urosario files/4d/4d277c8b-4568-46db-9bd6-}

\section{ebbc8235e08d.pdf}

DANE (2021). Departamento nacional de estadística. Obtenido de www.dane.gov.co

DANE (2007) Movilidad poblacional de Medellín y su área metropolitana. Censo General 2005. Recuperado de:

\section{https://www.dane.gov.co/files/censos/analisis/medellin/movil medellin.pdf}

Diez-Gutierrez E (2018). Neoliberalismo educativo. Otra educación es posible. Octaedro.

Di Gropello E (1999) "Los modelos de descentralización educativa en América Latina", Revista de la CEPAL nº 68

Departamento Nacional de Planeación DNP (2016) Evaluación de la descentralización municipal en Colombia. Recuperado de: 
https://colaboracion.dnp.gov.co/CDT/Desarrollo\%20Territorial/01 Libro.pdf.

El Colombiano (2019) En Sabaneta funciona una zona franca educativa, ¿de qué se trata?, 10 de septiembre. Recuperado de:

https://www.elcolombiano.com/antioquia/en-sabaneta-funciona-una-zona-francaeducativa-de-que-se-trata-IC11576970

El colombiano. (12 de agosto de 2016). El colombiano. Obtenido de:

http://www.elcolombiano.com/empresas-en-accion/sabaneta-un-lugar-lleno-decosas-buenas-be 4754276

El colombiano. (15 de septiembre de 2018). El colombiano. Obtenido de:

http://www.elcolombiano.com/antioquia/he-dicho-desarrollo-si-progreso-sidesorden-no-hb9333797

El país.com. (13 de septiembre de 2017). Colombia es el país latino que menos invierte en educación, según la ocde. Obtenido de:

https://www.elpais.com.co/colombia/es-el-pais-latino-que-menos-invierte-eneducacion-segun-la-ocde.html

Forero D., Moreno C. (2019) Gasto en el Sector Educativo en Colombia. En Fedesarrollo (2019) La educación rural en Colombia y las intervenciones educativas para mejorarla. Recuperado de:

https://www.repository.fedesarrollo.org.co/bitstream/handle/11445/3909/Capi\%CC $\% 81$ tulo\%203\%20-

\%20Gasto\%20en\%20Educacio\%CC $\% 81$ n $\% 20$ en $\% 20$ Colombia $\% 20 \% 28002 \% 29$.p df? sequence $=2 \&$ isAllowed $=y$

Formichella M, Krüger N, Rojas, M (2009) Los procesos de descentralización educativa y sus resultados. Un análisis para Argentina. Economía y Sociedad, vol. XIV, núm. 24, julio-diciembre. Recuperado de: Disponible en:

http://www.redalyc.org/articulo.oa?id=51015096005 
Fundación Empresarios por la Educación (2017) Rectores Lideres Transformadores. Informe Nro 1.

Galilea, S.; Letelier, L. y Ross, K. (2011) "Descentralización de servicios esenciales. Los casos de Brasil, Chile, Colombia, Costa Rica y México en salud, educación, residuos, seguridad y fomento". CEPAL, Colección documentos de proyecto. Recuperado de:

http://repositorio.cepal.org/bitstream/handle/11362/3835/S2010976.pdf;jsessionid= A9A8CC7B204BED716C0F254F7A7B53DE?sequence $=1$

García Largo A., Colmenares Laguado J., Rolon Omaña G. (2014) La realidad de la descentralización en Colombia a partir de la Constitución de 1991. Recuperado de: https://revistas.unilibre.edu.co/index.php/hipotesis libre/article/view/3720/3114.

Giraldo-Paredes y De La Cruz-Giraldo G (2016) La influencia neoliberal en las políticas educativas en Colombia. Revista Criterio Libre Jurídico. Vol. 13 Núm. 2. Recuperado de: DOI: 10.18041/crilibjur.2016.v13n2.26208

Gottret y Schieber (2007) Estudio del financiamiento de la salud: una guía para especialistas. Banco Mundial y Mayol Ediciones. Recuperado de:

http://documents.worldbank.org/curated/en/203041468315358077/pdf/370910SPA NISH0101OFFICIALOUSE0ONLY1.pdf

Granato, L. (2015) Federalismo argentino y descentralización: sus implicancias para la formulación de políticas públicas. Revista Prolegómenos Derechos y Valores, 18, 36, 117-134. Recuperado de:

http://www.scielo.org.co/pdf/prole/v18n36/v18n36a08.pdf

Juma S, Ramli M, Suhaida bte Abd, Azimi H (2015) A Review of Characteristics and Experiences of Decentralization of Education. International Journal of Education \& Literacy Studies, january. Recuperado de:

http://www.journals.aiac.org.au/index.php/IJELS/article/download/1476/1436 
Kameshwara, K Sandoval-Hernandez, A Shields, R Rai Dhanda, K (2020) A false promise? Desentralization in education system across the gobe. International Journal of Educational Research. Recuperado de:

https://researchportal.bath.ac.uk/en/publications/a-false-promise-idecentralizationin-education-systems-across-the

Latino (2021) Juntas Municipales de Educación. Recuperado de:

https://www.latinno.net/es/case/5106/

Maldonado Copello A. (2011) Descentralización territorial en Colombia: situación y perspectivas de política. Recuperado de: https://library.fes.de/pdffiles/bueros/kolumbien/08286.pdf

Maynou L, Saez M y Bacaria J (2013) Análisis de convergencia de las regiones de la zona euro (1990-2010) Ekonomiaz No 82, 1er cuatrimestre. Recuperado de: https://dugi-doc.udg.edu/bitstream/handle/10256/8787/Analisis-convergenciaregiones.pdf?sequence $=1$

Mcginn, N y Welsh T (1999) Decentralization of education: why, when, what and how? IIEP Unesco. Recuperado de:

https://www.researchgate.net/publication/44824547 Decentralization of education why when what and how

McKenzie, K (1999) Diseño institucional y política pública: una perspectiva microeconómica. Revista de Economía Institucional, vol. 1, núm. 1, noviembre. Recuperado de: $\underline{\text { https://www.redalyc.org/pdf/419/41900103.pdf }}$

Medina A y Narodowski P (2019) Enfoques y herramientas para el gobierno de la salud. Miño y Dávila.

Mesa Lago, C. (2005). Las reformas de salud en América Latina y el Caribe: su impacto en los principios de la seguridad social. Documentos de Proyectos, Cepal, Santiago de Chile. Recuperado de: 
http://repositorio.cepal.org/bitstream/handle/11362/3888/1/S2005077 es.pdf

Ministerio de Educación Nacional de Colombia MEN (2005). Ministerio de educación nacional. Obtenido de https://www.mineducacion.gov.co/1621/article214905.html

Ministerio de Educación de Colombia MEN (2009) Sistema General de Participaciones - Educación. Tipologías y asignación de recursos.

Ministerio de Educación Nacional de Colombia MEN (2010). Sabaneta, nuevo municipio certificado para administrar el servicio público educativo. Obtenido de https://www.mineducacion.gov.co/cvn/1665/w3-article-220606.html

Ministerio de Educación Nacional de Colombia MEN (2018) Guía para la administración de los recursos financieros del sector educativo. Actualización Guía 8.

Moreno Montes, M (2017) Desarrollo del sistema educativo en municipios certificados y no certificados en Colombia, en los años 2005, 2008 y 2011. Voces y Silencios. Revista Latinoamericana de Educación, vol. 8 (1). Recuperado de: https://revistas.uniandes.edu.co/doi/full/10.18175/vys8.1.2017.07

Moreno L, del Pino E, Marí-Klose P, Moreno-Fuentes F (2014) Los sistemas de bienestar europeos tras la crisis económica Eurosocial Colección estudios Nro 3, Madrid sia. Recuperado de: http://www.sia.eurosocial-ii.eu/files/docs/1400662339E3.pdf

Municipio de Sabaneta MS (2008). Plan educativo municipal.

Municipio de Sabaneta MS (2009) Plan de Ordenamiento Territorial. Acuerdo 22 de 2009. Documento diagnóstico. Recuperado de:

https://www.sabaneta.gov.co/files/doc varios/DocDiagn\%C3\%B3stico.pdf

Municipio de Sabaneta MS (2019) Plan Educativo Municipal. Acuerdo Municipal No. 26 del 9 de diciembre de 2019. Recuperado de:

https://www.sabaneta.gov.co/files/allfiles/15777399462548.pdf 
Municipio de Sabaneta (2016). Sabaneta ocupa el primer lugar a nivel departamental y el segundo en todo el país en las pruebas saber $11^{\circ}$. Obtenido de http://www.sabaneta.gov.co/salaprensa/paginas/sabaneta-ocupa-el-primer-lugar-anivel-departamental-y-el-segundo-en-todo-el-pa\%c3\%ads-en-las-pruebas-saber-

\section{$11 \% \mathrm{c} 2 \% \mathrm{~b} 0 . \mathrm{aspx}$}

Municipio de Sabaneta MS (2018) Qué es la JUME. Tríptico.

Narodowski P. y Zugbi L. (2020) La caída del salario en dólares puesta en contexto. Grupo Geopolítica y Economía desde el Sur Global. Nota en El País Digital. Recuperado de: https://www.elpaisdigital.com.ar/contenido/la-cada-delsalario-en-dlares-puesta-en-contexto/29058

OCDE (2012) "Mexico. Mejores políticas para un desarrollo incluyente". Serie Mejores Políticas. Recuperado de:

https://www.oecd.org/mexico/Mexico\%202012\%20FINALES\%20SEP\%20eBook.p df

OCDE (2016) Inversión Pública más Eficiente en Colombia. Mejorar la Gobernanza multinivel. Serie de Estudios Gobernanza Multinivel. Recuperado de: https://www.oecd.org/gov/mlg-colombia-summary-es.pdf.

OECD (2013), "Measuring Fiscal Decentralization: Concepts and Policies", OECD Publishing, Paris

OECD (2014), "Fiscal Federalism 2014: Making Decentralisation Work", OECD Publishing, Paris

OECD (2020) "Synthesising good practices in fiscal federalism", OECD Economic Policy Paper $\mathrm{N}^{\circ} 28$

Porto A (2008) "Federalismo fiscal en la práctica" ISBN 978-950-34-0519-2, Edulp Ediciones, La Plata.

Quinceno-Botero J., Rojas-Betancur M. y Hernandez-Quirama A. (2019) Deformación de la participación y la democracia en la elección de los personeros 
estudiantiles. Revista Logos, Ciencia \& Tecnología. 11(2):78-85. Recuperado de: http://www.scielo.org.co/scielo.php?pid=S2422-

$42002019000200079 \&$ script=sci arttext\&tlng=es

Restrepo D, Barberena Nisimblat V (2014) Descentralización para la inclusión política, social y económica del pos conflicto. En Ospina C. Descentralización enclave de paz. Fundación Konrad Adenauer.

Rosales-Yepes A., Montes-Miranda A. y Figueroa-Gutiérrez, V. (2020)El liderazgo escolar en las políticas educativas latinoamericanas. Revista Espacios Vol. 41 (33) 2020, Art. 9. Recuperado de:

https://www.researchgate.net/publication/344083877 El liderazgo escolar en las politicas educativas latinoamericanas

Secretaria de Planeación Municipal SPM (2016) Plan de desarrollo municipal "Sabaneta de Todos". Municipio de Sabaneta. Recuperado de:

https://www.sabaneta.gov.co/files/doc varios/PlanDesarrollo2016 2019.pdf

Secretaria de Planeación Municipal SPM (2019) Plan de desarrollo municipal. Municipio de Sabaneta. Recuperado de:

https://concejodesabaneta.gov.co/noticias/plan-de-desarrollo-sabaneta-2020$\underline{2023361}$

Secretaría de planeación y desarrollo territorial. (2020). Municipio de sabaneta. Anuario estadístico de Sabaneta.

Silva Lira, I. (2005), "Desarrollo económico local y competitividad territorial en América Latina", Revista de la CEPAL № 85, Santiago de Chile.

Soto D. (2003) La descentralización en Colombia: centralismo o autonomía. OPERA. 3, 3 (nov. 2003), 133-152. Recuperado de:

https://revistas.uexternado.edu.co/index.php/opera/article/view/1243/1182.

Subirats (2012) Nuevos tiempos. ¿Nuevas políticas públicas? Explorando caminos de respuesta Conferencia pronunciada en el VII Congreso Internacional del CLAD 
sobre la Reforma del Estado y de la Administración Pública, Cartagena, Colombia. Recuperado de: www.dgsc.go.cr/dgsc/documentos/cladxvii/subirats-conf.pdf

Subirats S (2007) España como sistema multinivel de gobierno: Logros y frustraciones. Notas para un balance de 25 años Postdata no.12 Ciudad Autónoma de Buenos Aires. Recuperado de:

www.scielo.org.ar/scielo.php?script=sci arttext\&pid=S1851-96012007000100002

Velásquez F (2014) Minería, descentralización y territorio: una mirada en la perspectiva del post-conflicto. En Ospina C. Descentralización en-clave de paz. Fundación Konrad Adenauer.

Velázquez F (1995) Descentralización y modernización del Estado en Colombia: Balance de una experiencia. Nómadas (Col), núm. 3, 1995. Universidad Central Bogotá, Colombia. Recuperado de:

https://www.redalyc.org/pdf/1051/105118914003.pdf.

Zapata J. y Núñez J. (2017) Transferencias intergubernamentales a los municipios en Colombia 2000-2015: Impacto fiscal, progresividad y criterios de asignación. Cepal. Recuperado de:

https://www.cepal.org/sites/default/files/events/files/zapata $0 . p d f$ 